\title{
Über die Regeneration von antennenähnlichen Organen an Stelle von Augen.
}

\author{
III. Weitere Versuche mit total exstirpirten Angen. \\ IV. Versuche mit theilweise abgeschnittenen Angen.
}

Von

Curt Herbst.

Mit Tafel VIII-X und 1 Figur im Text.

Eingegangen am 20. Juli 1899.

\section{Einleitung.}

Im Folgenden iubergebe ich die Fortsetzung meiner Untersuchungen süber die Regeneration ron antennenähnlichen Organen an Stelle von Augen ^ der Öffentlichkeit. Im Frühjahr 1895 hatte ich bekanntlich die merkwürdige Entdeckung gemacht, dass die gemeine Mittelmeergarneele Palaemon im erwachsenen Zustande an Stelle total exstirpirter Augen antenmenähnliche Organe wieder erzeugt, welche in gewissen Punkten mit einer Antenne des ersten Paares, mit einer Antennula iibereinstimmen. Kurz darauf gelang es mir, das gleiche Resultat auch mit Sicyonia zu erlangen; eine Thatsache, die zumal in Verbindung mit den zufälligen Befunden von Mirne-Edwards (33) an Palinurus und von Hofer (28) an Astacus darauf hinwies, dass der Giiltigkeitsbereich der gemachten Entdeckung. ein großer sein miusse und sich vielleicht auf alle Dekapoden oder sogar noch auf andere Gruppen des Krebsstammes erstrecke. Ich habe in Folge dessen im Laufe der Jahre mit einer ganzen Reihe von Krebsen Untersuchungen über die Regeneration total exstirpirter Augen angestellt, deren Resultate unten mitgetheilt werden sollen. Abgesehen von diesen Experimenten, bei denen die Augen mit dem ganzen Stiel dicht am Kopfbrustpanzer abgeschnitten worden waren, 
habe ich aber auch, um meinen Versuchen eine breite Basis zu verleihen, solche mit nur theilweise abgeschnittenen Augen und mit anderen amputirten Körperanhängen angestellt, deren specielle Versuchsanordnungen wir theils in dieser, theils in späteren Mittheilungen kennen lernen werden.

Die Schilderung der Resultate mit total exstirpirten Augen soll den Anfang machen, und zwar sollen zuerst die Erfahrungen, welche ich bei meinen weiteren Versuchen mit Palaemon im Laufe der letzten drei Jahre gemacht habe, zur Sprache kommen. Der bequemeren Citation wegen will ich einfach weiter numeriren und demnach mit dem III. Theil beginnen, da meine ersten Versuche mit Palaemon den I. und jene mit Sicyonic den II. reprïsentiren.

Die Versuche, welche im Folgenden geschildert werden sollen, erstrecken sich zum Theil auf einen Zeitraum von 11/2 Jahren; ja einzelne Krebse wurden sogar nọch bedeutend länger - bis zu drei Jahren - am Leben erhalten. Es ist klar, dass mir dieses nicht möglich gewesen wäre, wenn mir nicht die Hilfsmittel der zoologischen Station zu Neapel zur Verfügung gestanden hätten, eines Institutes, dem ich mich in einer Weise zu Danke verpflichtet fuhle, dass es mir trivial rorkommen würde, einen längeren Lobgesang auf dasselbe und seine Leiter und Beamten anzustimmen. Ein Arbeitsplatz wurde mir zu wiederholten Malen von dem Königlich Preußischen Ministerium der geistlichen, Unterrichts- und Medicinalangelegenheiten zur Verfügung gestellt, dem desshalb mein bester Dank abgestattet sein möge.

\section{Theil.}

\section{Weitere Versuche mit total exstirpirten Augen.}

\section{Versuche mit Palaemon.}

Ich will meine Darstellung mit einer

kurzen Schilderung des Entwickelungsganges

der an Stelle von Augen regenerirten Antennulae beginnen.

Hat man das Auge mit einer kleinen Schere dicht am Kopfbrustpanzer abgeschnitten, so bildet sich zunächst über der Mundfläche ein brauner Schorf, welcher bei der ersten Häutung mit der Haut abgestoßen wird. Die Wundfläche zeigt sich nunmehr verheilt, von einer Regeneration des amputirten Organs ist aber noch nichts 
zu bemerken. Erst nach den folgenden Häutungen kann man bei einer Anzahl der operirten Krebse deutliche Regenerate wahrnehmen und zwar zunächst als kleine, ungegliederte Stummel, denen man noch nicht sicher ansehen kann, was aus ihnen hervorgehen wird, wenn auch dem kritischen Beobachter wegen des Mangels des schwarzen Augenpigmentes und wegen der vom birnenförmigen Auge abweichenden Form Zweifel aufsteigen mögen, dass die kleinen wieder erzeugten Gebilde Anlagen zu neuen Augen repräsentiren.

Wie berechtigt diese $Z$ weifel sind, zeigt die weitere Ausgestaltung der Knospen: Es treten an ihnen nämlich lange, zarte Haare auf, die, falls bereits eine größere Zahl von ihnen gebildet worden ist, deutlich in einzelnen, getrennten Gruppen angeordnet sind. Zwei von diesen Anfangsstadien habe ich in meiner ersten Mittheilung in Fig. 1 und 2 wiedergegeben. Daselbst findet man auch eine genauere Beschreibung des charakteristischen Haarbesatzes, so dass ich an dieser Stelle nicht wieder darauf einzugehen branche. Die regenerirtell, hornförmigen Gebilde sind entweder noch nngegliedert wie die beiden in meiner ersten Arbeit abgebildeten Regenerate, oder sie lassen bei etwas weiterer Ausbildung eine Gliederung erkennen, die freilich namentlich an dem dickeren Basaltheil unregelmäßig ist und hier nicht um die ganze Peripherie herumreicht. Vergleicht man nun die erhaltenen Neubildungen mit den Stielaugen, so ist ohne Weiteres klar, dass sie ron den letzteren durchaus verschieden sind, denn der fransenartige Haarbesatz geht den Augenstielen vollkommen ab, und von einer Gliederung, wie sie die etwas weiter ausgebildeten Regenerate aufweisen, ist an ihnen ebenfalls nichts zu bemerkell. Das Einzige, was von Haarbesatz an den Augenstielen nachzuwejsen ist, wird durch ganz kleine, feine Stiftchen repräsentirt, welche den Angenstiel da, wo seine Chitindecke in die Cornea übergeht, kranzförmig rings umgeben. Wir sind also aus gutem Grunde berechtigt zu sagen, dass die Krebse, welche iiberhaupt etwas regenerirt haben, an Stelle des linken, abgeschnittenen Auges - an diesem vollzog ich immer die Operation - ein ganz anderes Organ zu regeneriren begonnen haben. Wir haben also im Sinne LoEB's (31) eine Heteromorphose vor uns, wie ebenfalls bereits in meinen beiden ersten Mittheilungen betont wurde.

Bei der Weiterentwickelung erhalten nun die mit fransenartigem Haarbesatz rersehenen Neubildungen seitlich einen neuen, gegliederten Ast, welcher diunner ist als der urspringliche und ganz einem Flagellum gleicht. Wir haben also jetzt einen gabelspaltigen Körper- 
anhang ror uns. Der längere Ast wird ron dem vielgliederigen Flagellum repräsentirt, welches am Ende der einzelnen Glieder mit meist bitschelförmig angeordneten, dünnen Stiftehen spärlich besetzt ist, während die langen, dünnwandigen Sinneshaare auf den kurzen, aber dickeren, urspriinglichen Ast beschränkt sind. Auch ron diesem Entwickelungsstadium habe ich in meiner ersten Arbeit zwei Beispiele abgebildet. Dicselben stammen ron Thieren, welche im Herbste 1894 operirt und am 25./4. 95 konservirt worden waren: sie repräsentiren ungefähr den Höhepunkt der Ausbildung der Heteromorphosen während eines normalen Winters in Neapel. Hält man die Thiere jedoch länger am Leben, bis in den Mai und Juni hinein, wie ich dies im darauffolgenden Winter 189596 that, so erhailt man weit größere Neubildungen. Denn wïhrend die Heteromorphosen rom April 1895 nur 0,5 cm lang waren, habe ich im Juni 1896 Krebse konserrirt, die von Oktober 1895 an Neubildungen bis zi ca. 1,5 cm Länge regenerirt hatten. Auch das in Fig. $1 b$ abgebildete Regenerat gehört dieser Versuchsserie rom Oktober 1895 bis Anfang Juni $1 \$ 96$ an. Es ist ebenfalls größer als die im April 1895 konservirten Neubildungen, wenn es auch den größten rom Juni 1896, da es nur ca. $1 \mathrm{~cm}^{1}$; lang ist, noch ziemlich nachsteht. Da die Regeneration verloren gegangener Theile ebenso wie die Embryonalentwickelung: bekanntlich durch Erhöhung der Temperatur beschleunigt wird, so bekommt man nach Operation im Friihjahre im Laufe des Sommers größere heteromorphe Seubildungen, als man in derselben Zeit nach Operation im Herbste im Laufe des Winters erhalten haben wiirde. Die in Fig. $2 a$ wiedergegebene Heteromorphose hat sich z. B. im Lanfe des Sommers 1897 an Stelle des linken Auges eines Palaemon rectirostris, der am 12./5. 97 operirt worden war, entwickelt. Sie stammt voll der Haut, welche das Thier am 22.;10. 97 abgeworfen hatte, und besitzt eine Gesammtläuge von $1,7 \mathrm{~cm}$, wobei noch zu beachten ist, dass das Ende des 46 gliederigen Flagellums abgebrochen ist. Um die Zeichnung nicht unnöthig groß zu machen, sind von letzterem nur die ersten neun Glieder wiedergegeben worden. Man wird an der prächtig entwickelten Heteromorphose bei nüherer Betrachtung wieder die beiden charakteristischen Haupttheile des oben geschilderten dritten Entwickelungsstadiums der au Stelle ron Angen wiedererzeugten Teuljildungen erkennen, nur dass in dem

1) Die Spitze ist freilich abgebrochen, so dass die Geißel noch etwas länger als $1 \mathrm{~cm}$ geresen sein mag. 
vorliegenden Falle Alles weit mächtiger entwickelt ist, als bei den verhältnismäßig kleinen Regeneraten, welche ich in meiner ersten Mittheilung abgebildet habe. Wir unterscheiden einen dickeren, kiirzeren Stamm und an diesem einen langen, diinnen, vielgliederigen Seitenast. Nach der gegebenen Zeichnung allein urtheilend, könnte man auch versucht sein, die dargestellte Neubildung so zu beschreiben, dass einem gemeinsamen, unregelmäßig gegliederten Basalstiick zwei Äste aufsitzen, ron denen der eine kurz und weniggliederig ist, während der andere durch ein langes, vielgliederiges Flagellum repräsentirt wird. Eine solche Schilderung wïrde aber den thatsächlichen Verhältnissen nicht entsprechen, da sie mit dem geschilderten Entwickelung'sgange in Widerspruch steht, ans diesem aber herrorgeht, dass das Basalstiick sammt dem kürzeren und dickeren, fransenartig mit langen Sinneshaaren besetzten Ast den ursprïnglichen Stamm des Gebildes ausmacht, und dass sich erst sekundïr an dessen Seite das Flagellum entwickelt hat. Die Znsammengehörigkeit von Basaltheil und kurzem Ast geht iibrigens auch daraus herror, dass dér fransenartige Sinneshaarbesatz sich in vielen Faillen auch noch unterhalb des Ansatzpunktes des Flagellums auf das Basalstiick fortsetzt, wie z. B. bei der in Fig. 4 dargestellten Neubildung zu sehen ist.

Eine etwas nühere Beschreibung unserer Heteromorphose nehmen wir am besten an der Hand ilurer bildlichen Darstellung : Fig. 2a vor. Wir betrachten zuerst den dickeren Stamm. Sein Basaltheil ist - wie bereits erwähnt - nnregelmäBig gegliedert. Die einzelnen Glieder sind ron sehr verschiedener Größe, die Einschnuirungen der Chitindecke, welche sie von einander trennen, reichen häntig nicht um den ganzen Stamm herum und sind nur zum Theil einander parallel gestellt. Der Theil oberhalb des Ansatzpunktes des Flagellums ist dreikantig, zwar besser als das Basalstiick gegliedert, weist aber auch Abschnitte von sehr verschiedener Größe auf. Das Charakteristische an ihm ist der fransenartige Besatz mit langen, zarten, an der Basis etwas dickwandigeren und dort geringelten Sinneshaaren, welche äußerst regelmäßig in parallelen Reihen angeordnet sind. Jede Reihe besteht aus einer rerschieden großen Anzahl Haare; an dem gerade vorliegenden Gebilde kann man von eins bis sechs zuihlen. Anf die größeren Glieder kommen gewöhnlich vier, auf die kleineren zwei Reihen zu stehen. Was endlich das 46 gliederige Flagellum anlangt, so sind dessen Abschnitte ebenfalls ungleich groß und - abgesehen ron den kleinen meist biischelreise an den 
Gliederenden angeordneten, feinen Ḧ̈rchen - mit keinen anderen Sinneshaaren besetzt.

Wir haben nummehr den Entwickelungsgang der an Stelle von total exstirpirten Augen regenerirten Heteromorphosen von Anfang an bis zu dem typischen Stadium verfolgt, welches bei Operation im Frühjahr im Laufe eines Sommers erreicht werden kann. Da der Krebs, ron dem die in Fig. $2 a$ dargestellte Neubildung stammt, am 12. Mai 1897 operirt worden war, und die Haut, nach der die Zeichnung angefertigt wurde, am 22. Oktober desselben Jahres abgeworfen wurde, die einzelnen Häutungen aber bei Palcemon rectirostris in der warmen Jahreszeit innerhalb 15-21 Tagen auf einander folgen könneu, so könnte man annehmen, dass zur Ausbildung eines solchen Regenerates, wie es die erwähnte Figur repräsentirt, acht bis zehn Häutungen nothwendig wären. Abgesehen aber davon, dass die Intervalle zwischen den einzelnen Häutungen desselben Thieres nicht immer dieselbe Größe haben, ist diese Angabe auch desshalb ron wenig Werth, weil von ihrer Generalisirung nicht die Rede sein kann; denn das Regenerationsvermögen ist bei den einzelnen Thieren so verschieden, dass nach der gleichen Anzahl Häutungen die an Stelle der Augen regenerirten Neubildungen die verschiedensten Entwickelungsgrade aufweisen. Die Mehrzahl der Thiere bekommt itbrigens iiberhaupt keine Regenerate, wie folgende Zahlen zeigen: Bei meiner ersten Versuchsserie vom Winterhalbjahr 1894/95 hatten von 46 iiberlebenden 10 Heteromorphosen erzeugt, bei den Versuchen von 1895/96 von 4821 und von Anfang Oktober 1897 bis 27. Mai 1898 endlich von 219 nur 49. Ein Auge oder auch nur den Ansatz zu einem solchen hat aber von den zahlreichen Thieren auch nicht ein einziges bei totaler Exstirpation wiedererzengt.

Die oben näher beschriebene und in Fig. $2 a$ abgebildete Neubildung können wir als den Typus bezeichnen, dem die Mehrzahl der an Stelle von Augen entstandenen Regenerate mehr oder weniger genau entspricht. Es kommen num aber auch verschiedenartige

\section{Abweichngen im Bau rom Typus}

vor, welche im Folgenden beschrieben werden sollen.

Wir können unter diesen zwei verschiedene Kategorien unterscheiden, je nachdem die Abweichung in mangelhafter Ausbildung resp. gänzlichem Wegfall eines der beiden Haupttheile der typischen Neubildung oder im Hinzutreten eines dritten Astes beruht, welcher unserem Typus abgeht. 
Handelt es sich um die erste Kategorie von Aberrationen, so sind wieder zwei Möglichkeiten gegeben, in so fern nämlich erstens das freie, über den Ansatzpunkt des Flagellums hinausragende Ende des dickeren Stammstiickes der Neubildung fehlen oder zweitens die Entwickelung des Flagellums unterdrückt sein kann. Zwei Entwickelungsstadien eines schönen Beispiels für den ersten Fall habe ich in Fig. $1 a$ und $b$ dargestellt, die übrigens zugleich auch zeigen, wie bedeutend eine an Stelle eines Anges erzengte Heteromorphose nach einer Häutung zunehmen kann. Dieselbe scheint im vorliegenden Falle nur aus einem Flagellum zu bestehen, das an seiner Basis dicker und unregelmäßig gegliedert ist und auf einem kaum nennenswerthen einseitigen Höcker einen Büschel der charakteristischen langen Sinneshaare trägt. Entstanden zu denken ist dieses scheinbar einheitliche Flagellum aber so, dass wie gewöhnlich auch hier zunächst ein hornförmiges, mit Sinneshaaren besetztes Gebilde entstanden, und aus diesem erst sekundär eine Geißel hervorgewachsen ist, aber nicht wie gewöhnlich an der Seite, sondern an der Spitze der ursprïnglichen Bildung. Der Umstand, dass ich die dargestellte, aberrante Neubildung in zwei Entwickelungsstadien beobachten konnte, schließt iibrigens die Annahme aus, dass in dem rorliegenden Falle doch auch urspriinglich zwei deutlich von einander abgesetzte Äste wie gewöhnlich rorhanden waren, von denen der eine, kürzere nur in Folge einer Verletzung sekundär verloren gegangen wäre. Da sich die an Stelle der Augen erzeugten Nenbildungen selbst wieder regeneriren künnen, so müsste nämlich der minimale Höcker in Abbildung $1 a$ nach der nächsten Häutung wenigstens etwas größer geworden sein, was aber nicht der Fall war. Im Ganzen habe ich nur zwei charakteristische Beispiele für diese Art ron Abweichung vom typischen Bau gefunden, zu dem übrigens mannigfache Übergänge allmählich ïberleiten. Das bildlich dargestellte Beispiel stammt von einem Palaemon serratus und das andere von einem Palaemon rectirostris. Die andere Art von Abweichung der ersten Kategorie, wo es sich also um Wegfall des Flagellums handelt, habe ich nur einmal an einem Palaemon rectirostris konstatiren können. Selbstverständlich kann man hier nur dann von wirklichem Wegfall reden, weun die Züchtung lange genug fortgesetzt wird, und sich trotz der fortschreitenden Ausbildung des ursprïnglichen Stammes doch nach keiner Häutung ein seitliches Flagellum ausbildet. Mit dem erwähnten Krebs war dies der Fall, denn er war im Oktober 1897 operirt worden und hatte bis zum 22. Februar 1899, wo er konservirt wurde, 
noch keine seitliche Geißel bekommen, obwohl der anfängliche Stamm sich wohl entwickelt hatte und von seiner, etwas schraubenförmig gewundenen Spitze bis fast an seine Basis mit regelmäßig parallelen Reihen von langen Sinneshaaren besetzt war ${ }^{1}$.

Wir kommen nunmehr zur zweiten Kategorie der Abweichungen ron dem gewöhnlichen Schema der an Stelle ron Augen erzeugten Heteromorphosen. Wie bereits gesagt, ist dieselbe durch das Hinzutreten eines neuen, dritten Astes charakterisirt. Während also die Vertreter der ersten Kategorie ron Abweichungen im Vergleich zu unserem Typus eine niedrigere Orgauisationsstufe reprïsentirten, weisen die der zweiten einen höheren Ausbildungsgrad als das Schema auf. Ich habe diese böher differenzirte Art ron Heteromorphosen zum ersten Male bei jener Vcrsuchsserie beobachtet, welche im Oktober 1897 begonnen worden war. Den Krebsen war damals im Gegensatz zu meinen früheren Versuchen, vom linken Auge abgesehen, auch noch der gabelspaltige Exopodit der linken Antennula abgeschnitten worden, und es mag dahin gestellt bleiben, ob nicht etwa diese gleichzeitige Operation die Entwickelung der an Stelle der linken Augen erzeugten Heteromorphosen zu einem höheren Ausbildungsgrade als gewöhnlich begiinstigt hat. In Fig. 3 habe ich eine ca. $71 / 2$ Nonate alte Neubildung abgebildet, welche die höhere Differenzirungsstufe zeigt. Im Gegensatz zu unserem, in Fig. $2 a$ dargestellten Typus besitzt dieselbe nämlich zwei Flagellen. Das eine ron diesen ist wie sonst mit dem kürzeren, die charakteristischen, büschelweise angeordneten Sinneshaare tragenden Ast basalwärts rerwachsen, welcher außerdem auffallende, unregelmäßige Wucherungen aufweist, die für gewühnlich an dem entsprechenden Theile der Heteromorphosen nicht $\mathrm{zu}$ finden sind. Dieselben sind aber kein Charakteristikum der zweiten Kategorie von Abweichungen rom Schema, sondern nur dem gerade vorliegenden Beispiele speciell

1) $\mathrm{Zu}$ der ersten Kategorie von Abweichungen vom Typus der an Stelle von Augen erzengten Heteromorphosen scheint auch noch jenes Regenerat zu gehören, welches ich in meiner ersten Mittheilung (pag. 549) beschrieben und in Fig. 5 der zugehörigen Tafel abgebildet habe. Es besteht nur aus einem Flagellum, ermangelt des kurzen Astes und weist auch keine fransenartig angeordneten Sinneshaare auf. Ich wusste lange nicht, wie diese Abweichung vom Typus aufzufassen sei, glaube aber jetzt, dass es sich gar nicht um eine solche handelt, da ich bei erneuter Betrachtung des Präparates eine Narbe an ihm entdeckt habe, die es mir wahrscheinlich macht, dass dort der kurze Ast mit den langen Sinneshaaren abgebrochen and bis zur Zeit der Konservirung des Thieres noch nicht wieder regenerirt worden war. 
eigen. Die Abweichung von der Regel wird dagegen durch das zweite lingere Flagellum (en) repräsentirt, welches ron einem, an seinem distalen Ende mit einigen Haaren besetzten Basalstiicke entspringt. Von der anderen, ursprünglichen Geißel $(e x)$ zeichnet es sich dadurch aus, dass es im Leben bräunlich-riolett gezeichnet war und abgesehen von den kleinen, feinen, meist buischelweise angeordneten Härchen an einigen seiner proximalen Glieder mit dickeren, resistenteren Stacheln besetzt ist. Das mit st bezeichnete Basalstiuck der ganzen Neubildung ist nicht der letzteren selbst zuzurechnen, sondern als Stumpf des Augenstieles zu betrachten. Ein noch weit besseres Beispiel einer weiter als gewöhnlich ausgebildeten Heteromorphose ist in Fig. 4 bildlich dargestellt. Dasselbe stammt wie das rorige ron einem Paluemon rectirostris, der im Oktober 1897 operirt worden war. Am 2./11.98, also nach etwa 13 Monaten, war die Neubildung abgeschnitten und konserrirt worden. Wie man sieht, sitzen ihrem rudimentiiren Basalstiick, das an seinem Ende einen Büschel Federhaare trügt, zwei sehr rerschieden ausgebildete Äste auf. In dem dickeren, gabelspaltigen $(e x)$ erkennen wir das Schema wieder, welches wir fuir die an Stelle ron Angen erzengten heteromorphen Neubildungen in Fig. $2 a$ aufgestellt haben, während der zweite diunere Ast en als neu hinzukommt. Der dickere, dreikantige Lst ist bis auf scine Gliederung sehr regelmäßig gestaltet. An der Basis ziemlich breit, verschmälert er sich nach der Spitze zu allmählich und ist rou dieser his proximalwärts iiber den Ansatzpunkt des langen, schlanken Flagellums hinaus in regelmäßiger Weise mit parallelen Rieihen ron langen Simneshaaren besetzt, wie wir das bereits oben beschrieben haben. Von dem langen Flagellum habe ich nur den Anfangs- und Endtheil wiedergegeben, da dasselbe ca. 110 Glieder besa $B$ und die Zeichnung desswegen bedeutend vergrößert haben wiirde. Von dem kleineren zeichnet es sich dadurch aus, dass es der starren, stachelartigen Haargebilde entbehrt, welche wir an jenen $(e n)$ bemerken. Ein Vergleich der beiden, höher differenzirten Neubildungen (Fig. 3 und 4) zeigt übrigens, dass die in Fig. 4 dargestellte, abgesehen von ihrer bedentenderen Größe, noch dadurch einen höheren Grad der Ausbildung aufweist, dass sie am Basalstïck einen Buischel Fiederhaare besitzt. Ich habe denselben bis Januar 1899 nur bei drei Heteromorphosen bemerkt, zu welchen die gewaltige Neubildung" gehürt, welche in Fig. $5 a$ und $b$ bildlich wiedergegeben ist. Eine ausfuhrliche Beschreibung derselben will ich nnterlassen, da die Betrachtung der Zeichnung dieselbe schließlich am besten 
giebt, und man bei einem Vergleiche der beiden Fig. 4 und 5 leicht die einzelnen Theile der weniger entwickelten Neubildung in jenen der mächtiger ausgebildeten wiedererkennen wird. Abgesehen ron den drei genannten und abgebildeten Vertretern der zweiten Kategorie der Abweichungen vom Schema sind mir bis zum 17./5. 99 noch fünf weitere Beispiele zu Gesicht gekommen, die aber an Größe den beiden weit entwickelten Regeneraten (Fig. 4 und 5) nachstauden. Erwähnenswerth ist aber, dass von diesen Fällen vier unter Krebsen zur Beobachtung kamen, denen abgesehen rom linken Auge auch die linke Antennula bis zur Basis abgeschnitten worden war, während die andere zweigeißelige Heteromorphose derselben Versuchsreihe, wie die in Fig. 3 wiedergegebene, angehört.

Abgesehen von den beiden in Fig. 4 und 5 dargestellten Neubildungen haben wir in unseren ersten Mittheilungen und anch bis jetzt in dieser nur Regenerate abgebildet und beschrieben, welche höchstens ein Alter von $\mathbf{~} 1 / 2^{1 / 2}$ Monaten besaßen, meistens aber noch jünger waren. Obwohl nun die beiden genannten, weiter entwickelten Bildungen bereits zeigen, welche beträchtliche Größe dieselben erreichen können, soll doch im Folgenden noch einmal besonders auf

\section{die Veränderungen der Heteromorphosen bei lang andauernder Züchtung}

eingegangen werden.

Die beiden weit entwickelten Bildungen sind aus Anfangsstadien herrorgegangen zu denken, welche der in Fig. 3 dargestellten Heteromorphose ähnlich waren - nur dass der mit den langen Sinneshaaren besetzte kiirzere und dickere Ast regelmäßiger gestaltet war - und Ende Mai 1898 anch ungefähr dieselbe Größe besaßen. Wir können letzteres mit gutem Grunde annehmen, da bei der genauen Durchmusterung der Krebse am 28./5. 98 kein Exemplar mit zweigeißeliger Heteromorphose gefunden wurde, die größer als die in Fig. 3 dargestellte gewesen wäre.

Die erste unserer beiden weit entwickelten Heteromorphosen (Fig. 4) wurde nun aber am 2./11. 98 abgeschnitten und konservirt. Sie hatte also während der fünf Monate bedeutend an Größe zugenommen, denn während die natürliche Größe der im Mai konservirten Neubildung (Fig. 3) nur $0,8 \mathrm{~cm}$ betrug, maß unsere Heteromorphose rom 2. Norember ca. $2,8 \mathrm{~cm}$; ihre Gesammtlänge hatte also um ungefähr $2 \mathrm{~cm}$ zugenommen! Das lange Flagellum ihres gabelspaltigen Theiles $\left\{e x_{2}\right\}$ zählte ca. 110 Glieder und der kürzere, 
dickere Ast derselben $\left(e x_{1}\right)$ wies 38 Reihen von Sinneshaaren auf, eine Zahl, die von den Heteromorphosen, die sich im Winter entwickelt haben und wie Fig.'3 im Frühjahr konservirt worden sind, nicht annähernd erreicht wird. Ja sogar jene wohl entwickelte Neubildung in Fig. $2 a$, welche sich in der heißen Jahreszeit vom 12./5. bis 22./10. 97 entwickelt hatte, wird an Zahl der Sinneshaarreiben von unserer Heteromorphose weit ïbertroffen, da erstere nur 18 davon anfweist, ein Beweis, wie bedeutend sich die an Stelle von Augen erzeugten heteromorphen Regenerate bei lang andauernder Züchtung weiter entwickeln können. Auffallend ist nur bei unserer weit entwickelten Heteromorphose (Fig. 4) die geringe Größe der mit en bezeichneten Geißel, welche sogar an Länge und Gliederzahl von dem entsprechenden Flagellum der am 27./5. 98 konservirten Neubildung (Fig. 3) übertroffen wird. Diese geringfügige Ausbildung rührt jedoch nicht etwa von einem Stillstand der Entwickelung seit dem Frühjahre her, sondern hat einen anderen Grund, wie wir im folgenden Abschnitt sehen werden.

Noch länger als der Krebs, von dem die erste der beiden weit entwickelten Neubildungen stammt, wurde jener weiter gezüchtet, dem die zweite, in Fig. $5 a$ und $b$ dargestellte Heteromorphose angehört. Dieselbe stammt von der Haut, welche das Thier am 17./12. 98, also mehr als 14 Monate nach der Operation abwarf. Auch die vorher abgeworfenen Häute wurden vom Oktober an gesammelt und nach Färbung mit Osmiumsäure in Balsam eingebettet. Eine Vergleichung dieser Häute unter einander und mit der gezeichneten lässt die stetige weitere Ausbildung deutlich erkennen. Im dargestellten Entwickelungsstadium betrug die Gesammtlänge des gabelspaltigen Astes mit dem 111 gliederigen Flagellum ca. $3 \mathrm{~cm}$ und die des anderen $2,7 \mathrm{~cm}$ bei einer Gliederzahl von 128! Die Zahl der Sinneshaarreihen am kurzen, dickeren Ast betrng ca. 33, während an der am 26./10. 99 abgeworfenen Haut nur ca. 21 gezählt wurden.

Aus einem Vergleich der abgeworfenen Häute ergiebt sich außerdem als bemerkenswerthes Resultat noch die Thatsache, dass das Wachsthum der heteromorphen Neubildungen von einem gewissen Zeitpunkte an nicht etwa im Zufügen neuer Äste, sondern nur in der weiteren Ausbildung der bereits vorhandenen Elemente und in einer Vermehrung ihrer Glieder and Haaranhänge besteht. Davon bin ich nicht nur durch die Weiterentwickelung der beiden erwähnten gewaltigen Neubildnngen, sondern z. B. auch durch das weitere Wachsthum jener Heteromorphose belehrt worden, welche oben als 
Typus aufgestellt und in Fig. $2 a$ abgebildet wurde. Wie dieselbe nach ca. sieben Monaten am 27./5. 98 aussah, zeigt die Fig. $2 b$, welche bei derselben Vergrößerung g'ezeichnet worden ist. Vom Flagellum sind wieder nur die Anfangsglieder wiedergegeben worden; wie lang dasselbe war, kann ich nicht genan angeben, da die Spitze abgebrochen war. Auch von dem kürzeren, dicken Ast mit den Sinneshaarreihen war vor der letzten Häutung der größte Theil durch eine Verletzung verloren gegangen, so dass auch dieser Ast uns keinen Aufschluss über das Wachsthum des Gebildes geben kann. Dagegen fällt sofort die Größenzunahme des Basalstückes $(e x)$ zwischen der Gabelung in den dickeren Ast und in das lange Flagellum und den Kopfbrustpanzer auf. Es hat nicht nur an Dicke, sondern auch an Länge und Zahl der Glieder zugenommen, die aber in Form und Größe immer noch Unregelmäßigkeiten anfweisen und an der Basis der Neubildung wegen mangelhafter Ausbildung der Einschnürung nicht vollständig von einander getrennt sind. Eine bedeutende Vermehrung hat der Besatz mit feinen, meist buischelförmig angeordneten Härchen erfahren, zu welchen sich außerdem,- mehr der Basis genähert, einige resistentere, starrere Haaranhänge gesellen. Von dem Hinzutreten eines ganz neuen Astes ist aber nicht die Spur zu bemerken; das Gebilde hat vielmehr denselben Habitus bewahrt, den es zu Anfang hatte, und hat sich jenen weiter differenzirten Heteromorphosen mit zwei" Flagellen (Fig. 4 und 5) um keinen Sehritt mehr genähert, als es ihnen bereits zu Beginn der Weiterzüchtung im Oktober 1897 genähert war. Nach einer gewissen Zeit besteht also die Weiterentwickelung der an Stelle von Augen erzeugten Neubildungen nicht - wie bereits betont - im Hinzufügen neuer Äste, sondern nur in einer Vermehrung der Glieder und Haaranhänge der vorhandenen unter Wahrung des anfänglichen Habitus.

Ebenso wenig konnte die Entstehung des zweiten, sekundären Flagellums bei zwei Krebsen mit heteromorpher Neubildung an Stelle des linken Auges beobachtet werden, von denen der im Mai 1897 operirte ebenfalls wie der oben erwähnte von Anfang Oktober 1897 bis 27. Mai 1898, der andere, im Oktober 1897 operirte, dagegen von Oktober 1898 bis 13. Januar 1999 isolirt weiter gezüchtet wurde. Ja nicht einmal das primäre Flagellum gelangt nach einem gewissen Zeitpunkte mehr zur Entwickelung, wie die Weiterzichtang jenes Palaemon rertirostris beweist, der im Oktober 1897 operirt worden war und nur den dickeren Ast mit den Sinneshaarreihen an Stelle 
des Auges regenerirt hatte. Noch im Februar 1899 war die Heteromorphose dieses Krebses genau von dem gleichen Habitus wie im Oktober 1898, wo das Thier behufs weiterer Beobachtung isolirt worden war.

Von welchem bestimmten Zeitpunkte an ist nun aber die Ausbildung der heteromorphen Neubildungen dem Habitus nicht der Größe nach als abgeschlossen zu betrachten? Leider ist es unmöglich eine sichere Antwort auf diese Frage zu ertheilen, da die Regeneration der Antennulae an Stelle der total exstirpirten Augen sehr verschieden rasch verläuft, so dass nach eimem bestimmten Zeitraum an gleichzeitig operirten Krebsen sehr verschiedene Ausbildungsgrade zu konstatiren sind. Die folgenden Angaben haben desshalb auch nur den Zweck, einigermaßen eine Vorstellung von der Länge des Zeitraumes zu geben, nach dessen Ablauf die habituelle, qualitative Ausbildung der heteromorphen Antennulae als abgeschlossen zu betrachten ist.

Die Krebse, welche von Oktober 1897 bis 27. Mai 1898 isolirt weiter geziichtet worden waren, waren am 12. Mai 1597 operirt worden und hatten den Habitus ihrer heteromorphen Neubildungen von Oktober an bewahrt. Derselbe war also nach ca. funf Monaten fertiggestellt, einem Zeitraum, den wir als Termin für die im Frïljahr operirten Krebse ansetzen können, womit aber keineswegs gesagt sein soll, dass der Abschluss der habituellen Ausbildung der Heteromorphosen nach Operation im Frihijahr nicht auch schon früher oder bisweilen auch erst später stattfinden kann. Als ungefähr zutreffenden Termin für die im Herbste operirten Krebse aber, bei denen die Regeneration also in die kältere Jahreszeit fällt, können wir das Alter jener in Fig. 3 dargestellten Nenbildung festsetzen, die von einem im Oktober 1597 operirten und am 27.5. 98 (also nach ca. sieben Monaten) konservirten Palaemon stammt.

Da der quantitative Zuwachs der an Stelle von Augen erzeugten Neubildungen nach einer einzigen Häutung ziemlich beträchtlich sein kann, wie z. B. ein Vergleich der beiden Fig. $1 a$ und $b$ lehrt, so wiirde die Größe der gewaltigen, in Fig. 4 und 5 wiedergegebenen Regenerate bald erreicht werden, wenn die Neubildungen nicht so häufig größere oder kleinere Stücke in Folge von Verletzungen verlören. Letztere würden natürlich eine bedeutendere Entwickelung. überhaupt vereiteln, wenn ihre Wirkung nicht theilweise durch 
die Regenerationsfähigkeit der Heteromorphosen ausgeglichen wirde, welche sich nicht nur in der Wiederherstellung einzelner, verloren gegangener Stuicke, sondern sogar in der nochmaligen Entwickelung der total exstirpirten Neubildung kund geben kann.

Die Wiederherstellung einzelner Theile kann bei jeder an Stelle eines Auges erzeugten Heteromorphose beobachtet werden. So sind die Endglieder des kürzeren dickeren Astes der in Fig. $2 b$ dargestellten Neubildung regenerirt worden, nachdem der Ast bis auf einen kurzen Stummel abgebrochen war, und die große Neubildung (Fig. 4) bekam nach einer einzigen Häutung die bereits wieder 21 gliederige, sekundäre Geißel $(e n)$ wieder, welche bis zur Basis abgebrochen war und desshalb der anderen, primären an Länge so bedeutend nachsteht. Die zahlreichsten und besten Beispiele fiur die Wiederherstellung einzelner Theile liefert uns aber die zweite, abgebildete große Heteromorphose (Fig. 5): So war z. B. die Geißel des gabelspaltigen Astes $\left(e x_{2}\right)$ vor der Häutung vom 26./10. 98 abgebrochen und besaß nur noch eine Gesammtlänge von $0,8-09 \mathrm{~mm}$, welche jedoch nach der nächsten Häutung bereits wieder auf $1,7 \mathrm{~cm}$ angewachsen war. Die sekundäre Geißel (en) maß an der am 26. 10. 98 abgeworfenen Haut 1,7 cm, an der vom 16./11, aber nur $1 \mathrm{~cm}$, da ihr Ende abgebrochen war; bei der nächstfolgenden Ḧ̈utung vom 17./12. hatte sie aber bereits die Länge von $2,7 \mathrm{~cm}$ erreicht, also zwischen zwei Häutungen um $1,7 \mathrm{~cm}$ an Lüngenausdehnung zugenommen. Bei dieser Häutung war aber wegen mangelhafter Funktionirung des Ablösungsprocesses der neuen von der alten Chitinhaut der sekundäre Ast $(e n)$ an der Basis abgerissen und in der abgeworfenen Haut stecken geblieben, ein Verlust, der bei der folgenden Häutung am 4./2. 99 zum Theil schon wieder ersetzt war, denn es war ein neues $0,8 \mathrm{~cm}$ langes Flagellum gebildet worden, während der stehengebliebene Stumpf nur $0,4 \mathrm{~cm}$ maB. Nicht so rasch wie die Regeneration der Geißeln geht die des kurzen, dicken Astes mit den Sinneshaarreihen vor sich; doch regenerirt sich auch dieser, wie z. B. Fig. $2 b$ zeigt und auch an der großen Neubildung (Fig. 5), welche uns die erwähnten Beispiele von Regeneration einzelner Theile zum großen Theil lieferte, beobachtet wurde.

Von mehr Interesse als die Wiedererzeugung einzelner Theile ist die der ganzen Neubildungen nach totaler Exstirpation; und zwar ist sie dies desshalb, weil man hierdurch eine Antwort auf die Frage erhält, ob die neuen Gebilde nach der zweiten Operation 
wieder den heteromorphen Antennulis gleichen oder ob an ihrer Stelle nun wieder andere Körperanhänge regenerirt werden.

Ich stellte meine Versuche mit vier isolirt geziichteten Krebsen der Species Palaemon rectirostris an und erhielt bei zweien von ilnen überhaupt keine, bei den beiden anderen jedoch positive Resultate, die zur Entscheidung der Frage vollkommen geniigen. Diesen beiden Thieren war die an Stelle des linken Auges seit Oktober 1897 regenerirte, mächtige Antennula an 2. November 1898 amputirt worden.

Der eine dieser Krebse, der schwächlichere von beiden wies nach der crsten Hiutung noch keine Neubildung auf, bekam dagegen nach der zweiten, die am 17./12. 98 stattfand, einen hornförmigen Ansatz, wie wir ihn oben als erstes Stadium der heteromorphen Antennulae kennen gelernt haben, die an Stelle von Augen erzengt werden. Er hätte also sicher eine solche erhalten, wenn er nicht bereits am 30./12. 98 gestorben wäre.

Dals zweite, krättigere Thier - es ist jenes, welches nach der ersten Operation die in Fig. 4 dargestellte Antennula regenerirt hatte - hekam bereits bei der ersten Häutung am 21./11. 98 einen hornförmigen Ansatz. Derselbe wandelte sich bei der zweiten Häutung am 10./12. $98 \mathrm{zu}$ einer typischen kleinen Antennula von $0,5 \mathrm{~cm}$ Länge um, an der man bereits den kiirzeren, dickeren Ast mit den langen Sinneshaaren und die lïngere, dünnere Geißel unterscheiden konnte. Dieses Resultat iberraschte mich insofern einigermaßen, als mir bei meinen zahlreichen Versuchen nie so kurze Zeit nach der Operation ein heteromorphes Regenerat von dieser Ausbildung zu Gesicht gekommen ist. Am 27./1. 99 nach der dritten Häutung maß die Antennula $0,9 \mathrm{~cm}$ und nach der vierten, die auffallend spät, nämlich erst am 21./3. 99 stattfand, hatte sie eine Länge von $1,25 \mathrm{~cm}$ erreicht, besaß aber immer noch nur eine Geißel. Ob sie schließlich noch cine zweite Geißel wie die nach der ersten Operation erzeugte Autennula bekommen haben würde, ist nicht zu sagen, da das Thier leider bereits am 1./4. 99 starb, nachdem es schon lange vorher matt gewesen war. Nun, das Resultat steht aber auch so fest:

Wird eine an Stelle eines Auges erzeugte Antennula a eschuitten, so wird - falls ủberhaupt kegeneration eintritt - das zweite Mal wieder eine Antennula, nicht etwa aber ein auderer Körperanhang regenerirt').

1) Wenn die Vermuthung Przmbram's (40 und 41), dass die von mir beschriebenen heteromorphen Neuhildungen an Stelle von Augen sPäliminargebilde seien und bei weiterer Züchtung durch Augen ersetzt worden wären, 
Ebenso wie in unseren beiden ersten Mittheilungen (24 und 25) haben wir auch in dieser bis jetzt nur die äußere Form der an Stelle von Augen erzengten Neubildungen berücksichtigt,

\section{den inneren Bau}

dagegen unbeachtet gelassen. Das Versäumte nacbzuholen, soll der Zweck der folgenden Zeilen sein; und zwar wollen wir mit jenem hornförmigen Anfangsstadium beginnen, welches sich durch den Besitz der langen Sinneshaare bereits als Heteromorphose zu erkennen giebt.

Schon an tingirten Totopräparaten sieht man, dass die betreffenden kurzen Gebilde zum größten Theil von spindelförmigen Zell--

nicht schon durch meine ersten Mittheilungen widerlegt wäre, in denen verschiedene Entwickelungsstadien dieser Heteromorphosen beschrieben, abgebildet und kritisch mit den normalen Antennulis verglichen wurden, so wäre ils durch die Thatsachen, welche oben in den beiden Abschnitten siber die Verïnderungen der Heteromorphosen bei lang andauernder Züchtung und über ihre Regenerationsfaihigkeit mitgetheilt wurden, jeder Grund und Boden entzogen. Er stuitzt seine Vermuthung auf eine gewisse Ähnlichkeit, die er zwischen meinen Regeneraten und den abnormen Bildungen entdeckt haben will, welche er bisweilen an Stelle eines oder mehrerer Glieder der großen Ruderantenne bei Daphnia erhielt. Nun sind aber meine Regenerate, wie er aus meinen Arbeiten erfahren haben musste, rudimentïre Antennulae, die seinigen aber nicht. Er kann also die vermeintliche $̈$ ihnlichkeit nur durch einen Vergleich oberflächlicher Art entdeckt haben. Er bezeichnet weiter seine abnormen Präliminargebilde als Heteromorphosen. Dieser Beyriff bezieht sich aber nur auf jene Fälle, wo an Stelle eines Organs oder eines Körpertheils ein anderes Organ oder ein anderer Körpertheil desselben Thieres erzeugt wird. LoEB (31) schuf den Begriff bekanntlich für die Regeneration eines Köpfehens an Stelle eines Stolo bei Tubularia. Sind nun die Przibram'schen Präliminargebilde Anhänge, welche der Daphnia sonst an anderen Körperstellen zukommen? Nein. Also sind sie keine Heteromorphosen, sondern einfach als besonders abnorme Bildungen jener Anhänge aufzufassen, die sich auch sonst an diesen Stellen vorfinden. Endlich hat er einige Versuche mit Palaemon serratus angestellt, um zu sehen, ob auch er an Stelle der Augen Antennulae erhalten wïrde, bekam aber an Stelle derselben wieder Augen. Da er den Schnitt durch den distalen Theil des Augenstieles geführt und also nur das Auge entfernt, den Stiel aber stehen gelassen hat, so wäre es nach meinen Resultaten nicht zu verwundern, wenn er thatsächlich wieder Augen erhalten hätte, was freilich nur durch eine Untersuchung auf Schnitten sicher festgestellt werden kann. Ganz unbegreiflich ist es mir aber, wie er aus seinen wenigen Versuchen den Schluss zu ziehen sich erlaubt, dass die Schnittstelle keinen Einfluss auf die Natur des Regenerats habe, da er doch nicht ein einziges Mal den Schnitt an der Basis des Stieles gefiihrt hat, wie ich dies bisher immer gethan habe. Anf die regenerirten Augen werden wir an geeigneter Stelle noch einmal zurückkommen. 
gruppen angefüllt sind, welche unter den Sinneshaaren deutlich von einander isolirt sind, an der gegenüberliegenden Seite und im proximalen Theile des Regenerates dagegen so dicht zusammenliegen, dass sie eine einheitliche, unregelmäßige, wulstförmige Zellenmasse darstellen. An Schnitten durch solche Neubildungen erkennt man nun, dass diese spindelförmigen Zellgruppen Ganglien repräsentiren, welche zu den langen, charakteristischen, fransenartig angeordneten Sinneshaaren gehören. Man sieht nämlich im unteren Theile der letzteren an gut mit Pikrinosmiumessigsäure fixirten Objekten (Fig. 6) deutlich ein Bündel dunkel gefärbter Nervenfasern, welche in eine gremeinsame kernlose Grundmasse eingebettet sind. Nach ihrem Austritt aus dem Haar wenden sich die Nervenfasern, zu einem gemeinsamen Strange vereinigt, scharf proximalwärts und verlaufen, im Strange dentlich von einander unterscheidbar, eine Strecke weit nach hinten, bis sie in eines der vielzelligen, spindelförmigen Ganglien einmünden, in dem sich der Strang in die einzelnen Fasern auflöst. Weit weniger dentlich als der ins distale Ende des Gauglions eintretende Nervenstrang lässt sich der Austritt eines Nerven aus dem proximalen Ende auf diesem Entwickelungsstadium nachweisen. Immerhin gelingt anch dieses in einigen Fällen; vou einer Vereinigung dieser proximalwïrts strebenden, diunnen stränge zu einem dickeren, gemeinsanen Nervenstamm ist jedoch noch nicht die Rede, so dass man glauben könnte, es bestände üherhaupt noch keine Verbindung mit dem Centralorgan, falls man nicht durch physiologische Versuche eines Besseren belehrt wiirde. Die einzelnen Ganglien mit ihren beiden Nervensträngen sind von einer dünnen, bindegewebigen Hïlle umgeben, welche beim Eintritt der distalen Stränge in die Sinneshaare verloren geht. Wie bereits erwähnt, sind im unteren Theil der letzteren die einzelneu, durch Osmium dunkel gefärbten Nervenfasern immer dentlich zu sehen und zwar an allerdentlichsten in dem kurzen, etwas angeschwollenen Basalstiicke; im oberen Theil dagegen ist dies nicht der Fall. Der gesammte Inhalt der Haare nimmt nämlich in diesem, der $2 / 3$ oder $3 / 4$ der ganzen Länge repräsentirt, eine andere Beschaffenheit an, welche seine Konservation sehr erschwert. Gewöhnlich ist er zu einem wenig gefiirbten, von der Chitinhaut abgehobenen Strange zusammengeschrumpft, in dem man nichts mehr von Nervenfasern beobachten kann, woraus natürlich nicht folgt, dass dieselben hier iiberhaupt nicht mehr vorhanden sind. Der Unterschied zwischen dem kleineren, basalen und dem größeren, distalen Theil der Sinneshaare tritt 
iibrigens nicht nur bei Konservation mit Pikrinosmiumessigsäure, sondern auch bei anderen Methoden scharf hervor und er äußert sich anch äußerlich darin, dass die Chitinhaut distalwärts dünner ist als proximalwärts und hier dentlicher gegliedert ist als dort, wo außerdem die einzelnen Glieder größer als im unteren Theile des Haares sind.

Abgesehen von dem im Vorstehenden beschriebenen Nervenapparat und seinen Bildungsherden, welche wir in den dicht gedrängten Zellenmassen mit kleinen, auf den Präparaten intensiv gefärbten Kernen im Basaltheil und an der den Sinneshaaren gegenüberliegenden Seite der Neubildung (Fig. 6 bh) zu suchen haben, habe ich in den hornförmigen Anfangsstadien nur noch äußerst zarte, mannigfach verzweigte Blutgefäße bemerkt; von Muskeln war jedoch nichts zu sehen, wenn nicht etwa ein kleiner Rest rom Augenstiel stehen geblieben war und in diesem sich Reste der Angenmuskeln vorfanden.

Weit typischer als bei den Anfangsstadien, wo Alles noch in Bildung begriffen ist, ist der innere Bau der weiter entwickelten Heteromorphosen, wie sie z. B. in Fig. 4 und 5 dargestellt sind.

An Totopräparaten von ihnen bemerkt man zunächst ebenfalls die Ganglien unter den parallelen Sinneshaarreihen und außerdem sieht man in den Flagellen je ein Blutgefäß bis zur Spitze verlaufen, das sehr dünwwandig ist und bei der Konservation häufig an verschiedenen Stellen seines Verlaufs zerreißt. Wegen der zarten Beschaffenheit ihrer Wandung kann man diese langen Blutgefäße besser an ganzen Objekten als an Schnitten beobachten, die jedoch zum Studium des Nervenapparates unerlässlich sind.

Letzterer hat sich in dem kürzeren Ast mit dem fransenartigen Sinneshaarbesatz bei den weiter entwickelten Heteromorphosen ganz bedeutend mehr entfaltet als in den hornförmigen Anfangsstadien. Mit Zunahme der langen Sinneshaare an Zahl und regelmäßiger, paralleler Anordnung in einzelnen Reihen, sind auch die Ganglien $(g)$ regelmäßiger gelagert, und der ganze Nervenapparat besser zu überblicken; sein allgemeiner Charakter hat sich jedoch nicht geändert. Wir schen nämlich (vgl. Fig. 7), wie auch hier aus jedem Haar ein Nervenstrang austritt, der sofort scharf proximalwärts umbiegt, unter der nächstfolgenden Sinneshaarreihe wegläuft und dicht hinter der zweiten in ein zellenreiches Ganglion eintritt und sich dort auffasert (Fig. $7 d n^{*}$ ). Von jedem Ganglion geht am proximalen Ende ein zweiter Nervenstrang $(p r n)$ ab, welcher sich der dem Sinneshaarbesatz gegeniberliegenden Seite des Astes zuwendet und von hier 
gemeinsam mit den austretenden Nervensträugen der ïbrigen Ganglien dem Gehirn zustrebt $(g n)$. Bei den weit entwickelten Gebilden entstelit aus der Vereinigung der einzelnen Stränge ein ziemlich dicker Nervenstamm, der in den Fiallen, wo der fransenartige Sinneshaarbesatz fast bis zur Basis reicht (Fig. 4), bis dahin noch immer neven Zazug von Nervenbündeln erhält. Der definitive, den gesammten Nervenapparat des kürzeren, dickeren Astes mit dem Gehirn verbindende Nervenstamm ist in Folge dessen bei solehen Regeneraten sehr kur\%, während in den Fällen, wo die langen Sinneshaare weiter distalwärts aufhören, der gemeinsame Theil des gabelspaltigen Astes wie in Fig. $2 b$ also verhältnismäßig lang ist, natürlich auch ein längerer, gemeinsamer Nervenstamm existirt. Wie sich der letztere im Gehirn auftheilt, werden wir in einem späteren Kapitel kennen lernen. Hier soll nur noch erwähnt werden, dass man bei Neubildungen, welche juinger und mithin weniger ansgebildet sind als die in Fig. 2, 4 und 5 dargestellten, also etwa bei Fig. 6 vergebens nach einem deutlichen gemeinsamen Nervenstamm, der die Ganglien der Sinneshaare mit dem Gehirn verbindet, suchen wird. Da die spindelförmigen Nervenzellengruppen ebenso wie die dazu gehörigen Haare auf diesen frïheren Stadien im Vergleich zu später noch verhältnismäbig gering an Zahl sind, und die aus ihnen austretenden proximalen Nervenstränge der Hypodermis dicht angeschmiegt nach dem Centralorgane hin verlanfen, so kommt es hier noch nicht zu einem dicken Sammelstamm, der wie bei der Neubildung in Fig. $2 b$ direkt in den stehen gebliebenen Opticusstumpf übergeht, sondern es endet letzterer an der Operationsstelle noch ziemlich frei. Trotzdem treten aber auch in diesen jüngeren Regeneraten - wie schon einmal erwähnt - bereits Nervenfasern an ihn heran; und wir werden in einem späteren Kapitel sehen, dass dieselben mindestens zum Theil bereits ibren Weg in das Oberschlundganglion gefunden haben.

Ganz bedentend schwieriger als in dem kurzen Ast mit dem fransenartigen Sinneshaarbesatz sind Nerven in den dünnen Flagellen nachzuweisen, da dieselben wegen der kleinen und spärlichen Haare, die sie zu innerviren haben, weit dünner sind und ihre Konservirung wegen der geringen Durchlässigkeit des Chitins mit großen Schwierigkeiten verbunden ist. Trotzdem ist es mir gelungen, wenigstens in dem langen primären Flagellum der in Fig. 4 dargestellten Heteromorphose einen Nervenstrang neben dem Blutgefäße herlaufen zu sehen, da derselbe wegen der Länge der Geißel verhältnismäßig dick war. 
Interessant ist noch, dass ich im Basaltheil der gleichen Neubildung auch zwei rudimentäre Muskelbündel gefunden habe, obwohl sich das ganze Gebilde ebenso wenig bewegte wie seine einzelnen Theile und wie die ubbrigen Heteromorphosen. Das eine, kleinere dieser Bündel lag in der Nähe des Ursprungsortes des kleinen sekundären Flagellums $(e n)$, während das zweite, größere an der gegenüberliegenden Seite des Basalstückes, etwas weiter proximalwärts zu sehen war. Das Wichtigste hierbei ist nun, dass an den Fasern beider Bündel eine mehr oder weniger deutliche Querstreifung zu beobachten war, die also nicht unter dem Einflusse der Funktion entstanden sein konnte, wie nebenbei bemerkt sein möge.

Es wird dem Leser anfgefallen sein, dass ich in der vorstehenden Schilderung des inneren Baues der an Stelle von Augen erzeugten Gebilde und auch in den anderen Abschnitten bis jetzt immer nur das indifferente Wort *Heteromorphose gebraucht habe, obwohl ich sie doch in meinen beiden ersten Mittheilungen antennenähnlich genaunt und den ersten Antennen, den Antennulis gleichgesetzt hatte. Die Beweise, die ich dort für diese Auffassung beigebracht habe, geniigen nun zwar zur sicheren Begriindung derselben vollkommen, da mir nun aber in Folge der fortgesetzten Versuche jetzt eine noch grïßere Zahl von Indicien zur Entscheidung der Frage zu Gebote steht, und nummehr sogar eine bis ins Einzelne gehende Vergleichung der Heteromorphosen mit normalen Antennulis möglich ist, so habe ich es für gut befunden, noch einmal von Anfang an ganz induktiv vorzugehen und zunächst nur von Heteromorphosen zu reden. Es soll desshalb nummehr zum zweiten Mal auf den

\section{Vergleich der heteromorphen Neubildungen mit ersten} Antennen

eingegangen werden.

Von den Übereinstimmungspunkten zwischen den an Stelle von Augen erzeugten Heteromorphosen und normalen Antennulis fïllt als

1) erster und bedeutungsvollster jener fransenartige Besatz mit Sinnesharen auf; welche der Krebskundige beim Lesen meiner $\mathbf{A b -}$ handlung schon längst als sogenannte "Riechschläuche« erkannt haben wird, die ein Charakteristikum der Antennulae sind und sich an keinem anderen Körperauhange vorfinden. Ilır Vorhandensein an den 
Regeneraten hatte mich desshalb schon in meiner ersten Mittheilung mit Recht dazu veranlasst, die Heteromorphosen als rudimentäre Antennulae anzusprechen.

2) Wie man sich erinnern wird und anßerdem an den Fig. $2 a$, 4 und $5 b$ deutlich erkennt, sind die *Riechschläuche" an den weiter entwickelten Neubildungen in parallelen Reiben regelmäßig angeordnet, also ganz ebenso wie sie es auch an dem kurzen Aste des Exopoditen der ersten Antennen sind (vgl. 56 ).

3) Letzterer ist dreikantig and trägt den fransenartigen Besatz auf der nach außen und unten gerichteten Fläche. Auch dieses ist bei meinen Heteromorphosen der Fall, die natiirlich bei schrägem Wuchs nach oben den Haarbesatz auf ihrer vorderen Seite tragen.

4) Der innere Bau des Astes mit dem Haarbesatz (Fig. 7) stimmt in beiden Fällen, bei den Regeneraten und normalen Antennulis überein, wie die Kenner der Arbeiten von Kraepelis (29) und namentlich von vom RaTH (42) bereits bemerkt haben werden.

5) Kein anderer Körperanhang besitzt ferner zwei derartig gestaltete, vielgliederige Geißeln wie die Antennulae und die an Stelle von Angen erzengten Neubildungen, welche in Fig. 3-5 dargestellt sind.

6) Auch die Insertion dieser Geißeln ist in beiden Fällen die gleiche. Während nämlich die eine, welche wir als primäre bezeichnet haben, von der Seite des kuirzeren, dickeren Astes mit dem frausenartigen Simmesharbesatz entspringt oder, wie wir auch sagen können, eine Strecke weit mit diesem verwachsen ist, ist die andere, sekundüre (en) direkt dem gemeinsamen Basalstick inserirt.

7) Selbst in der Färbung der regenerirten Flagellen spricht sich die Ähnlichkeit mit denen der ersten Antennen aus, da letztere eine bräunliche, bisweilen namentlich am Endopoditen ins Violette überrehende Färbung mit hellen Ringen besitzen, und ich die gleiche Färbung und Zeichnung an den Flagellen einiger weiter entwickelter Heteromorphosen, so an der Geißel in Fig. $2 a$ und $b$ und an der mit $e n$ bezeichneten in Fig. 3 und 5 bemerkt habe.

8) Betrachten wir weiter den Haarbesatz der Geißeln der normalen Antennula (Fig. 5b), so finden wir einen durchgreifenden Untersthied zwischen dem freien und dem von der Seite des kürzeren, dickeren Astes entspringenden Flagellum. Letzteres ist nämlich gewöhnlich nur mit den feinen, zarten, meist büschelförmig angeordneten kleinen Härchen besetzt, während das andere, der Endopodit, außer den kleinen, über die ganze Geißel vertheilten Härchen stets in 
seinem unteren Theile mit starreren, stachelartigen Hautanhängen versehen ist, die in charakteristischer Weise angeordnet sind. Jedes Glied besitzt nämlich zwei solche stacheln und zwar den einen längeren an der mach innen gekehrten Seite und den anderen, kleineren anf der nach oben gekehrten Fläche, nahe der äußeren seite. Diese charakteristischen Stacheln finden sich nun auch an dem freien Flagellum (en) der in Fig. $5 b$ (links) dargestellten mächtigen Heteromorphose vor und sie sind auch an den entsprechenden Theilen der Fig. 3 und $t$ zu erkennen, wenn auch hier ihre Anordnung wegen der geringeren Ausbildung des Flagellums nicht so typisch ist.

9) Endlich will ich noch auf ein Übereinstimmungsmerkmal aufmerksam machen, das mir nur dreimal an weiter ausgebildeten Heteromorphosen aufgestoBen ist. Wie die beiden Abbildungen 4 und 58 zcigen, findet sich nämlich bisweilen an dem kleinen, rudi-

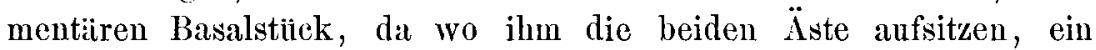
Büschel Fiederhaare, wie sie sich in derselben Wcise am Protopoditen der normalen Antennula vortinden. Wollten wir noch mehr ins Einzelne gehın, so wiirden wir noch mehr Übereinstimmungspunkte heranstinden können; dic angefuihrten geniigen aber zur Gleichsetzung der einzelnen Theile einer an Stelle eines Auges regenerirten Heteromorphose mit solchen der normalen Antennulae vollkommen. Bei Betrachtung der Fig. 56 ist nämlich ohne Weiteres klar, dass der gabelspaltige Ast $(e x)$ des regenerirten Gebildes dem Exopoditen der normalen Antennula entspricht, während der Endopodit der letzteren dem freien, direkt auf dem Basalstïck inserirten Flagellum der Heteromorphose (en) gleichzusetzen ist. Der dreigliederige, große Protopodit der normalen Antennula $(p r)$ ist jedoch am Regenerat nur durch ein minimales Rudiment, nämlich durch das kleine Basalstiick (pr) mit dem Büschel Fiederhaare vertreten. Es ist bemerkenswerth, dass im vorliegenden Falle sogar die Größenverhältnisse der Neubildung und des distalen Theiles der normalen linken Antennula fast übereinstimmten (vgl. Fig. 5a). Denn während, wie bereits erwähnt, die Länge des Exopoditen der ersteren an der am 17.j12. 98 abgeworfenen Haut bei einer Gliederzahl von $1113 \mathrm{~cm}$ betrug, maß der entsprechende Ast am normalen Körperanhang $3,7 \mathrm{~cm}$ und besaß 153 Glieder. Der Endopodit des letzteren wurde von dem anderen sogar noch ein wenig an Länge (jedoch nicht an Gliederzahl) ubbertroffen, denn dieser war $2,7 \mathrm{~cm}$ lang und zählte 128 Glieder, während jener 139 Glieder besaß und nur 2,6 cm lang war.

Ausgelend von dieser mächtig entwickelten Heteromorphose 
können wir nunmehr auch die einzelnen Theile der tubrigen solchen der normalen Antennulae gleichsetzen. Zunächst ist klar, dass in den beiden Fig. 3 und 4 der gabelspaltige Ast als Exopodit, das ungetheilte Flagellnm mit den stachelartigen Haaren als Endopodit, und die gemeinsame Basis beider $(p r)$ als Rudiment des Protopoditen zu bezeichnen ist. In diesem Rudiment finden sich bei der in Fig. 4 dargestellten Heteromorphose - wie bereits oben pag. 234 erwähnt — zwei rudimentäre Muskelbündel vor, welche wir ebenfalls solchen im Protopoditen gleichsetzen können. Das kleinere von ihnen entspricht nämlich der Lage nach jenem, welches vom dritten Protopoditengliede in den Endopoditen tritt, während das andere, größere zu der mächtigeren Muskelgruppe des Exopoditen gehört.

Wenden wir uns nun den weniger ansgebildeten Heteromorphosen mit nur einem Flagellum zu, wie sie gewöhnlich an Stelle von Augen erzeugt werden, so ergiebt sich, dass in diesen Fällen nur der gabelspaltige Exopodit regenerirt worden ist. In Fig. $2 a$ und $b$ entspricht also das einheitliche Stammstiick $e x$ dem Theil des Exopoditen einer normalen Antennula, in welchem der kürzere Ast mit dem fransenartigen Sinneshaarbesatz und das Flagellum noch mit einander verwachsen sind, während letzteres und das freie Ende des ersteren den mit $e x_{2}$ und $e x_{1}$ bezeichneten Theilen in Fig. $2 a$ und $b$ gleichzusetzen sind. In derselben Weise sind alle anderen Heteromorphosen mit nur einem Flagellum, welche von mir beobachtet worden sind, bis auf eine einzige Ausnahme aufufassen. Diese Ausnahme wird durch jene Neubildung repräsentirt, welche ich in meiner ersten Mittheilung in Fig. 4 abgebildet habe. Das Flagellum derselben zeichnet sich vor dem der anderen eingeißeligen Heteromorphosen durch den Besitz von einigen stachelartigen Haaren aus, welche für den Endopoditen charakteristisch sind. Zwar habe ich auch noch in einem anderen Falle, wo man über die Zugehörigkeit der Geißel zum Exopoditen wegen seines Insertionspunktes oberhalb des Beginnes des fransenartigen Haarbesatzes nicht in Zweifel sein konnte, ein ähnliches Haar an dem Flagellum bemerkt; dasselbe war aber - wie gesagt - nur in der Einzahl vorhanden, während in dem Ausnahmefalle auf zwei Gliedern je zwei solcher stachelartiger Haare zu finden waren, von denen, ganz wie beim Endopoditen, das vom kurzen Ast abgewandte und der Medianebene des Körpers zugekehrte das größere war. Diese Sachlage sowie auch der Umstand, dass das Flagellum unterhalb des Beginnes des fransenartigen Haarbesatzes dem kleinen gemeinsamen Basalstück inserirt war, machen 
es wahrscheinlich, dass die einzig vorhandene Geißel hier entgegen der Regel dem Endopoditen entspricht und die des Exopoditen, welche gewöhnlich immer vorhanden ist, in diesem Falle nicht ausgebildet worden ist.

Was endlich jenes hornförmige Anfungsstadium der an Stelle von Augen erzeugten Heteromorphosen anbetrifft, so miussen wir dasselbe als Anlage des kurzen Astes des Exopoditen bezeichnen, da es mit diesem den Besitz der langen, charakteristischen Sinneshaare gemeinsam hat.

Aus den gesammten vorstehenden Thatsachen geht nun aber mit der allergrößten Deutlichkeit hervor, dass bei Palaemon an Stelle total exstirpirter Augen Antennulae regenerirt werden, und dass die Regeneration derselben mit Anlage des kurzen Exopoditenastes, welcher die »Riechhaare* trägt, ihren Anfang nimmt.

Wir hätten desshalb in unserem Titel auch von der Regeneration von Antennulis an Stelle von Augen sprechen können; dass wir aber den indifferenteren Ausdruck »antennenähnlich * gebraucht haben, hat darin seinen Grund, dass die heteromorphen Neubildungen zwar erste Antennen sind, diesen aber doch nicht absolut entsprechen.

Es ist desshalb unsere Aufgabe nach den Übereinstimmungspunkten nunmehr die Differenzpunkte zwischen den normalen Antennulis und den an Stelle von Augen erzeugten kurz aufzuzählen:

1) Zunächst sei noch einmal daran erinnert, dass längst nicht alle Heteromorphosen den Differenzirungsgrad der in Fig. 4 and 5 dargestellten aufweisen, sondern gewöhnlich weniger Theile einer normalen Antennula besitzen, und dass die fehlenden Theile auch nach lang andauernder Züchtung nicht nachträglich noch gebildet werden, wenn sie nicht gleich mehrere Monate nach der Operation angelegt worden sind, wie oben pag. 226 des Näheren dargelegt wurde.

2) Zweitens will ich darauf aufmerksam machen, dass die einzelnen Äste der an Stelle eines Auges regenerirten Antennula anders zu einander liegen können wie bei einer normalen ersten Antenne, wofuir die mächtige, in Fig. 5 dargestellte Heteromorphose ein schönes Beispiel abgiebt. Ein Blick auf sie zeigt nämlich, dass der Endopodit nach außen gekehrt und somit um ca. $180^{\circ}$ verlagert ist, was auch daran zu erkennen ist, dass die größeren Stachelı anstatt 
nach innen nach außen und die kleineren anstatt nach oben nach unten gewandt sind.

3) Weiter mag daran erinnert werden, dass an den heteromorphen Antennulis die große Unregelmäßigkeit in der Größe und Abgliederung der einzelnen Glieder auffällt, was an den normalen Antennulis nur selten zn beobachten ist.

4) Als vierter und sehr wichtiger Unterschied ist sodann der Mangel der aktiven Beweglichkeit der an Stelle von Augen regenerirten Antennulae anzuführen; und zwar kann weder das ganze Gebilde gegen den Cephalothorax bewegt werden, noch führt der Exopodit allein jene charakteristischen Schläge aus, welche ihm bei der normalen Antennula eigen sind. Selbst die am weitesten entwickelten Heteromorphosen waren bewegungslos, obwohl ich im Basalstiick der in Fig. 4 dargestellten Muskelbündel - allerdings in rudimentärer Ausbildung - gefunden habe. Nur einmal konnte ich an einer kleinen regenerirten Antennula schwache Bewegungen gleich jenen des Auges konstatiren. Dies rührte aber daher, dass hier die Basis des Augenstiels mit einigen Muskeln erhalten geblieben war, so dass also die Ausnahme die Regel bestätigt.

5) An letzter Stelle soll endlich noch auf das Fehlen oder die mangelhafte Ausbildung des normaler Weise dreigliederigen Protopoditen hingewiesen werden, denn derselbe ist bei den an Stelle von Augen regenerirten Antennulis entweder überhaupt nicht oder nur in ganz rudimentärem Zustande vorhanden, wie die Fig. 4 und 5 zeigen. Hand in Hand mit dieser Hemmung der Bildung des Protopoditen geht natürlich die der Statocyste, welche bekanntlich im ersten Gliede des ersteren liegt.

Die Regeneration der an Stelle von Augen erzengten Antennulae steht somit in scharfem Gegensatz zu derjenigen normaler erster Antennen, deren dreigliederiger Protopodit gleich von allem Anfang an am Regenerat zu sehen ist. Wir mïssen also hiernach unseren obigen Ausspruch, dass Palaemon an Stelle total exstirpirter Augen Antennulae regenerirt, dahin prïcisiren, dass vor allen Dingen der distale Abschnitt der ersten Antennen wieder erzeugt wird und mehr oder weniger vollständig zur Ausbildung gelangt.

\section{Die Zahl der an Stelle von Augen regenerirten Antenuulae}

hat im Laufe der Jahre eine beträchtliche Größe erreicht. Sic belänft sich nämlich gegenwärtig, d. h. bis zum 17. Mai 1899, auf 99, 
in welcher Zahl jene 10 Heteromorphosen meiner ersten Versuchsserie vom Winter 1894/95 mit inbegriffen sind. Von diesen 99 Neubildungen waren 47 durch hornähnliche, mit dem charakteristischen, fransenartigen Sinneshaarbesatz versehene Gebilde repräsentirt, während die übrigen 52 eine höhere Entwickelungsstufe aufwiesen; 14 von ihnen besaßen nämlich jenen Differenzirungsgrad, welcher unserem Typus entspricht, und die anderen 8 hatten sich über diesen hinaus zu weiter ausgebildeten Heteromorphosen mit zwei Flagellen entwickelt, waren also den in Fig. 3, 4 und 5 dargestellten ähnlich. Ich habe die 99 Heteromorphosen insgesammt unter ca. 370 uberlebenden Individuen ${ }^{1}$ ) aufgefunden, von denen die tibrigen ganz ohne Regenerat geblieben waren und niemals - dies sei noch einmal ganz besonders betont - auch nach lang andauernder Zuichtung die Regeneration eines Auges oder anch nur einen Ansatz dazu erkenuen ließen.

Die Palaemon-Arten, an denen die Regeneration von Antennulis an Stelle von Augen beobachtet wurde,

sind folgende: Palaemon squilla, rectirostris und serratus. Die meisten Heteromorphosen entfallen auf die zweite Species, doch nicht etwa desswegen, weil dieselbe sich besonders gut zu den Versuchen eignet und ein bedeutenderes Regenerationsvermögen als die anderen besitzt, sondern einfach desshalb, weil die meisten Versuche mit ihr angestellt wurden. An Brauchbarkeit sind sich also die drei Arten ungefähr gleich, alle drei übertreffen darin aber alle anderen Dekapoden, welche ich außer ihnen zu meinen Versuchen verwandte. Die Thiere lassen sich jabrelang ohne große Mühe am Leben er=halten und bäuten sich fortwährend in verhältnismäßig geringen Zwischenräumen, deren Größe natürlich in der kalten Jahreszeit bedeutender als in der wärmeren ist, wie z. B. aus folgenden Datenangaben hervorgeht. Dieselben beziehen sich auf die Häutungen jenes Krebses, dessen an Stelle des linken Auges erzeugte Antennula in Fig. 5 abgebildet ist. Im Herbste 1898 beobachtete ich an ihm am 11./10. die erste Häutung, der bereits am 26./10. die zweite nachfolgte. Am 16./11. fand die dritte und am 17./12. die vierte Häutung. statt, zwischen welcher und der nächstfolgenden eine längere Pause zu verzeichnen war, denn letztere fand erst am 4. Februar 1899 statt. Bei einem anderen Krebse erfolgten die Häutungen am 3./11. 99,

1) Die Zahl der operirten war natürich bedeutend größer. 
Über die Regeneration von antennenähnlichen Organen etc. III. 241

30./11. und 13./1. 99 und bei einem dritten am 21./11. 98, 10./12., 27./1. und 21./3. 99, Daten, welche eine Verlangsamung in der kälteren Jahreszeit erkennen lassen, zugleich aber auch zeigen, dass in der letzteren doch immer noch Häutungen stattfinden. Ich muss hierzu noch bemerken, dass die drei Exemplare von Paluemon rectirostris, dereu Häutungssdaten aufgezählt wurden, nicht etwa kleine und junge, sondern alte und grobe Vertreter ihrer Species waren, demn ihre Lünge, vom freien Ende des Rostrums bis zu dem des Telsons gemessen, schwankte um $6 \mathrm{~cm}$, während die kleinsten, die ich zu meinen Versuchen verwendete, und die ebenfalls Antennulae an Stelle von Augen erzeugten, nur ca. $3,5 \mathrm{~cm}$ maßen.

\section{Versuche mit Palaemonetes varians.}

Am 18. November 1997 selmitt ich einer Anzahl Palaemonetes das linke Auge dicht am Kopflorustpanzer ab und ïberließ die Thiere in drei Glasgefäßen, die reichlich mit Wasserpflanzen besetzt waren, ihrem Schicksal. Da im Lauf des Winters viele starben und andere ihren Genossen zum Opfer fielen, fanden sich am 29./5. 98 von den zallieichen operirten Thieren - es mochten an 100 gewesen sein nur noch zehn Stiick vor, von denen fünf an Stelle des abgeschnittenen Anges eine deutliche Heteromorphose gebildet hatten und konservirt wurden. Die übrigen fünf ohne ausgeprägtes Regenerat brachte ich wieder in das Gefäß und iiberließ sie den Sommer iiber wieder ihrem Śchicksal. Am 5. Oktober lebten von ihnen noch zwei, ron denen das eine eine heteromorphe Neubildung besaß, während das andere ganz ohne Regenerate geblieben war und anch bei der Weiterzilichtnng bis Mitte Mai 1899 kein solches erhielt.

Die am wenigsten weit ansgebildete Neubildung wurde durch ein hornähnliches Gebilde repräsentirt, das undeutlich dreigliederig war und an seinem freien Ende einige von jenen Sinneshaaren trug, welche dem »Riechast* der ersten Antennen eigen sind. Ebenso wie bei Palaemon wird also auch bei Palaemonetes an Stelle des abgeschnittenen Auges zunächst der kürzere, dickere Ast des Exopoditen der Antennula angelegt; eine Entwickelungsstufe, welche die übrigen fünf Heteromorphosen bereits überschritten hatten, wie Fig. 8 zeigt.

Wir bemerken nämlich hier, dass sich der Außenast, an dem man drei Reihen zu je drei und eine zu zwei Riechhaaren bemerkt, an seiner Spitze zu gabeln beginnt und daselbst bereits zwei Glieder 
seiner Endgeißel erkennen lässt. Anßerdem ist aus dem minimalen Basalstück eine andere, sechzehngliederige Geißel hervorgewachsen, welche an ihren proximalen Gliedern neben zarteren Härchen lïngere, stachelartige aufweist, welche sich in gleicher Weise nur am Endopoditen der inmeren Antennen vorfinden. Zwar kann man auch an der Geißel des Außenastes bei Palaemonetes im Gegensatz zu Palucmon einige starrere Haare wahrnehmen, dieselben sind jedoch an Ausbildung keineswegs jenen Stacheln am Innenast gleichzusetzen, denen die steifen Anhänge an dem langen Flagellum unserer Neubildung gleichen. Wir miissen desshalb dasselbe als Endopoditen einer Antennula bezeichnen. Ich habe denselben unter den sechs Heteromorphosen an vieren feststellen können, so dass also sein Auftreten hier im Gegensatz zu Palcemon weit häufiger ist, denn dort waren von 99 Neubildungen nur acht mit ihm versehen. Im Vergleich mit den Befunden bei Palaemon fällt auch die langsame Entwickelung. der Geißel des Außenastes auf, von welcher an der in Fig. 8 dargestellten Heteromorphose erst zwei Glieder zn sehen sind, während die Innengeißel deren bereits 16 aufweist. In einem anderen Falle war letztere sogar schon 21 gliederig, von dem Flagellum des Exopoditen dagegen noch kein einziges Glied vorhanden.

Von diesen geringfügigen Abweichungen abgesehen, liegen aber die Verhältnisse bei dem einen Krebs ganz wie bei dem anderen, und es sei noch ganz besonders darauf hingewiesen, dass auch bei Palaemonetes vor allen Dingeu der distale Theil einer Antennula an Stelle eines total exstirpirten Auges zur Ausbildung gelangt. Von dem langen, dreigliederigen Protopoditen mit seinem mannigfachen Fiederhaarbesatz ist nämlich in unserer Figur nichts zu seben, denn die Neubildung nimmt in derselben an der mit einem Stern bezeichneten Stelle ihren Anfang, während das dicke, basalwärts davon gelegene Stiick bereits dem Cephalothorax angehört.

Wenn ich nun schließlich noch erwähne, dass auch der innere Bau der Heteromorphosen mit dem des distalen Abschnittes einer Antennula iibereinstimmt und dass im Speciellen hier wie dort unter den $\gg$ Riechhaaren« spindelförmige Ganglien liegen, welche einen distalen Strang zu den einzelnen Simnesharen und einen proximalen nach dem Gehirn entsenden, so wird aus der Ähnlichkeit der Befunde bei Palaemonetes und Palaemon eine wahre Kopie. 


\section{Versuche mit Astacus fluviatilis.}

Weit weniger gliicklich als bei meinen Versuchen mit den beiden ersten Gattungen war ich bei denen, die mit Astacus fuviatilis angestellt wordeu waren. Die Thiere hielten sich zwar anfänglich gut, häuteten sich auch alle einmal, nahmen aber nach einer Reihe von Monaten keine Nahrung mehr zu sich, so dass sie allmählich eingingen. Nach der ersten Häutung konnte man an Stelle des Anges gewöhnlich einen kleinen weißen, ungegliederten Höcker bemerken, dem man jedoch nur in einem Falle mit Sicherheit ansehen konnte, dass etwas Anderes als ein Ange aus ihm werden sollte, denn er war bereits mit einigen Sinneshaaren besetzt, wie sie am Augenstiel bei der Neapeler Form fehlen. Diese Andeutung, dass auch bei Astacus ähnliche Verhïltnisse wie bei Palaemon, Palaemonetes und Sicyonia vorliegen, wird dureh jene weiter entwickelte Heteromorphose, welche in Fig. 9 dargestellt ist, zur Gewissheit. Sie stammt von einem Krebse, der am. 29./1. 96 operirt worden war und Ende März 1597 kurze Zeit vor einer weiteren Häutung an Ermattung zu Grunde ging, da er seit fünf Monaten nichts mehr gefressen hatte. Wie man an der Abbildung sieht, hatte sich die neue Chitinhant an manchen Stellen bereits von der alten etwas abgehoben und war hier und da sogar schon aufgerissen. Unter der alten Hant liegt die neue in zahlreichen, unregelmäBigen Falten zusammengequetscht, so dass also die an Stelle des Anges erzeugte Ileteromorphose bedeutend an Größe zugenommen haben würde, wenn der Krebs nur noch einige Zeit gelebt und die Kraft besessen hätte, sich aus der alten Haut zu befreien. Nun, wir sind aber auch so in der Lage, unsere heteromorphe Neubildung als Antennula zu erkennen.

Ich habe an der Abbildung den Beginn des Regenerates mit zwei Sternen bezeichnet, von welchen aus man proximalwärts zunächst ein breites und ziemlich dickes Stammstück bemerkt, an welchem vor Allem zwei Gruppen von charakteristischen Haaren mit rings um den Schaft angeordneten Fiedern auffallen. Die basale Gruppe ist durch eine Einschnurung am Stamm von der weiter proximalen getrennt und liegt außerdem mehr ventralwärts, so dass die Ansatzpunkte der einzelnen Haare nicht zu sehen sind. Außerdem bemerkt man links an der Seite oberhalb der zweiten Haargruppe einen kurzen, kräftigen Stachel, welcher die alte Chitinhaut weit vorgewölbt hat. Vergleichen wir nunmehr diesen Theil der

Neubildung mit dem Protopoditen einer Antennula, so fällt zwar 
sofort der große Unterschied zwischen beiden auf, da letzterer dreigliederig, viel regelmäßiger gestaltet und mächtiger entwickelt ist, man wird aber auch eine gewisse Übereinstimmung bemerken, da sich, von dem gleichen Haarbesatz abgesehen, am ersten Protopoditengliede ein gleicher gedrungener Stachel, der vielleicht besser als Zahn zu bezeichnen ist, vorfindet. Ähnliche Zühne sind zwar auch an der zweiten Antenne vorhanden, da wir aber bei allen anderen Krebsen an Stelle von Augen Antennulae und keine großen Antennen entstehen sahen, so treffen wir offenbar auch hier das Richtige, wenn wir den Zahn jenem am Protopoditen der ersten Antemne gleichsetzen. Letzterer ist nun aber am distalen Theil der ventralen, inneren Kante des ersten Protopoditengliedes gelegen, während er bei unserer Neubildung an der iußeren Seite liegt und sogar noch etwas dorsalwärts geriickt ist. Das Basalstiick des Regenerates ist also im Vergleich mit dem Protopoditen einer normalen linken Antennula um $90^{\circ}$ oder noch etwas mehr verdreht, wobei wir freilich beachten muissen, dass ein Theil dieser Verlagerung durch die vom Zuwachs bedingte Faltenbildung unterhalb der alten Chitinhaut hervorgerufen sein kann und sich bei der Häutung vielleicht wieder ausgeglichen haben wiirde. ت̈hnliche Verlagerungen sind bei den an Stelle von Augen erzeugten Heteromorphosen nicht selten zu beobachten, wie wir oben im Abschnitt uiber Palaemon kennen gelernt haben.

Wenn also der nach oben gewendete Zahn am distalen Eude des Basalstiuckes unserer Neubildung dem gleich gestalteten Gebilde an oberen Theil der ventralen Innenkante des ersten Protopoditengliedes der ersten Antenne entspricht, so müssen wir die beiden Fiederhaargruppen, die unterhalb des Zahnes liegen, jenen am oberen Innenrande des normalen Antennulabasalstïckes gleichsetzen.

Welchem Theile entspricht nun aber das dicke, unregelmäßig gegliederte Flagellum, welches bei unserer Neubildung dem Basalstiick aufsitzt? Legen wir eine normale Antennula so, wie unsere Heteromorphose am Kopfbrustpanzer inserirt ist, d. h. also mit dem Zahn nach außen hin, so sieht man, dass der dickere geißelförmige Exopodit am freien Ende der dem Zahn gegenüberliegenden Kante des Protopoditen inserirt ist. Das Gleiche ist nun aber mit dem Flagellum unserer Neubildung der Fall, welches demnach als Exopodit zu bezeichnen ist, obwohl ihm noch die charakteristischen, kurzen sogen. Riechhaare abgehen. Sein Haarbesatz besteht nämlich - wie Fig. 9 zeigt - meist nur aus starreren, relativ dickwandigen Haaren, neben denen nur einige zartere vorkommen. 
Abgesehen von dem ca. 10 gliederigen, geißelförmigen Exopoditen trïgt nun aber der Protopodit, ventralwärts von ersterem und somit in der Abbildung nicht sichtbar, eine kleine, noch ungegliederte Hervorragung, welche ich als Anlage des Endopoditen ansehe, und welche nach der Häutung sicherlich bedeutend an Größe zugenommen haben würde.

Aus den vorstehenden Erörterungen geht also hervor, dass wir die an Stelle des linken Auges erzeugte Heteromorphose für eine rudimentäre Antennula ansehen, dass sich also Astacus ebenso wie die anderen bis jetzt untersuchten Dekapoden verhält.

Die von Horer (2૪) an Stelle eines Auges aufgefundene Heteromorphose, welche von ihm mit dem nichtssagenden Ausdrucke: "Gliedmaße * belegt wurde und einer Antennula trotz ilhrer klar zu Tage liegenden Ähnlichkeit nicht entsprechen sollte, ist also eine nicht vollständig entwickelte erste Antenne gewesen, bei welcher vor allen Dingen ganz wie bei Palaemon etc. der distale Theil in Gestalt der beiden Flagellen zur Ausbildung gekommen war $\left.{ }^{1}\right)$.

\section{Versuche mit Palinurus vulgaris.}

Nur ein einziges Mal habe ich bei Palinurus das linke Auge total exstirpirt, und dieser eine Versuch hat ein Resultat ergeben, das an Deutlichkeit nichts zu wünschen übrig lässt. Am 10. Juni 1890 wurde die Operation all einer ca. $11 \mathrm{~cm}$ langen Languste vollführt, und bei der Häutung in der Nacht vom 17.-18. November war an Stelle des Auges eine heteromorphe Neubildung vorhanden. Ich muss diese Häutung der Beobachtung nach zwar als die erste bezeichnen, glaube aber, dass ihr im Sommer vielleicht bald nach der Operation eine andere vorhergegangen war, die ich aber wegen meiner Abwesenheit von Neapel nicht notiren konnte. Die zweite Häutung fand in der Nacht vom 17. auf den 18. März 97 statt, doch

1) Es ist sehr zu bedauern, dass Hoyer nicht an Stelle der vagen Auseinandersetzungen über die Frage, ob der Augenstiel der stieläugigen Krebse als Gliedmaße oder als abgeschnürter Theil des Kopf brustpanzers aufzufassen ist, eine eingehendere Beschreibung des Haarbesatzes der Heteromorphose und eine Vergleichung desselben mit dem einer normalen Antennula gegeben hat; wir wiirden dann im Stande sein, die einzelnen Theile der Heteromorphose solchen der normalen Bildung gleichzusetzen. Nach seinen Angaben zu urtheilen dürfte die längere und dickere Geißel, welche er als Innenast bezeichnet, thatsächlich dem Exopoditen der Antennula entsprochen haben, der natiirlich dann ebenso wie in unserem Falle um ein Betrüchtliches verlagert gewesen wïre. 
konnte nach derselben eine bedeutende Längenzunahme der heteromorphen Nenbildung nicht konstatirt werden. Die Languste hielt sich hierauf den ganzen Sommer 1897 hindurch vortrefflich; im Herbste begann sie jedoch matt zu werden, sie nahm fast keine Nahrung mehr zu sich und starb am 18. Januar 1898 während der Häutung. Sie hatte im Laufe der Zeit eine Länge von ca. $19 \mathrm{~cm}$ erreicht, war also in der Gefangensehaft ganz betriichtlich größer geworden.

Fig. 10 zeigt den Vordertheil des Cephalothorax des Thieres ungeführ in der Größe, welche es bis zum 18./1. 95 erreicht hatte. Man bemerkt an der rechten Seite das normale Auge, während an Stelle des linken ein ca. $1 \mathrm{~cm}$ langes flagellumartiges Gebilde nit dichtem Haarbesatz inserirt ist. Die Ähnlichkeit desselben mit einem der Endflagellen der ersten Antennen wird dem Kenner schon an diesem Habitusbild anffallen, doch tritt dieselbe noch unverkennbarer an jener größer gezeichneten Abbildung (Fig. 11) entgegen, wclche von der heteromorphen Neubildung nach der im Mïrz 1897 abgeworfenen Haut angefertigt worden ist.

Wie man sieht, besteht das Gebilde aus einem 22 gliederigen Flagellnm, das an der Basis ziemlich breit ist, sich in seinem mittleren Theil allmählich und an seiner Spitze rasch verschmälert. Die Glieder an letzterer sind bedeutend lïnger als breit; weiter basalwärts nimmt aber ziemlich plötzlich die Länge immer mehr ab und die Breite zu, so dass der Charakter der Geißel ein ganz anderer wird. Nahe an der Basis werden die Segmente sodann wieder etwas länger; Hand in Hand damit geht aber zugleich auch eine auffallende Unregelmäßigkeit in der Gliederung, die nicht mehr um die ganze Peripherie herumreicht und auch andere Anomalien - wie aus der Figur zu ersehen ist - anfweist $\left.{ }^{1}\right)$.

Sehr auffallend ist der mächtig entwickelte Haarbesatz, welcher distalwärts von dem unregelmäßig gegliederten Basalstück gleich einer dicken Franse am Flagellum inserirt und naeh unten und außen gerichtet ist. In derartig kolossaler Ausbildung haben wir bis jetzt den Sinnesharbesatz noch bei keiner der untersuchten Formen kennen gelernt. Seine Hauptmasse wird wieder wie sonst durch die langen, zarten, hellen Haare repräsentirt, welche gewöhnlich als »Ricchschliuche* bezeichnet werden und in regelmäßigen Reihen angeord-

1) Es ist hier nicht der Ort, näher auf die Unregelmäßigkeiten einzugehen. Man vgl. T. H. Mongav (34), A Study of Metamerism pag. 435 "Modifications in Antennae of Arthropods\&. 
net sind. In unserem Falle kommen auf jedes Glied, vom proximalen und distalen Ende des Besatzes abgesehen, zwei solcher Reihen, und auf jede Reihe 6-12 oder gar 14 einzelne Riechhaare. Letztere erheben sich gemeinsam von einer Chitinfalte, welche sich von der iibrigen Oberfläche des Gliedes deutlich abhebt. Entsprechend der Zweizahl der Haarreihen sind auf jedem Fiihlerabschnitt natiirlich anch zwei solcher Falten vorhanden.

Abgesehen von den Riechhaaren sind aber noch andere Haarbildungen von bedeutender Länge und in. beträchtlicher Zahl an der Neubildung vorhanden. Dieselben flankiren die zarten Riechschlïnche auf beiden Seiten und haben offenbar den Zweck, zum Schutze derselben zu dienen.

Von außen nach innen gehend bemerken wir von diesen zunächst auf jedem Gliede ein, selten zwei Fiederhaare, von denen einige durch besondere Lünge und Dicke auffallen. Während die Fiedern der letzteren ziemlich weit von einander entfernt sind, und, schwertförmigen Blättchen ähnlich, mit breiter Basis dem Schafte aufsitzen, der in Folge dessen an Stellen, wo dieselben abgefallen sind, ein gestreiftes Aussehen zeigt, sind die Fiedern an den kleineren Haaren enger an einander gereiht und sitzen kleinen Verdickungen der Chitinhaut auf, welche dem Haarschafte im optischen Längsschnitte ein geperltes Aussehen verleihen.

An der Innenseite werden die Riechschläuche von einer zweiten Gruppe von Haaren flankirt, unter denen eines, das nächste an den zarten Sinneshaaren, durch seine größere Starrheit und Länge hervorragt, wie vor allen Dingen auch an dem größeren Loche jener Glieder zu sehen ist, wo die betreftende innere Haargruppe abgefallen ist.

Ganz dorsal liegt schlieBlich noch eine andere Reihe starrer Haare, welche einzeln auf jedes Glied vertheilt sind und in unserer Figur links zum Theil hervorragen.

Auf dem stark verjiungten Endtheile der Neubildung hört der fransenartige Haarbesatz auf; nur gefiederte und glatte Tasthaare sind auf demselben noch anzutreften. Es verdient noch der Erwähnung, dass man an ihm sowohl wie auch noch etwas weiter basalwärts eine Reihe von Haaren sieht, welche nicht vollständig ausgestiilpt sind, sondern zum Theil noch unter der Chitinhaut liegen und nur mit ihrer Spitze aus der Chitinröhre hervorragen 1).

1) Über die Beziehung dieser Chitinröhren zum Haarwechsel vgl. Hensen (23) und Braun (13). 
Noch bedeutender ist der Haarbesatz auf jenem Stadium, das bei der Häutung am 18./1. 98 erreicht wurde und in Fig. 12 sammt Gehirn und rechtem Auge dargestellt worden ist. Man sieht, wie an symmetrischen Stellen des Gehirnes die beiden sogenannten Optici aus dem Gehirn austreten und wie der rechte sammt dem Ocnlomotorius in das Ange und der linke, dickere in die heteromorphe Neubildung eintritt 1 ). Letztere nimmt an der mit zwei Sternen bezeichneten Stelle ihren Ursprung, während das weiter proximalwiirts gelegene Stück jener Falte angehürt, welche, scharf vom Cephalothorax abgesetzt, sich von einem Auge zum anderen erstreckt und desshalb von mir (25) »interoculare Briicke * genannt worden ist. In auffallendem Maße hat die. Nenbildung seit der Häutung am 18./3. 97 zwar nicht an Lünge zuigenommen, doch ist immerhin ein Zuwachs zu verzeichnen, demu sie besitzt jetzt 32 Glieder, also 10 mehr als fruher. Nahe ihrer Basis bemerkt man cine neue rudimentire Knospe, welche aus zwei nicht ganz von einander getremnten Gliedern besteht.

Der Haarbesatz stimmt im Großen und Ganzen mit jenem an dem oben beschriebenen ersten Stadium überein und weicht nur darin von ihm ab, dass die verschiedenen Haargruppen noch besser ausgebildet sind, wie namentlich deutlich an der etwas größer gezeichneten Fig. 13 zn sehen ist, die desshalb nur eine andere Reihenfolge der verschiedenen Haarreihen erkennen lässt, weil sie nicht wie Fig. 11 von der Ventralseite, sondern mehr von außen und oben gezeichnet worden ist, also ungefähr in der Lage, wie die Nenbildung am Cephalothorax inserirt war. Da letztere einen etwas gewundenen Verlauf nimmt, wie ans der großen Abbildung Fig. 12 zu ersehen ist, so bekommt man den Haarbesatz in den verschiedensten Stellungen zu sehen. Die drei in Fig. 13 dargestellten Segmente stammen aus jener Region, wo er am besten zu überblicken war. An meisten dorsal (in unserer Figur rechts am Rande) bemerken wir zunïchst an jedem Segment ein starres Haar mit spärlichen Fiedern, welches jener dorsalen Reihe von Haaranhängen angehört, die bereits oben bei der Beschreibung des ersten Stadiums crwähnt wurde, dort aber noch aus ungefiederten Haaren bestand. Gehen wir num nach anßen anf dem Segmente weiter, so treffen wir zu-

1) Eine genanere Analyse dieses Thatsachenbestandes werde ich in einer späteren Mittheilung geben, dieselbe wird entscheiden, ob die Bezeichnung sInnervirung der heteromorphen Antennula durch den sogen. Opticuse berechtigt ist oder nicht. 
nächst auf eine Reihe von Fiederhaaren, von denen zwei kurz sind, während das andere äußerst lang und kräftig ist und sogar noch die langen Riechschläuche iberragt. Auf dem ersten Stadium war von dieser Gruppe auf den meisten Gliedern nur ein Haar vorhanden und anch dieses war nur in einigen Fällen von hervorragender Länge. An den Riechschläuchen selbst bat sich nur die eine Veränderung. vollzogen, dass ihre basale Gliederung jetzt dentlich sichtbar ist, wïhrend sie dies an der ersten abgeworfenen Haut nicht war. Noch weiter ventralwärts und bereits auf die Innenseite übergreifend, findet sich sodann noch eine andere Gruppe vor, welche aus einem langen, dicken, stachelartigen Anhang und aus einem Büschel kürzerer und diinnerer, an ihrer Spitze gebogener Haare besteht. Diese Gruppe war anf dem ersten Stadium auch schon angelegt, aber, wie die gegebene Abbildung erkennen lässt, noch längst nicht so weit entwickelt.

Vergleichen wir nunmehr die Neubildung mit den Endflagellen einer Antennula -- demn nur diese kommt als Vergleichsobjekt in Frage - so ist man über die minutiöse Ähnlichkeit des Haarbesatzes des Exopoditen einer solchen mit jenem unserer Heteromorphose geradezu uberrascht, denn beide sind sich so ähnlich, dass sie durch eine und dieselbe Figur illustrirt werden können. Wir müssen also das charakteristisch gebaute Flagellum mit dem üppigen, fransenartigen Sinneshaarbesatz als Exopodit einer ersten Antenne bezeichnen. Die kleine Knospe, welche an der basalen Innenfläche der Neubildung entstanden ist, ist dann aber als Anlage des Endopoditeu aufzufassen. Von dem langen, dreigliederigen Protopoditen ist dagegen keine deutliche Anlage vorhanden. Es ist also anch hier an Stelle des total exstirpirten Auges der distale Theil und von diesem wieder an erster Stelle der Exopodit einer Antennula regenerirt, der proximale Theil dagegen unterdrückt worden. Ersterer ist aber dafuir um so sorgfältiger ausgebildet worden, denn er weist nicht nur die typische normale Form und den normalen Haarbesatz auf, soudern hat auch annähernd die Größe eines Antennulaexopoditen von einem Thiere gleicher Größe erreicht, da er circa $1 \mathrm{~cm}$ maß.

Ebenso typisch wie die äußere Gestalt und der Haarbesatz war anch der innere Bau eines Antennulaexopoditen an unserer heteromorphen Nenbildung ausgebildet, wie auf Schnitten festgestellt werden konnte.

Gleich wie bei Palaemon fällt auf denselben zunächst die Menge spindelfürmiger, zellenreicher Ganglien in dic Augen (Fig. 14 $g$, 
welche dicht an einander gedrängt in der mittleren Partie der Nenbildung liegen. Von diesen Ganglien sieht man nun mit der wünschenswerthesten Deutlichkeit Stränge paralleler Nervenfasern $\left(d^{\prime} n\right.$ ) am distalen Ende ausgehen, die sich distalwärts wenden und sich in ihrem, zum Theil etwas geschlängeltem Laufe immer mehr der Peripherie nähern, bis sie in eines der Sinneshaare eintreten. Mit der allergrößten Deutlichkeit ist der Strang dann auch noch in dem basalen Theile aller Haare nachzuweisen, weiter nach der Spitze zu machen sich jedoch Unterschiede zwischen den verschiedenen Haarkategorien bemerkbar. Während es nämlich bei den dickwandigeren Fiederhaaren leicht ist, den Nervenstrang bis in die Spitze zu verfolgen, gelingt das bei den dünnwandigeren, zarten Riechschläuchen nicht. Zwar habe ich auch in diesen bisweilen dic Faserm weit in den Schaft hinein verfolgen können, viel weiter, als dies bei Palaemon möglich war, aber bis zum freien Ende des Haares habe ich ihre Anwesenheit doch nicht feststellen können.

Die Ganglien liegen nicht direkt unter den Haaren, zu welchen sie gehören, sondern weiter nach dem Centralorgan zu; sie beginnen erst in dem näehstfolgenden Segment und reichen sogar — besonders wemn sie zu der zweiten hinteren Haarreihe gehören - in das zweitfolgende hinein. Nervenstrang wie Ganglien sind von einer bindegewebigen Hülle umgeben, zu welcher sich in und unter der Vorwöllbung, welcher die Riechfäden aufsitzen, die Matrixzellen des Haares gesellen. Bisweilen kommt es ror, dass bei der Hüutung der von diesen Zellen gebildete Haarschaft nicht ganz ausgestiulpt worden ist. Dann ist der Nervenstrang vor seinem Eintritt in das Haar von einer gefalteten Chitinröhre eingeschlossen, die einem halbumgestiilpten Handschuhfinger gleicht. Im Haare selbst habe ich bei den dïnnen Riechfäden und auch bei den kleineren Fiederharen keine Matrixzellen nachweisen können. Nur selten habe ich eimmal in einem Riechfaden einen Kern gesehen, der sich dann aber als Kern eines eingedrungenen amöboiden Blutkörperchens zu erkennen gab. Konstant dagegen bemerkte ich in dem Basaltheile der äußerst mächtigen, dicken Haare, welche die Riechfäden seitlich flankiren, eine Anzahl von Zellen, welche wohl den Matrixzellen beizuzählen sein dürften.

Wie bei Palaemon fasert sich der von den Sinneshaaren kommende Nerv im Ganglion anf, und ich bin in der Lage gewesen, die Art und Weise dieser Auffaserung hięr deutlich wahrnehmen zu kömnen. Jede Faser tritt nämlich - wie dies zuerst vом Ratu (42) 
Über die Regeneration von antennenähnlichen Organen etc. III. 251

richtig beschrieben hat - mit einer einzelnen Ganglienzelle in Verbindung, welche einen zweiten centripetalen Fortsatz entsendet. Aus der Sammlung dieser proximalen Fasern geht ein anderer Nervenstrang hervor, welcher dem Centralorgan zustrebt $(p m)$, und sich während seines Verlaufes mit anderen zu dickeren Strängen verbindet, welche häufig mit einander durch Seitenäste kommuniciren. Da die Nervenstränge nicht immer den geradesten Weg einschlagen, so kommt an der dem Haarbesatze gegenüberliegenden Seite der Nenbildung ein Durcheinander von über einander wegziehenden und anastomosirenden Nerven zu Stande, ans dem erst weiter proximalwärts ein reggelmäßiger Verlauf und ein vẹrhältnismäßig einheitlicher Stamm hervorgeht. Ganz kompakt ist letzterer aber auch damn noch nicht, denn mannigfach finden sich Lücken in ihm vor, in denen Blut cirkulirt, und auch richtige Blutgefäße mit eigener charaktcristischer Wandung ziehen in und neben ihm hin.

Letztere sind nicht nur im basalen Theile der Neubildung vorhanden, sondern erstrecken sich auch, zahlreiche Seitenzweige abgebend, distalwärts in den Theil des Flagellums hincin, welcher den Ganglicnapparat enthält.

Näher auf den Bau und die Verzweigung dieser Blutgefäße cinzugehen, wiirde nicht mit dem Zwecke dieser Zeilen in Einklange stehen, die nur die Ähnlichkeit des inneren Baues der an Stelle des linken Auges erzeugten Heteromorphose mit dem des distalen Theiles einer Anteunula demonstriren sollten. Ich will desshalb auch von anderen Details alssehen und nur noch erwähnen, dass ich ebenso wie in der weit entwickelten Neubildung von Palaemon auch in der von Palinurus Muskelbiindel nachgewiesen habe, deren Fasern znm Theil eine mehr oder weniger deutliche Querstreifung zeigten, obwohl sich das Gebilde nicht bewegte. Ich habe im Ganzen folgende drei Muskelgruppen unterscheiden können:

Die eine Gruppe liegt da, wo die Gliederung in Segmente ihren Anfang nimmt und erstreckt sich von unten außen nach oben innen, die andere tritt aus dem Anfangstheil der Neubildung in die kleine, erst zweigliederige Knospe hinein, an deren freiem Ende sich ebenfalls Bündel inseriren, und die dritte endlich, aus nur wenigen langen Fasern bestehend, liegt in dem ungegliederten Basalstïck. Wollen wir diese Gruppen Muskeln einer normalen Antennula gleichsetzen, so werden wir nicht fehl gehen, wenn wir die erste Gruppe als Anlage der Bewegungsmuskeln des Exopoditen bezeichnen, während die zweite offenbar den Muskeh des hier erst als Knospe angelegten 
Endopoditen entspricht, und die dritte als ganz rudimentiire Anlage eines der Protopoditenmuskelbündel anzusehen ist, welche normaler Weise die hier in ihrer Ausbildung unterdrückten einzelnen Protopoditenglieder gegen einander zu bewegen haben.

Also selbst an diesen wenig entwickelten Muskelanlagen liisst sich eine Ähnlichkeit mit einer normalen Antennula feststellen, mit der jedoch vollkommene Identität im Bau des Nervenapparates besteht, wie aus einer Vergleichung meiner Befunde namentlich mit denen von Kraepelin (29) und vom Rath (42) hervorgeht.

Es wird also auch bei Palinurus vulgaris an Stelle eines total exstirpirten Auges eine Antennula regenerirt, von welcher aber vor allen Dingen der distale Theil und von diesem wieder zuerst der Exopodit mit dem charakteristischen Sinneshaarbesatz zur Ausbildung gelangt.

Haben wir nun durch diese Feststellung bewiesen, dass die vou Milne-Edwards (33) beschriebene Anomalie ebenfalls durch heteromorphe Regeneration entstanden zu denken ist? So ohne Weiteres nicht; denn in jenem Falle war der Angenstiel und sogar ein Theil der Cornea vorhanden, deren anderer Theil durch das $4 \mathrm{~cm}$ lange Flagellum ersetzt war. Wir haben dagegen das Auge mit Stumpf und Stiel exstirpirt und können in Folge dessen nicht so ohne Weiteres erklären, dass auch an Stelle eines Theiles des Auges ein antennenihnliches Gebilde regenerirt wird.

Betonen möchte ich jedoch, dass auch in dem Milne-Edwardsschen Falle der distale Theil einer Antenuula und zwar, nach dem fransenartigen Harbesatze am Ende zụ schließen, der Exopodit einer solchen dem Augenstiel aufsitzt. Die auf demselben beobachtete Geißel war zwar $4 \mathrm{~cm}$ lang, während die Endflagellen bei Palinurus vulgaris immer ganz bedentend kürzer bleiben, aber gerade diese Abweichung ist eine Bestätigung meiner Auslegung, denn Palinurus penicillatus, an welchem die Anomalie anfgefunden wurde, gehört nicht den gewöhnlichen Langusten mit kurzen Endflagellen auf dem dritten Protopeditengliede, sondern den $\triangleright$ Langoustes longicornes an, welche sich nach Milne-Edwards ${ }^{1}$ ) durch den Besitz langer Endflagellen auszeichnen ${ }^{2}$.

1) Hist. nat. des Crust. Paris 1837. Bd. 2. pag. 295.

2) Es ist sehr zu bedauern, dass Mulve-Edwards keine eingehendere Beschreibung des Haarbesatzes und des inneren Baues der merkwiirdigen Missbildung gegeben und zumal nicht untersucht hat, ob im Augenstiel noch die Augenganglien und vom Auge selbst noch einige Ommatidien vorhanden waren. Namentlich das Fehlen der ersteren wïrde ans spïter zu erfahrenden Grïnden von ganz besonderem Interesse sein. 


\section{Versuche mit Scyllarus arctus.}

Im Frühjahr 1896 schnitt ich einer Anzahl scyllerus das linke Auge sammt Augenstiel total $a b$ und itberließ die Thiere, welche reichlich mit kleinen Muscheln gefiittert wurden, den Sonmer iiber ihrem Schicksal. Bei der Durchmusterung am 11. November stellte es sich herans, dass 14 Stiick am Leben geblieben waren, und dass von diesen ein knapp $10 \mathrm{~cm}$ lang'es Thier eine kleine heteromorphe Neubildung bekommen hatte. Die uibrigen 13 Scyllari wurden weiter geziichtet, ohne dass aber im Laufe der Zeit noch ein anderer cine solche Neubildung bekommen hätte. Sogar im Mai 1899 waren noch drei Stitck von ihnen am Leben, aber kein einziger hatte ein specifisch ausgebildetes Regenerat, das als Anlage einer Antemnula oder eines Auges zu deuten wäre, erhalten. Wir können also sagen, dass jene Thiere, welche nicht gleich mehrere Monate nach der Operation an Stelle des total exstirpirten Auges eine Heteromorphose bekommen haben, in der Folgezeit, anch wenn die Zuichtung iiber mehrere Jahre ausgedehnt wird, iiberhaupt an der betreffenden Stelle kein Organ und vor allen Dingen nicht etwa ein Auge regeneriren, Obgleich also die Zahl der bei Scyllarus beobachteten Heteromorphosen auf eine beschränkt blieb, so ist das mit ihr gewonnene Resnltat doch von der größten Deutlichkeit und steht hinter dem bei Palinurus erzielten kaum zurtick.

Wie bekannt sein dürte, sind die normalen Antenunlae beider Formen sehr ähnlich gebaut. Einem langen dreigliederigen Protopoditen sitzen nämlich zwei kleine gegliederte Endäste auf, von denen der Endopodit die Form einer viclgliederigen Geißel besitzt, die ihre größte Breite in der Mitte hat, etwas gewunden ist und einen Besatz von verschiedenen, gefiederten und ungefiederten Tasthaaren trägt. Ganz abweichend ist dagegen. der noch kiirzere Exopodit gestaltet. Er ist stark seitlich abgeplattet und besteht aus zwei verschiedenen Theilen, welche beide die äußere Form eines ungleichschenkeligen, rechtwinkeligen Dreiecks haben und durch eine Chitinfalte von einander abgetrennt sind. Die beiden Theile sind so an einander gefigt, dass die kurze Kathete gemeinsam ist, und die rechten Winkel an einander grenzen. Der kleinere proximale $\mathbf{A b -}$ schnitt ist ungegliedert und entbehrt, von spärlich vorbandenen, kleinen Stiftchen abgesehen, eines reichen Haarbesatzes, welcher dagegen dem zweiten größeren Abschnitt zukommt. Letzterer ist im unteren Theile ebenfalls noch ungegliedert, weiter distalwärts ist 
er aber aus zahlreichen, breiten, aber kurzen Segmenten zusimmengesetzt, welche an ihrer äußeren Ventralseite den charakteristischen, fransenartigen Haarbesatz mit den zarten Riechfäden trageu. Die Segmente nehmen nach der Spitze zu allmählich an Breite ab und bekommen schließlich unter Zunahme an Länge und unter Abrundung eine ganz andere Gestalt, so dass das distale Ende einem gewöhnlichen, aber wenig gliederigen, runden Flagellum gleicht. Dasselbe ist mit langen, dickwandigen, aber schlanken Haaren ohne Seitenfiedern besetzt. Der fransenartige Besatz von Riechfidden, von denen auf jedem Segmente, abgesehen vom Endflagellim, zwei Reihen vorhanden sind, bietet wie bei Pulinurus noch die besondere Eigenthämlichkeit dar, dass er seitlich von langen, kräftigen Schutzhaaren flankirt wird. Letztere treten an der äußeren Seite als lange, kräftige Haare mit zum Theil abgefallenen Seitenfiedern und an der inneren als dünnere, ungefiederte, schlanke Haaranhänge auf, welche zu zweien oder dreien auf jedem Gliede vorhanden sind und in ähnlicher Ausbildung sich auch an distalen Theile der dem fransenartigen Riechhaarbesatz gegeniiberliegendeu Seite vorfinden.

Vergleichen wir nun unsere in Figur $15 a$ dargestellte heteromorphe Neubildung mit der vorstehenden Beschreibung des distalen Theiles einer normalen Antennula, so füllt die frappante Ähnlichkeit beider sofort in die Augen, und zwar ist es vor allen Dingen der Exopodit der letzteren mit dem charakteristischen, fransenartigen Haarbesatz, welcher die Vergleichung beider herausfordert.

Der dreieckige Basaltheil ist zwar in unserer Figur noch nicht deutlich vorhanden, doch ist immerhin seine Abgliederung durch die Anlage von Chitinfalten angedeutet. Ausgezeichnet ist dagegen der proximale Abschnitt mit dem weniggliederigen, runden Flagellum und dem fransenartigen Haarbesatz ausgebildet. Seine Gliederung ist in oberen Theile regelmäßig ausgebildet und zeigt wegen des Vorhandenseins der breiten aber kurzen Segmente dieselbe Eigenthiimlichkeit, wie der oben beschriebene Außenast einer normalen Antennula. Auch die langen, kräftigen Haare mit den zum Theil abgefallenen Seitenfiedern flankiren - wie man sieht - nach außen die zarten Riechschlänche, an deren Basis eine dentliche Anschwellung (Fig. 15b) zu sehen ist. Sogar in dieser Kleinigkeit zeigt sich die Übereinstimmung des Hauptastes unserer Neubildung mit dem Exopoditen einer Antennula, da auch dessen Riechfäden die gleiche Eigenthümlichkeit aufweisen.

Dem Basaltheil unserer Heteromorphose sitzt außerdem eine 
kleine Knospe auf, welche der Lage nach dem Eudopoditen einer ersten Antenme entspricht, als dessen rudimentäre Anlage wir sie also zu betrachten haben. Von dem langen, dreigliederigen, beweglichen Protopoditen ist dagegen nichts zu sehen, so dass also auch bei Scyllarus an Stelle des total exstirpirten Auges der distale Theil einer Antennula und von diesem zunächst der Exopodit regenerirt worden ist.

\section{Versuche mit Eupagurus Prideauxii.}

Bei Eupugurus habe ich in vier Fällen das Auftreten einer heteromorphen Neubildung an Stelle eines total amputirten Auges feststellen können. Sie kamen alle an Individuen zur Beobachtung, welche Anfang Mai 1897 operirt worden waren und im Laufe der heißen Sommermonate starben. Da die Zuichtung der Thiere sich also auf cine nur verhältnismäßig kurze Zeit erstreckte, so haben auch die Heteromorphosen keine derartige Ausbildung erreicht, wie ich sie bei anderen Gattungen erzielt habe.

Die am wenigsten entwickelte Neubildung, welche in Fig. $16 a$ wiedergegeben ist, sitzt jenem schuppenförmigen Anhang des Basalstiickes des Augenstieles an, der bei der Operation nicht mit entfernt worden war. Sie repräsentirt - wie man sieht - eine kleine unregelmäßige Knospe, welche an ihrem freien Ende drei Sinneshaare trägt, deren zarte Beschaffenheit nicht eine Vergleichung mit den wenigen, starren Haaranluängen am Augenstiel, sondern nur eine solche mit den Riechfäden des Exopoditen einer Antennula gestattet.

Eine etwas längere Neubildung, die aber immer noch nur wenige Glieder aufweist und von den Riechfäden keinen erkennen lässt, ist in der folgenden Figur $(16 b)$ wiedergegeben. Im Gegensatz zum ersten Beispiel war hier der Schnitt noch weiter proximalwärts gefuihrt worden, wie man an dem Fehlen des schuppenförmigen Anhanges erkennt. Irgend eine Ähnlichkeit mit einer ersten Antenne, die im ersten Falle wenigstens angedentet war, lässt sich bei diesem Ausbildung'sstadium mit dem mangelhaften Haarbesatz absolut nicht erkennen.

Dies ist dagegen bei jener dritten Heteromorphose der Fall, welche in Fig. $16 \mathrm{c}$ dargestellt ist und den Höhepunkt der Entwickelung, so weit ich sie feststellen konnte, repräsentirt. Wir haben hier ein mehrgliederiges Flagellum vor uns, an dem die Unregelmäßigkeit der Gliederung und zwar besonders auch die spiralige Modifi- 
kation') derselben auffällt. An der Spitze der Geißel sitzt ein Biischel langer und schlanker Haare, welche mit Riechfiden jedoch nichts gemein haben und sich unter der Haut in handschulfingerartig eingestiilpte Chitiuröhren mit faltiger änßerer Wandung fortsetzen. Abgesehen von diesen Anhängen bemerkt man an der linken Seite einige wenige Haare, die aber gleichfalls nicht nit Riechfidden zu vergleichen sind. $\Lambda$ ls solche muissen wir jedoch jene drei Haare bezeichnen, welche auf der gegenüberliegenden Seite wahrzunehmen sind und mit den Buchstaben sh bezeichnet sind. Auch die nene Haaranlage (ash), welche noch ganz unter der IIant liegt und nur mit einer kleinen Spitze hervorragt, miissen wir wegen ihres Aussehens den sogenannten Riechfäden zuzählen.

Da sich nun aber letztere nur auf dem Exopoditen der Antennula vorfinden, so muissen wir unserer Neubildung, obwohl sie wegen der ganz rudimentären Ausbildung des normalen fransenartigen Riechhaarbesatzes und der unregelmäßigen, anomalen Gliederung von einem solchen bedeutend abweicht, doch eine gewisse Ähnlichkeit mit dem :üßeren Aste einer ersten Antenne zusprechen. Trotz der milngelhaften Entwickelung der beobachteten Neubildungen sind wir also auch bei Eupagurus Prideauxii zu einem ähnlichen Resultate wie bei den anderen Dekapodengattungen gelangt.

Im Anschluss an meine Versuche mit dieser Species muss ich noch einiger Angaben Morian's (35) gedenken, aus denen hervorgeht, dass anch dieser Forscher bei Eupagurus longicarpus an Stelle von total exstirpirten Augen im Sommer 1897 rudimentäre Nenbildungen erhalten hat, die er als antennenähnlich bezeichnet, die aber, nach den beigegebenen Abbildungen zu urtheilen, noch weniger weit ausgebildet waren als meine Heteromorphosen, so dass er nicht im Stande war, aus ihrem Bau eine Ïhnlichkeit mit einer Antenne des ersten Paares herauszulesen.

\section{Kurze Zusammenfassung der bis jetzt gewonnenen Ergebnisse.}

Fassen wir nummehr die Hauptergebnisse unserer Versuche, so weit wir sic bis jetzt mitgetheilt haben, kurz zusammen, so ergicht sich, dass Palaemon squilla, rectirostris und serratus, Pulacmontes varians, Sicyonia sculpta2), Astacus furiatilis, Palinurus vulgaris,

1) Vgl. Morgax (34).

2) Vgl. sÜber die Regeneration antennenähnlicher Organe etc.s II. Mittheilung. 
Scyllarus arctus und Eupagurus Prideauxii, welehe sich auf die Familien der Carididen, Astaciden, Loricaten oder Palinuriden und Paguriden vertheilen, an Stelle total exstirpirter Augen niemals wieder Augen, sondern - sofern iiberhaupt Regeneration eintritt - stets eine heteromorphe Neubildung erzeugen, welche bei genügender Ausbildung in allen Fällen mehr oder weniger einer Antennula gleicht, und zwar wird von der letzteren vor allen Dingen der distale Theil und von diesem wieder zunächst der äußere-Ast mit den Riechhaaren ausgebildet, während der lange, bewegliche, dreigliederige Protopodit entweder nur als Rudiment angelegt wird oder tiberhaupt nicht in irgend wie deutlicher Weise zur Ausbildung gelangt. Eine deutliche rudimentäre Anlage von ihm habe ich nur einige Male bei Palaemon, ferner bei Sicyonia und Astacus beobachten können, doch gab sich auch in diesen Fällen das Protopoditenrudiment nur an seinem Haarbesatz; nicht aber an seiner gestaltlichen Differenzirung und sonst so typischen Gliederung als solches zu erkennen.

Da die Familien, auf welche sich meine Untersuchungen erstreckt haben, im System ziemlich weit aus einander stehen, so dürte der Guiltigkeitsbereich der von mir ermittelten Thatsachen durch künftige Untersuchungen noch bedeutend ausgedehnt werden können. Von welchen Grenzen er höchst wahrscheinlich eingeschlossen wird, werden wir in einem späteren Kapitel zur Sprache bringen.

IV. Theil.

\section{Versuche mit theilweise abgeschnittenen Augen.}

\section{Verletzung des Auges durch calottenförmige Abtragtng.}

A. Das Problem.

Bereits im vorigen Kapitel, als von meinen Versuchen mit Palinurus vulgaris die Rede war, habe ich darauf hingewiesen, dass durch dieselben noch nicht bewiesen sei, dass die von Mrune-Edwards aufgefundene Anomalie ebenso wie meine antennulaähnlichen Organe durch heteromorphe Neubildung nach einer Verletzung entstanden zu denken sei. Denn bei meinen Versuchen hatte ich stets das rollständige Auge mit dem Augenstiel möglichst dicht am Kopfbrust- 
panzer abgeschnitten, in dem MiLne-Edwards'schen Falle war dagegen der Angenstiel sammt einem Theile der Cornea erhalten, deren fehlender Theil durch das lange Flagellum mit dem fransenartigen Sinnesharbesatz eingenommen wurde. Die Frage ist also nun, ob auch dann, wenn nur eine größere oder kleinere Calotte rom Auge entfernt wird, der iibrige Theil des zusammengesetzten Auges mit dem Augenstiel dagegen erhalten bleibt, ans der Wundfläche eine antennulaähnliche Geißel hervorwächst.

\section{B. Die Versuche.}

a. Versuche mit Palaemon. Vom 24.-27. Oktober 1895 wurde bei ca. 100 Palaemon, welche mehreren Arten angehörten, das linke Auge theilweise durch calotten-

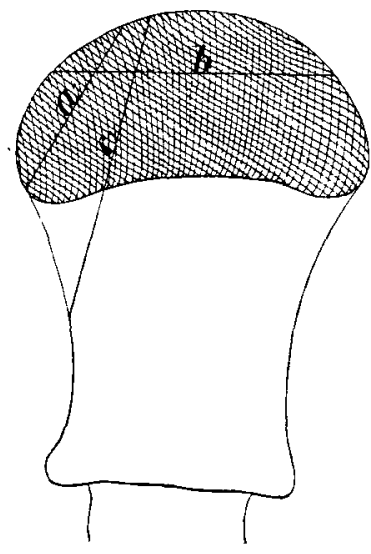
förmige Verletzung abgetragen, und zwar wurden die Schnitte in verschiedenen Richtungen geführt, wie aus beistehender Figur zu ersehen ist. Einmal wurde nämlich durch den Schnitt, der etwas schräg zur Längsachse des Auges geführt worden war, ein kleines calottenförmiges Stück abgeschnitten, wie durch den Strich bei $a \mathrm{zu}$ erkennen ist; ein anderes Mal wurde der Schnitt senkrecht zur Längsachse gefübrt und auf diese Weise ein größerer oder kleinerer Theil entfernt $(b)$, und zum dritten wurde durch eine äußerst schräge Schnittrichtung sammt einem Theil des eigentlichen Auges zugleich auch etwas vom Augenstiel abgetrennt $(c)$. Außerdem wurde die Operation auf diese Weise variirt, dass die Schnitte in parallelen Richtungen oder an der entgegengesetzten Seite des Auges ausgeführt wurden.

Als am 26./3. 96 die Krebse durchmustert wurden, lebten noch 77 Stïck, von denen aber keiner irgend eine Spur einer Antennulaanlage auf der Wundfläche des Auges aufwies. Letztere hatte sich zwar geschlossen, war aber trotzdem vor Allem wegen ihres dunkleren Aussehens noch dentlich wahrnehmbar. Das Gleiche stellte sich am 10. Juni heraus, und ebenso wenig konnte im November 1896 an den wenigen uiberlebenden Krebsen eine heteromorphe Neubildung, die aus der Wundfäche hervorgesprosst wäre, bemerkt werden. Wie im Frïhahre war letztere auch jetzt noch, trotzdem sie zugeheilt 
war, an dem schwärzeren Aussehen und an dem Fehlen der charakteristischen Facettirung zu erkennen. Ein Krebs blieb sogar bis Mitte Mai 1897 am Leben, ohne dass er ein anderes Resultat als die früher gestorbenen ergeben hätte. Die Schnittstelle war auch hier noch sichtbar und frei von Facettirung. Bei der Untersuchung auf Schnitten stellte es sich heraus, dass die Hypodermis zwar über die Wundfläche hinweggewachsen, die Bildung neuer Krystallkegel jedoch unterblieben war.

b. Versuche mit Palinurus vulgaris. Die Verletzung des Auges durch calottenförmige Abtragung habe ich bei der Languste nur einmal und zwar am 18./3. 97 ausgeführt. Der Krebs häutete sich in der Nacht vom 11.-12. Mai zum ersten Male und starb im August desselben Jahres, ohne dass auf der Wundfäche die Anlage eines Antennulaflagellums zu sehen gewesen wäre. Für sich allein ist dieses Experiment zwar absolut nicht beweisend, Hand in Hand mit den vorstehenden zahlreichen Versuchen bei Palaemon und mit der Thatsache, die im nächsten Abschnitt zur Sprache kommen wird. dass nämlich selbst bei Abtragung des ganzen Auges bis auf den Augenstiel keine antennulaähnliche Geißel aus dem freien Ende des letzteren hervorsprosst, hat aber anch dieser eine Befund einige Bedeutung.

\section{Das Resultat.}

Aus unseren Versuchen geht also hervor, dass bei calottenförmiger Abtragung des Auges die Wunde zwar verheilt, aber kein antennenähnliches Gebilde aus ihr hervorwächst, selbst wenn man die Thiere - wie dies mit den operirten Palaemon der Fall war - ein Jahr und länger am Leben erhält. Das antennulaähnliche Gebilde, welches MILNe-Edwards anf dem nur theilweise fehlenden Auge einer Languste gefunden hat, kann demnach nicht nach einfacher Verletzung, durch die weiter nichts als ein calottenförmiger Theil des Facettenauges entfernt worden wäre, entstanden sein. Man achte auf den Zusatz durch die weiter nichts als ein calottenförmiger Theil .... entfernt worden wäre wohl, da wir nur dieses and nicht etwa das bewiesen haben, dass die erwähnte Anomalie überhaupt nicht durch heteromorphe Regeneration entstanden sein könne. Wir haben also nur bewiesen, dass - falls überhaupt die Geißel aus dem Auge als heteromorphe Neubildung nach einer Verletzung hervorgesprosst sein sollte - letztere andere Anfangsbedingungen geschaffen haben muss, als bei unseren Versuchen realisirt waren, wo einfach durch einen 
glatten Scherenschnitt ein Theil des zusammengesetzten Auges entfernt worden war. Worin diese Anfangsbedingungen wahrscheinlich bestanden, soll in einem späteren Abschnitt erörtert werden.

\section{Die Entfernung des Auges unter Erhaltung des Stieles.}

\section{A. Das Problem.}

Wie bekannt ist, wurde bei allen meinen Versuchen, welche die Regeneration antennulaähnlicher Organe an Stelle ron Augen ergaben, der Schnitt möglichst dicht am Ansatzpunkte des Augenstieles am Kopíbrustpanzer geführt. Durch denselben wurden aber mit dem eigentlichen Auge und seinem Stiel sammt den dazugehörigen Muskeln und Blutgefäßen noch einige andere wichtige Dinge mit entfernt, deren An- oder $A$ bwesenheit von ausschlaggebendem Einfluss auf die Natur des regenerirten Gebildes sein konnte.

Es ist nämlich zuerst durch Claus (16 und 17) bei Branchipus und Nebalia und später besonders deutlich ron Parker (37) bei Astacus festgestellt worden, dass mit der Größenzunahme des Körpers auch die Vermehrung der Ommatidien des zusammengesetzten Auges ron einer bestimmten Wachsthumszone ans einhergeht, welche sich bei den beiden ersten Krebsen nach CLaUs als güirtelförmiger Streifen auf der dorsalen Augenfläche, beim Flusskrebse dagegen nach Parker's Angaben an der vorderen Ecke des Auges, da, wo dasselbe in den Augenstiel iubergeht, nachweisen lässt.

In der Mitte der Dorsalseite des Anges von Palaemon findet sich nun neben dem eigentlichen Auge gleichsam ein kleines Nebenauge vor, das sich besonders durch seine schwärzere Fürbung ron dem übrigen Auge unterscheidet und aus nicht typisch ausgebildeten Ommatidien besteht. In diesem kleinen schwarzen Flecke oder richtiger in den Hypodermiszellen, welche denselben umgeben, erblicke ich die Knospungszone, von der normaler Weise - wenn auch rielleicht nicht ausschließlich - die Bildung never Elemente des zusammengesetzten Auges ausgeht. Durch den an der Basis des Augenstieles gefuhrten Schnitt wird natürlich diese Knospungszone mit entfernt, und es ist nicht ausgeschlossen, dass bei dieser Operationsmethode desshalb die Wiedererzeugung ron neuen Augen zur. Unmöglichkeit gemacht ist, weil nur den Hypodermiszellen am distalen Ende des Augenstieles und speciell denen der genannten Stelle der Dorsalseite die Potenzen zur Bildung ron Ommatidien zukommen, die den Zellen an der Übergangsstelle des Augenstieles in den Kopfbrustpanzer 
fehlen. Wir diurften also bei distaler Fïhrung des Schnittes, d. h. bei Entfernung des Auges nuter Erhaltung des Stieles, kein antennulaähnliches Gebilde entstehen sehen, sondern miissten - falls überhaupt Regeneration eintritt - die Wiedererzeugung eines neuen Auges beobachten.

Abgesehen von den am distalen Augenstielende gelegenen Hypodermiszellen, von denen normaler Weise beim Wachsthum des Thieres die Vergrößerung des Auges ausgeht, werden nun aber bei der Schnittfiihrung an der Basis des Stieles noch andere wichtige Theile mit entfernt, deren Fehlen oder Vorhandensein ebenfalls ron großer Bedeutung für die morphologische Beschaffenheit des Regenerates sein kann. Es sind dies die vier Augenganglien, welche bekanntlich bei fast ${ }^{1)}$ allen stieliuugigen Krebsen in den Augenstielen liegen und mit dem Gehirn durch einen Nerrenstamm, den sogenannten Opticus, rerbunden sind. Diese Ganglien bleiben natïrlich erhalten oder werden - richtiger gesagt - nur an ihrem distalen Ende verletzt, wenn man nur das eigentliche Auge durch den Seherenschnitt entfernt, den'Stiel jedoch stehen lïsst. Da nun während der Embryonalentwickelung die Anlage des Auges im engen Anschluss an jene der Augenganglien erfolgt, so konnte man auf die Vermuthung kommen, dass von den letzteren ein formativer Reiz auf die distale Flïche des Augenstieles ausgeïbt wird, welcher die Hypodermiszellen derselben zur Umwandlung in Ommatidienelemente zwingt. Gesetzt den Fall, eine solche Reizwirkung bestïnde wirklich, so mïsste dann natiirlich wieder untersucht werden, $a b$ dieser Reiz nur aktivirend auf die Augenbildungsmechanismen wirkt, welche in den distalen Hypodermiszellen des Augenstieles lokalisirt und ausschließlich auf diese beschränkt sind, $o b$ er also einfach auslösend wirkt, einfach das Ventil öffnet, oder ob er zugleich auch jenen Zellen, die er trifft, die morphologische Beschaffenheit des Organs aufzwingt, welches aus ihnen hervorgeht. Im letzteren Falle wären natiurlich die Potenzen zur Angenbildung nicht auf bestimmte Zellen beschränkt, sondern es wären dazu alle fähig, welche von dem formativen Reize der Augenganglien getroffen werden können. Welche von diesen beiden Möglichkeiten nun aber auch das Richtige treffen mag, sicher ist, dass, falls iiberhaupt eine formative Reizwirkung der Augenganglien auf die Hypodermiszellen vorhanden ist, das Versuchsresultat anders aus-

1) Wir werden später sehen, dass es mindestens eine Ausnahme von der Regel giebt. 
fallen muss, wenn man das Auge mitsammt dem ganzen Stiel entfernt, als dann, wenn man es allein amputirt, den Stiel dagegen stehen lässt. Im ersteren Falle ist dann natürlich wegen Fortfall des formativen Reizes die Möglichkeit zur Entstehung eines neuen Auges genommen, während dieselbe im zweiten bei Schonung des Stieles gegeben ist. Nun, wir werden im Folgenden sehen, ob wir thatsächlich bei Erhaltung des Stieles andere Resultate als bei jenen Experimenten bekommen, wo der Schnitt an der Ansatzstelle des Augenstieles am Kopfbrustpanzer geführt worden war.

B. Die Versuche.

a. Versuche mit Palaemon. In der letzten Hälfte des November 1896 operirte ich, um eine Antwort anf die im Vorstehenden aufgeworfene Frage geben zu können, mehr als 100 Stiick Palaemon von verschiedener Species derart, dass auf der linken Seite mittels eines Scherenschnittes das eigentliche Auge mit dem dorsalen, schwarzen Fleck der Bildungszone entfernt, der Augenstiel dagegen geschont wurde. Lange Zeit ließ sich an den so operirten Thieren nichts von einer Regeneration, wenn wir von dem Wundverschluss absehen, wahrnehmen. Am 12. Mai 1897 waren noch 82 Stück von ihnen am Leben; aber kein einziger von diesen hatte an Stelle des amputirten Auges ein antennulaähnliches Gebilde auf dem Augenstiel regenerirt, während wir bei totaler Exstirpation des letzteren nach den Resultaten unserer Versuche sicherlich eine ganze Anzahl derartiger heteromorpher Neubildungen erhalten haben würden. Ebenso wenig wie von der Wiedererzeugung einer rudimentären Antennula an Stelle des Auges konnte man aber auch von einer solchen des letzteren selbst trotz vorhandener Andeutungen mit Sicherheit reden. Hierzu war man jedoch eher bei einer Reihe von Krebsen berechtigt, welche im Sommer 1897 gestorben und konservirt worden waren. Wie man an dem in Fig. 17 a dargestellten Augenstiel sieht, hat sich nämlich an dessen freiem Ende eine ziemlich scharf umschriebene Pigmentanhäufung entwickelt, welche vielleicht als die Anlage eines neuen Augès aufzufassen ist. Hierfür spricht vor allen Dingen die plötzliche Verdünnung der Chitindecke über der Pigmentansammlung, während freilich von einer typischen Eintheilung in scharf begrenzte, viereckige Facetten noch nichts zu sehen ist, denn das Chitin weist zwar eine Eintheilung in einzelne kleine Felder auf, doch weicht dieselbe nicht auffallend von der gewöhnlichen Chagrinirung der Augenstielwand ab. Rings um die ziemlich scharf umgrenzte Pigmentansammlung finden sich noch 
einige kleine, zerstreute Pigmentflecke vor, die sich nur an einer Stelle zu einem etwas größeren Fleck ansammeln. Auf diese Weise kommt es neben der großen Pigmentanhäufung zu einer kleineren Nebenansammlung, ein Verhalten, das ich bei der Mehrzahl der beobachteten Neubildungen realisirt fand. Die beiden Pigmentherde kounten entweder dicht genähert (Fig. 17 a) oder weiter von einander entfernt sein (Fig. 17 b). Die Anordnung, Gestalt und Größe der Pigmentanhäufungen war überhaupt ziemlich rerschieden; in ihrer einfachsten Ausbildung, wie sie bei einigen wenigen Exemplaren zur Beobachtung kam, bestanden sie aus einer größeren Anzahl kleiner, isolirter, schwarzer Flecke, die am distalen Ende des Augenstieles lagen und von denen einer durch bedeutendere Größe auffallen konnte. Im Vergleich zu dem normalen rechten Auge fiel an allen Pigmentanhäufungen, die zur Beobachtung kamen, die intensivere, schwarze Färbung auf, in der sie jenem Fleck in der Mittellinie der Dorsalfläche von normalen Augen glichen. Ihre Entstehung wurde tibrigens - wie nicht unwichtig ist zu bemerken an solchen Thieren beobachtet, bei denen durch die Operation nur wenig vom Augenstiel selbst mit dem Auge entfernt worden war. War der Schnitt tiefer, mehr der Basis des angeschwollenen Theils des Stieles genähert, und somit ein großer Theil des letzteren und der in ihm gelegenen Augenganglien amputirt worden, so habe ich weder im Sommer 1897 noch auch bei der Weiterzuichtung der Thiere im Winter 1897/98 eine größere Pigmentanhäufung entstehen sehen. Ein Krebs mit ziemlich gekïrztem Augenstiele lebte sogar noch im Frühjahr 1899, ohne dass er eine auffallende Neubildung wie die anderen mit größeren Stielresten bekommen hätte. Ebenso wenig war bei ihm wie auch bei allen anderen Thieren mit zu sehr gekürztem Augenträger die Entstehung einer antennulaähnlichen, heteromorphen Neubildung wahrzunehmen, die mit Sicherheit hier und da aufgetreten wäre, wenn der Schnitt noch etwas tiefer gefuhrt und der letzte Rest des angeschwollenen Stieltheils mit dem Überbleibsel der Augenganglien darin amputirt worden wäre. Unter den 28 Krebsen, welche im Sommer 1897 gestorben und konservirt worden waren, befanden sich im Ganzen 10 Stück mit Pigmentanhäufungen am distalen Ende des Augenstieles. Zu diesen kommen zwei weitere Exemplare. welche erst Ende Mai 1898 konservirt wurden, so dass also die Gesammtzahl der erhaltenen Neubildungen sich auf 12 beläuft. Diese Zahl repräsentirt jedoch nicht alle Krebse, welche itberhaupt derartige Pigmentanhäufungen bekommen hatten, da eine Reihe von 
ihnen bei der Weiterzüchtung gestorben und von den anderen Insassen des Aquariums aufgefressen worden war. Die 12 Neubildungen vertheilen sich auf die beiden Arten Palaemon serratus und rectirostris und zwar maßen die Vertreter der ersteren Species bis zu $10,2 \mathrm{~cm}$, die der zweiten bis zu $6,8 \mathrm{~cm}$, so dass sie also zum Theil zu den größten Exemplaren ihrer Art gehörten.

Wir hatten oben darauf hingewiesen, dass die Pigmentanhäufungen vielleicht als Anfangsstadien wiedererzeugter Augen aufzufassen seien. Die Betrachtung der inneren Organisation der Regenerate wird nun in der That die volle Berechtigung dieser Vermuthung ${ }^{1}$ ) erkennen lassen.

In Fig. 18 ist ein Theil eines Sagittalschnittes durch die Hauptpigmentanhäufung vom distalen Ende des Augenstieles eines Krebses dargestellt, der im Sommer 1897 gestorben war. Auf den ersten Blick erkennt man an diesem Schnitt zwei ganz differente Schichten, von denen die äußere unpigmentirt $(k r)$, die innere dagegen mit dunklem Pigment beladen ist $\langle\boldsymbol{r e}\rangle$. Die etwas eingehendere Beschreibung der ersteren dieser beiden Zelllagen soll den Anfang machen.

Wie aus der Fig. 18 ersichtlich ist, fällt an derselben zunächst die regelmäßige Anordnung in einzelne, parallel zu einander gestellte, lange und verhältnismäßig schmale Zellengruppen auf, die mit ihrer distalen Fläche der Chitindecke anliegen, mit ihrem fadenförmig auslaufenden, proximalen Ende sich dagegen in der Pigmentschicht verlieren. Jede dieser einzelnen peripheren Gruppen besteht aus zwei differenten Zelllagen, wie ebenfalls aus der Abbildung hervorgeht. Unter der Chitindecke, die eine Eintheilung in einzelne Felder entsprechend den darunterliegenden Zellengruppen noch nicht mit Sicherheit erkennen lässt, liegt nämlich zunächst eine Reihe von

1) Es bleibt jedoch eine Vermuthung, wenn Przibram (41) neuerdings ohne Weiteres jene drei Neubildungen, die er auf dem Augenstiel von Palaemon serratus nach Abtragung des eigentlichen Auges in drei Füllen erhielt, als neue Augen bezeichnet, ohne von einer Untersuchung auf Schnitten irgend etwas za erwähnen. Es ist zwar nach meinen Resultaten möglich, dass er nicht bloße Pigmentflecke, sondern wirkliche Anlagen zu neuen Augen vor sich gehabt hat, ich muss ihm jedoch den Vorwurf machen, dass er bei jenem Versuche vom 19./5. 97, wo er den Schnitt durch die linke Cornea führte, nicht das ganze Auge entfernt hat, wie aus seiner Abbildung hervorgeht. Auch seine Angabe von der Entstehung zweier neuer Augen auf einem Stiele hätte er durch eine Untersuchung auf Schnitten priifen sollen, da nicht alle Pigmentflecke Anlagen zu Augen repräsentiren. Vgl. hierzu meine Befunde pag. 267. 
Zellen, in welchen wir die Producenten der Chitindecke zu erblicken haben. Dicht unter dieser ersten Lage bemerkt man die Kerne der zweiten Reihe von Zellen, welehe durch das fadenförmig auslaufende proximale Ende und durch den charakteristischen Bau ihres Zellleibes ausgezeichnet sind. Derselbe weist nämlich in seinen verschiedenen Regionen eine höchst eigenthümliche Differenzirung auf. Nach Tinktion mit Hämalaun und Eosin bemerkt man zunächst um die Kerne herum eine Schicht intensiv blau gefärbten Protoplasmas, welche dem folgenden Zellabschnitt calottenförmig aufgelagert ist. Letzterer repräsentirt den bei Weitem größten Theil der ganzen Zelle; er ist durch das Eosin matt rosa gefärbt und besteht aus einer merkwiirdigen, granulirten Substanz. Auf diesen Hauptabsehnitt folgt endlich weiter proximalwärts der fadenförmig ausgezogene Theil, der aus einer dritten, durch die Farbstoffe lila gefärbten Substanz besteht und den granulösen Abschnitt calottenförmig umfasst. Da dieser untere Theil der Zellgruppen von Pigment rings umschlossen ist, so ist er nur selten deutlich auf Längsschnitten zu sehen. Dagegen ist an letzteren bereits an der hier und da sichtbaren, mittleren Trennungslinie zu konstatiren, dass der granulüse Abschnitt jeder Zellengruppe keine einheitliche Bildung ist, sondern mehreren Zellen angehört. Über die wirkliche Zahl derselben werden wir am besten durch Tangentialschnitte anfgeklärt, welche die Zellgruppen quer getroffen haben. An denselben bemerken wir nun zunächst, von der Peripherie der angeschnittenen Neubildung ausgehend, zwei unter der Chitindecke gelegene Zellen, deren Kerne einander genau gegeniiberliegen. Auf diese folgen nach innen vier Kerne, welche den distalen, intensiv blau gefärbten Theil der einzelnen Zellgruppen umlagern. Letzterer gehört also vier dicht an einander gepressten Zellen an, deren proximale Fortsetzung der granulöse und der fadenförmig ausgezogene Theil repräsentirt. Wir haben also im Ganzen in jeder Zellgruppe des pigmentlosen Abschnittes der Neubildung sechs Zellen ror uns: erstens nämlich zwei Hypodermiszellen und zweitens vier auf die folgende, eigenthümlich gebaute, lange Zellen, welche basalwärts bis in die Pigmentzone hineinreichen.

Vergleichen wir nunmehr diesen eingehend beschriebenen, peripheren Abschnitt mit einem normalen Auge, so ist ohne Weiteres klar, dass derselbe sowohl in Bezug auf Struktur wie auf Zahl der Zellen dem distalen Abschnitt eines Ommatidiums entspricht, dass also die zwei peripheren Zellen als Corneaerzenger nnd die vier folgenden als Krystallkegelzellen zu bezeichnen sind. Die eigent- 
lichen chitinösen Krystallkegel waren zwar in der in Fig. 18 dargestellten Neubildung noch nicht zur Ausbildung gelangt, doch konnte ich solche in einigen Ommatidien eines anderen Regenerats nachweisen, das ron einem Ende Mai 1898 konservirten Thiere herstammt.

Nachdem wir also somit den pigmentlosen Theil unserer Neubildungen als die periphere Schicht eines normalen Auges erkannt haben, müssen wir den Pigmentabschnitt der ersteren dem retinalen Theile des letzteren gleichsetzen; und zwar entsprechen zunächst die schwarzen Pigmentzellen, welche die basalen Theile der Krystallkegelzellen umgeben, den sogenannten Irispigmentzellen der deutschen Autoren resp. den »distal retinular cells \& Parker's. Neben diesem schwarzen Pigment kommt in geringerer Quantität ein gelbliches vor; welches nach Herrick's Befunden bei Alpheus (27, pag. 446) den accessorischen Pigmentzellen zuzutheilen ist. Auch die eigentlichen Retinulazellen sind in der Pigmentschicht der Neubildungen nachzuweisen, obwohl es zu einer Abscheidung der Sehstäbchen ihrerseits noch nicht gekommen ist. Im Gegensatz zu dem peripheren Abschnitt kann ich über die Zahl der Zellen im proximalen keine bestimmten Angaben machen, da die einzelnen Gruppen hier nicht so deutlich wie dort von einander getrennt waren 1 .

Nach innen gegen die Augenganglien zu ist die ganze Neubildung von einer Membran begrenzt, welche kontinuirlich in die Basalmembran der Hypodermis übergeht. Hierdurch wie durch die Thatsache, dass die qualitative und quantitative Ausbildung der Ommatidien vom Centrum der Neubildung nach der Peripherie hin abnimmt, wo sie zunäehst in langgestreckte Hypodermiszellen und schließlich in solche von gewöhnlicher Größe übergehen, dokumentiren sich die regenerirten Augenanlagen als Umwandlungsprodukte eines beschränkten Hypodermisbezirks, der am freien Ende des Augenstieles gelegen ist.

Ich hatte oben erwähnt, dass häufig neben der größeren Pigmentanhäufung, die wir mittlerweile als Augenanlage kennen gelernt

1) Abgesehen von den Retinulazellen, deren Zahl bekanntlich immer ; beträgt, ist übrigens die Zahl der übrigen Elemente im proximalen Theile des normalen Auges, namentlich was die Irispigmentzellen und die sogenannten »rudimentary retinular cellss anbelangt, noch keineswegs sichergestellt, wie atus einer Vergleichung der Arbeiten von Parker (37) einerseits und Rosenstadt (43; andererseits zu ersehen ist, doch scheint mir, was die Irispigmentzellen anbetrifft, der Erstere im Recht zu sein. 
haben, in einiger Entfernung eine zweite, kleinere zu beobachten ist (Fig. 17b). Die Untersuchung solcher Objekte auf Schnitten belehrt uns, dass auch diese kleineren Pigmentanhäufungen Augenanlagen repräsentiren können, von denen es also am freien Ende eines Augenstieles zwei geben kann, eine Angabe, die jedoch nur die von mir beobachteten Thatsachen wiedergeben, dagegen keineswegs das gelegentliche Vorkommen einer noch größeren Zahl ausschließen soll. Bemerkt sei jedoch, dass längst nicht alle Pigmentanhäufungen einer deutlichen Augenanlage entsprechen, denn ich habe solche an verschiedenen Stellen auch in tiefer liegendem Gewebe unterhalb der Basalmembran der eigentlichen Augenanlage vorgefunden, ohne dass ihnen darüber in der Hypodermis ein Bildungsherd von Krystallkegelzellen entsprochen hätte. Es genügt aber schon das Vorkommen von zwei Augenanlagen auf einem Stiele zum Beweis, dass nicht nur jene Zellen, welche in der Nähe der dorsalen Knospungszone des normalen Auges liegen, sondern auch noch weiter davon entfernte Hypodermisbezirke zur Augenregeneration befähigt sind.

Wir hatten bei der Amputation des Auges den Schnitt gewöhnlich möglichst distalwärts zu führen gesucht, um eine möglichst geringfügige Verletzung der Augenganglien zu erzielen; denn die vollkommene Vermeidung einer solchen ist absolut ausgeschlossen, wovon man sich bei Betrachtung eines Sagittalschnittes durch das Auge sofort überzengen wird. Man findet in Folge dessen unterhalb der neuen Augenanlagen den Ganglienapparat in mehr oder weniger derangirter Weise vor; ja derselbe war sogar bei dem Thiere mit der weit entwickelten Neubildung, das erst 18 Monate nach der Operation, Ende Mai 1898, konservirt worden war, nicht vollständig normal gestaltet, obwohl man deutlich sah, dass eine Ausbesserung stattgefunden hatte und zumal das am meisten distalwärts unter der Augenanlage gelegene Ganglion, die »lame ganglionnaire "Viallanes' (47), in Wiederherstellung begriffen war. Eine gewisse Regulationsfähigkeit nach geringfügigen Verletzungen kommt also dem Ganglienapparat zu, obgleich er nach vollständiger Exstirpation nicht wiedererzeugt werden kann, wie wir im ersten Kapitel sahen. Dort konstatirten wir nämlich die Thatsache, dass nach Amputation des ganzen Augenstieles ein heteromorphes Gebilde erzeugt wird und in demselben nicht etwa die Serie der vier Augenganglien, sondern ein ganz anderer Nervenapparat zur Entwickelung gelangt.

Wegen der größeren oder geringeren Derangirung der Angenganglien nach Entfernung des Auges rermisst man auch zunächst 
die nervöse Verbindung derselben mit der oder den Angenanlagen. Nur in dem bereits erwähnten Falle, wo nicht nur die drei proximalen Ganglien, sondern auch das vierte distale - wenn auch noch nicht in typischer Ausbildung - vorhanden waren, konnte die Anlage der Verbindung zwischen dem letzteren Ganglion und dem in Bildung begriffenen Auge nachgewiesen werden.

Länger als bis zu 18 Monaten nach der Operation habe ich Thiere mit Augenanlagen nicht am Leben erhalten, so dass ich nicht sagen kann, ob sich aus den letzteren bei noch länger andauernder Zuichtung schließlich typische Augen mit vollständig ausgebildeten Ommatidien entwickeln können, die vielleicht nur in Bezug auf die Zahl der letzteren von normalen abweichen. Ebenso muss dahingestellt bleiben, ob in den Fällen, wo sich zwei getrennte Augenanlagen vorfinden, schließlich doch durch Umwandlung der dazwischenliegenden Hypodermispartien ein einheitliches Auge entstehen kann. Wichtiger freilich als dies zu wissen, wäre eine genaue Kenntnis der Wiederherstellung des derangirten Ganglienapparates. Die Ausfüllung dieser Luicke steht aber mit unserer Problemstellung in keinem direkten Zusammenhang, sie mag desshalb künftigen, eigens zu diesem Zwecke angestellten Untersuchungen tiberlassen bleiben.

b. Versuche mit Palinurus vulgaris. Den ersten Versuch mit Palinurus begann ich am 4. December 1896, an welchem Tage einem ca. $10 \mathrm{~cm}$ langen Thiere das linke Auge abgeschnitten, der Augenstiel aber gelassen wurde. Die erste Häutung fand in der Nacht rom 24.-25./2. 97 statt, ohne dass nach derselben eine Spur von homo- oder heteromorpher Regeneration zu sehen war. Das Gleiche war nach der zweiten Häutung der Fall, die in der Nacht vom 11.-12./5. 97 vor sich ging und noch um ca. 3 Monate tuberlebt wurde. Ein anderer Krebs wurde in gleicher Weise am 27./12. 97 operirt; aber anch er regenerirte anf dem Augenstiel weder ein Auge noch eine rudimentäre Antennula wie jener im ersten Kapitel erwähnte Palinurus, dem das Auge mit dem Stiel total exstirpirt war, obwohl er noch im Mai 1899 am Leben war und drei Häutungen nach der Operation durchgemacht hatte. Die beiden Thiere mit amputirtem Auge, aber zuriickgelassenem Augenstiel verhielten sich also ähnlich wie jene Individuen von Palaemon, denen beim Abschneiden des Auges zugleich ein größeres Stück des Stieles mit dem darin befindlichen Ganglienapparat genommen war.

c. Versuche mit Eupagurus Prideauxii. Meine ersten Versuche mit Eupagurus datiren vom 17./1.96 und zwar wurden die- 
selben mit 20 Exemplaren angestellt, denen das linke Auge unter Schonung des Stieles amputirt war. Nach der ersten Häutung war an dem Stumpf des letzteren noch nichts von einer deutlichen Regeneration $\mathrm{zu}$ sehen; derselbe schloss vielmehr mit einer vollkommen weißen Fläche ab. Dies war jedoch nach der zweiten Häutung nicht mehr der Fall; und, als am 9.6. der Versuch abgebrochen wurde, konnte bei fünf Exemplaren die Entwickelung von Pigmentanhäufungen auf den Augenstielstumpfen konstatirt werden. Je nach ihrer quantitativen Ausbildung zerfallen dieselben in zwei Kategorien: die kleineren von ihnen waren nämlich am freien Ende eines zugespitzten Regenerats entstanden, das dem stehengebliebenen Rest des Augenstieles aufsaß, während die weiter ausgebildeten mit einer breiteren Fläche abschlossen. Von der letzten Kategorie ist das am weitesten entwickelte in Fig. 19 dargestellt. Man konnte demselben bereits äußerlich ansehen, dass es die Anlage eines neuen Auges repräsentirte.

Einmal war nämlich die Chitindecke ïber der Neubildung bedeutend rerdünnt und zum Anderen war die Pigmentauhäufung rings von einer röthlichen Zone umgeben, wie sie sich auch an den normalen Augen rorfindet. Besonders dieser letztere Vergleichspunkt veranlasste mich, in den Regeneraten von Anfang an Augenanlagen zu sehen, obwohl an ihrer Cornea die sonst so typische und scharf ausgeprägte Eintheilung in regelmäßige Facetten noch nicht zu konstatiren, sondern an ihrer Stelle erst eine weniger dentliche Chagrinirung vorhanden war.

Wie recht ich mit dieser Beurtheilung der Natur der Neubildung nach ihrem iußeren Aussehen hatte, lehrte das Studium der inneren Organisation. Nach demselben konnte es nämlich nicht im geringsten mehr zweifelhaft sein, dass Eupagurus ebenso wie Palaemon bei Entfernung des Auges unter Schonung des Stieles wieder Augen zn regeneriren beginnt. Die Augenanlage stellte auch hier ein Derivat der Hypodermis des freien Augenstielendes dar. Am Rande der Neubildung machten nämlich die differenzirten Augenelemente zunächst undifferenzirten, langgestreckten Zellen Platz (Fig. 20), welche dann in die Hypodermiszellen von dem gewöhnlichen Habitus iibergingen. Ganz wie bei Palaemon war auch bei Eupagurus besonders der distale Theil des Auges, die Krystallkegelschicht, ausgebildet, während der Retinaabschnitt $(r e)$ in der Entwickelung zurück war und vor allen Dingen der Rhabdome noch vollkommen entbehrte, obwohl die Retinulazellen ron dem charakteristischen Aussehen des normalen Eupagurus-Auges bereits vorhanden waren. Am besten 
waren wieder die Krystallkegelzellen $(k r)$ ausgebildet; sie waren wie immer in der Vierzahl vorhanden und hatten absolut das Aussehen von normalen. Man unterschied an ihnen nämlich an den Präparaten eine dünne, äußere Schicht, welche durch die Tinktionsmittel wenig gefärbt war und scheidenförmig den intensiver gefärbten, eigentlichen Krystallkegel umschloss. Auch der fadenförmig ausgezogene proximale Abschnitt, der sich zwischen den Retinulazellen verliert, bestand aus dieser weniger gefärbten Substanz. Wie beim normalen Auge wurden auch hier die Gruppen der Krystallkegelzellen proximalwärts von den sog. Irispigmentzellen eingescheidet, welche die Zwischenräume zwischen den einzelnen Ommatidien einnehmen.

Das Studium der inneren Organisation ließ auch erkennen, dass durch die Operation der Ganglienapparat mit seinem komplicirten Faserverlauf zum Theil ganz beträchtlich verletzt und derangirt war, sie zeigte aber außerdem, dass Eupagurus in bedeutend höherem Maße die Fähigkeit zur Wiederherstellung dieser komplicirten Ganglienanordnung als Palaemon hat, obwohl er ihn bei vollständiger Exstirpation ebenso wenig wie dieser wiederzuerzeugen vermag. Hand in Hand mit der größeren Leichtigkeit der Ausbesserung dieser letzteren geht auch die frühzeitigere Anlage der Retinafasern, welche sich rom Augen- zum distalen, vierten Augenganglion erstrecken. Schon bei ganz kleinen Neubildungen sieht man, wie ein zelliger Strang die Augenanlage mit dem Rest des Ganglienapparates verbindet. Es ist natürlich von großem Interesse, des Näheren die Ausgestaltung der verschiedenen Faserzuige, welche die Retina mit dem vierten Ganglion und die Ganglien unter sich verbinden, bei der Regeneration zu erforschen, doch würde dies - wie schon betont eine Arbeit für sich beanspruchen, für die Eupagurus das günstigste Material abgeben würde.

Es ist erfreulich, dass auch Mongax (35) im Sommer 1897 an Eupagurus longicarpus bei Exstirpation des Auges. unter Schonung des Stieles das gleiche Resultat wie ich, nämlich die Anlage von neuen Augen, erhalten hat, von denen er aber leider nicht angiebt, wie weit sie entwickelt waren, ob sie bereits Rhabdome aufwiesen und mittels der Retinafasern schon in Verbindung mit dem ebenfalls wiederhergestellten Ganglienapparat standen.

Endlich habe auch ich neuerdings noch eine zweite Versuchsserie mit reichhaltigem Material angestellt und das gleiche Resultat wie im Winter 1895/96 erhalten. Die Thiere waren am 23./10. 98 operirt worden, und zwar suchte ich bei der Entfernung des Auges den Stiel 
so viel wie nur möglich zu schonen. Bereits bei der Kontrolle am 22./2. 99 hatten von 46 iuberlebenden Krebsen 14 deutliche Augenanlagen aufzuweisen, 5 besaßen einen weißen Stumpf noch ohne Anlage und 27 hatten sich überhaupt noch nicht gehäutet, doch schienen 7 von ihnen bereits eine Augenanlage unter dem Schorf zu besitzen. Diese Thiere wiurden also bereits nach der ersten Häutung den Ansatz zu einem neuen Auge aufweisen, während ein solcher bei frühzeitigerem Eintritt der ersten Häutung erst nach der zweiten sichtbar wird. Die zweite eingehende Kontrolle nahm ich am 17. Mai vor. Es waren jetzt nur noch $13^{1}$ ) Thiere am Leben, von welchen 9 Anlagen zu neuen Augen aufwiesen. Bei 3 Stück von ihnen war die Augenregeneration sehr weit vorgeschritten; ja in einem Falle uibertraf der Ausbildungsgrad des neuen Auges sogar das in Fig. 19 dargestellte Stadium noch bedeutend. Vier der überlebenden Thiere hatten sich auch jetzt noch nicht ein einziges Mal gehäutet, doch konnte man bei dreien von ihnen die Anlage eines neuen Auges unter dem Schorf bemerken.

\section{Das Resultat.}

Unsere Erwartung, dass bei Amputation des eigentlichen Auges unter Schonung des Stieles die Regeneration vielleicht ganz anders als bei totaler Exstirpation mit dem Stiel verlaufen würde, hat sich also in vollem Umfange bestätigt. Denn weder bei Palaemon, noch bei Palinurus, noch bei Eupagurus wuchs aus dem Augenstielstumpf ein antennulaähnliches Organ hervor, was bei totaler Entfernung in den Fällen, wo überhaupt Regeneration stattgefunden hätte, mit Sicherheit geschehen wäre. Ja bei Palaemon und Eupagurus, denen wir nach Chastran's ${ }^{2}$ ) Untersuchungen auch noch Astacus

1) Schlechtes Wasser hatte die Reihen der Versuchsthiere im März und Anfang April ganz bedenklich gelichtet.

2) Chantran (15) sah nämlich nach Amputation der Augen, die er nicht an der Stielbasis, sondern weiter distalwärts vollzog, wieder Augen entstehen, ein Resnltat, das mit den meinigen bei Palaemon und Eupagurus nach Entfernung des Auges bei Schonung des Stieles vollständig übereinstimmt, während ich nach totaler Exstirpation mit dem Stiele das Auftreten einer rudimentären Antennula bei Astacus ebenso wie bei den anderen Krebsen feststellen konnte. In meiner zweiten Mittheilung pag. 450 glaubte ich außerdem aus den CHANTRAN'schen Angaben herauslesen zu können, dass alte Krebse Antennulae an Stelle von Augen, junge dagegen vielleicht wieder Augen regeneriren; nach meinen jetzigen Resultaten bin ich jedoch zu der Überzeugung gelangt, dass 
anreihen können, entstanden sogar auf den Stielstumpfen die Anlagen zu neuen Augen.

Sollen wir nun hierfür den Umstand verantwortlich machen, dass bei alleiniger Entfernung des Auges ohne den Stiel am distalen Ende des letzteren jene Zone von Hypodermiszellen erhalten bleibt, welche vielleicht allein noch die Potenzen zur Augenbildung erhält, oder sollen wir letztere von der Anwesenheit der nur theilweise verletzten Augenganglien abhängig erklären?

Nun wurde zwar bei Palaemon durch den Schnitt mit Sicherheit auch die deutlich gekennzeichnete dorsale Bildungszone mit entfernt und auch bei Eupagurus der Schnitt in einiger Entfernung rom eigentlichen Auge geführt, so dass man hiernach der zweiten Alternative zuneigen könnte. Wir dürfen uns aber für dieselbe trotzdem nicht entscheiden, weil nicht ausgeschlossen, bei Palaemon durch das Auftreten ron zwei Augenanlagen auf einem Stielstumpf sogar mit Sicherheit bewiesen ist, dass nicht nur die Hypodermiszellen der Bildungszone, sondern auch weiter ron ihr entfernte Elemente des freien Stielendes zur Erzeugung von Ommatidien fähig sind. Eine Lokalisation der Augenbildungspotenzen ist natürlich auch so noch möglich, nur wären dieselben nicht auf jene Zellen im Umkreise des dorsalen, schwarzen Augenfleckes beschränkt, sondern auf einen größeren Bezirk am distalen Angenstielende ausgedehnt. Für diese Beschränkung der Augenregenerationsfähigkeit auf den distalen Augenstieltheil aber könnte man die Art und Weise der embryonalen Eutstehung des gesammten Stielauges verantwortlich machen. Aus der-

die Befunde Chantran's, welche leider ungenügend geschildert sind, doch nicht zum Ziehen dieses Schlusses ausreichen. $O b$ an Stelle eines Auges wieder ein Auge oder eine Antennula regenerirt wird, hängt nämlich davon ab, ob der Schnitt durch den distalen Theil des Augenstieles oder durch seine Basis geführt wird; dem Alter der Versuchsthiere aber hierbei eine Rolle zuzuschreiben, dazu liegt zuniichst noch gar kein Grund vor. Der sourgeon opaque et bifide" könnte nach meiner jetzigen Ansicht nur dann ein wirklicher Antennulaansatz gewesen sein, wenn durch den Schnitt, den Chaxtran ungefähr in der Mitte des Stieles fiihrte, in diesem Fall anch der Ganglienapparat entfernt oder vollständig zerstört worden wäre, da von der Abwesenheit desselben die Entstehung heteromorpher Antennulae allem Ansehein nach ablängt, wie wir weiter unten sehen werden. Der Unterschied, welchen CHAxTras zwischen jungen und alten Flusskrebsen aufdeckte, ist also nicht principieller Natur, sondern besteht nur darin, dass einjährige Thiere nach Amputation der Angen nnter Schonung eines Theiles des Stieles und des darin befindlichen Ganglienapparates besser und rascher Augen regeneriren als zweijähige und ausgewachsene, welche außerdem sehr zur Produktion von Monstrositiaten neigen. 
selben geht nämlich hervor, dass nur der distale Theil des Augenträgers von Anfang an in enger räumlicher Beziehung zu der Augenanlage steht, während der größte Theil seiner Wandung weiter entfernte und erst nachträglich abgeschnürte Partien des Cephalothorax repräsentirt. Wegen dieser räumlichen Zuordnung mögen also vielleicht nur die distalen Stielzellen die Potenzen zur Augenbildung erhalten haben, die den proximal gelegenen abgehen.

Bei dieser Sachlage ist natülich der sicherste Weg zur Entscheidung der Frage der, dass man das Auge entfernt, den Stiel jedoch stehen lässt und die Ganglien in demselben auf irgend eine Weise abtödtet oder ausreißt. Ich habe derartige Versuche mit Palaemon, Palinurus und Eupagurus im Wintersemester 1898/99 in Angriff genommen und werde in einer späteren Mittheilung iuber ihre Resultate berichten.

Ich bin jedoch auch jetzt schon in der Lage einen Beweis, wenn auch keinen absolut bindenden, zur Entscheidung der Frage vorzubringen; und zwar spricht derselbe nicht für die erste, sondern für die zweite Alternative, nach welcher die Wiedererzeugung der Augen von der Anwesenheit der Augenganglien abhängig wäire. Ließen sich nämlich Krebse ausfindig machen, welche zwar Stielaugen besitzen, deren Augenganglien aber nicht in den Augenträgern, sondern im Cephalothorax liegen, und wïrden bei diesen Krebsen nach totaler Exstirpation der Augen mit dem Stiel stets wieder Augen, nie aber antennulaähnliche Organe entstehen, so liegt auf der Hand, dass dieses zu Gunsten jener Ansicht schwer in die Wagschale fallen würde, welche in der Wiedererzeugung der Augen eine formative Reizwirkung erblickt, die von den Augenganglien auf die distalen Zellen des Stieles ausgeübt wird.

Wir werden im folgenden Abschnitt sehen, dass es in der That Krebse giebt, welche die erwähnten Verhältnisse aufweisen.

\section{Die totale Exstirpation der Augen bei Porcellana und ihre Folgen.}

Um meine Versuche über die Regeneration antennulaähnlicher Organe an Stelle total exstirpirter Augen auf ein möglichst zahlreiches Krebsmaterial zu stützen, wurde auch vom 22.-28./11. 95 bei ca. 80 Stuck Porcellanen das linke Auge vollständig amputirt, und zwar verfuhr ich dabei so, dass ich die Augen mit der Scherenspitze aus ihren Höhlen ausstach, eine Operation, die sehr leicht auszuführen ist, weil die Thiere ihre Stielaugen nur wenig bewegen und 
nicht wie die Brachyuren in Höhlen seitlich einklappen können. Wie bekannt sein dürfte, zeichnen sich die Augen der Porcellanen durch die Kürze ihrer Stiele aus, die aber trotzdem deutlich genug ausgebildet sind und gleich den Augenstielen anderer Podophthalmen Muskeln zu ihrer Bewegung enthalten (Fig. 23 am). Mit dem Cephalothorax sind sie durch eine dünne Gelenkhaut verbunden, welche in verschiedene Falten gelegt ist, bei deren Ausgleichung die ganze Haut eine beträchtliche Länge erreichen würde. Beim Ausstechen der Augen wird natürlich diese dünne Gelenkhaut zerrissen und zum größeren oder geringeren Theile mit entfernt. Die größte Mehrzahl der operirten Thiere gehörte der Art Porcellana platycheles, der kleinere Theil dagegen Porcellana longicornis Milne-Edw. an. Ich kann nicht sagen, dass sich eine dieser beiden Arten viel besser zu den Versuchen als die andere eignete, doch duirfte $P$. platycheles desshalb den Vorzug erhalten, weil sie größer und desshalb bei der Operation leichter zu fassen ist. Da sich die Thiere gut in den Aquarien halten, so hätte ich sicher eine bedeutend größere Zahl mit Regeneraten bekommen, wenn nicht im Januar 1896 in dem Bassin eine Epidemie die Reihen bedenklich gelichtet hätte. Dieselbe brachte es mit sich, dass Anfang Juni 1896 bei Abbruch des Versuchs nur noch neun Individuen am Leben waren, von denen sieben deutliche Neubildungen aufwiesen. Sechs von diesen gehörten $P$. platycheles, das siebente dagegen der kleineren Art longicornis an.

Sehr erstaunt war ich num aber tiber die Natur der entstandenen Neubildungen, die nicht, wie ich nach den bei Palaemon und Sicyonia erhaltenen Resultaten erwartet hatte, antennulä̈hnliche Organe repräsentirten, sondern typische neue Augen waren. Schon an den lebenden Thieren war dies unter dem Mikroskop mit der größten Deutlichkeit festzustellen, denn die Cornea war deutlich facettirt und unter derselben waren die charakteristischen Krystallkegel selbst bei den am wenigsten weit entwickelten Neubildungen sichtbar (Fig. 21) und die Untersuchung auf Schnitten zeigte, dass diese Beurtheilung der Natur der erhaltenen Neubildungen nach dem äußeren Aussehen vollkommen das Richtige traf (Fig. 22). Die Regenerate erwiesen sich nämlich als noch weit typischer entwickelte Augenanlagen, als dies bei Palaemon und Eupagurus nach Abtrennung des Auges unter Schonung des Stieles der Fall war. Denn dort war ron einer typisch ausgebildeten, regelmäßig facettirten Cornea wie bei normalen Augen noch nicht die Rede, während dies bei Porcellana selbst bei den weniger weit entwickelten Neubildungen der Fall war. Außerdem 
konnte ich in letzterem Falle bei allen fünf Regeneraten, welche in Schnitte zerlegt wurden, nicht nur die Anlage der Retinula, die ja auch bei Palaemon und Eupagurus zu konstatiren war, sondern auch die Neubildung der Rhabdome feststellen. Da auch die Retinafasern $(r f)$, welche das eigentliche Ange mit dem distalen Augenganglion verbinden, vorhanden waren, so hatte ich also in der typischsten Weise regenerirte Sehorgane vor mir, die sich von normalen höchstens durch ihre geringere Größe unterschieden. In einem Falle fiel aber sogar dieses Unterscheidungsmerkmal weg; hier war das regenerirte Auge derartig weit entwickelt, dass derjenige, welcher nicht wusste, welches Auge ausgestochen worden war, wohl kaum das regenerirte herausgefunden haben wtirde. Betreffs des Größenunterschiedes zwischen den regenerirten und den normalen Augen sei noch erwähnt, dass derselbe nicht nur durch dic geringere Zahl der.Ommatidien, sondern anch durch die geringere Größe der Bestandtheile der Einzelaugen bei den Neubildungen bedingt war. Am auffallendsten waren die Größenunterschiede bei den Krystallkegeln, während dieselben bei der Retinula weniger ansgeprägt waren. So verhielt sich z. B. die Länge der Krystallkegel des regenerirten Auges zu dem normalen bei einem Thiere wie $1: 2$, während das Verhältnis der Retinulahöhe ca. wie 9:11 war.

Die Carapaxbreite der Exemplare von Porcellana platycheles, welche an Stelle der exstirpirten Augen wieder Augen regenerirt hatten, schwankte $\mathrm{zwischen} 51 / 4$ und $10 \mathrm{~mm}$. Es waren also unter ihnen sowohl juingere als alte Individuen von für die Species bereits als groß zu bezeichnenden Dimensionen vorhanden, während die kleinste Porcellana gerade zu den beiden Exemplaren gehörte, bei denen eine Neubildung unterblieben war.

Wie kommt es nun aber, dass die Porcellanen im Gegensatz zu allen anderen untersuchten Dekapoden bei vollständiger Amputation des Stielauges wieder ein Auge und keine Antennula regeneriren? Es kommt daher, weil wir hier durch die Operation ganz andere Anfangsbedingungen wie dort gesehaffen haben. Letztere entsprechen nämlich keineswegs jenen, die bei Palaemon und Eupagurus nach totaler Exstirpation des Stielauges nahe an der Stielbasis gegeben sind, sondern sind vielmehr mit denen identisch, die wir bei den beiden Krebsgattungen nach Amputation des Anges unter Schonung des Stieles erreicht hatten. Unsere Versuche mit Porcellana gehören also nicht in das erste Kapitel dieser Mittheilung, welches über die 
Resultate nach totaler Exstirpation handelt, sondern sind - wie wir sehen werden - mit Recht dem zweiten über die Versuche mit nur theilweise abgeschnittenen Augen eingereiht worden.

Mir wurde dies sofort klar, als ich an eine genanere Untersuchung der Regenerate an Totopräparaten und an Schnittserien ging (Fig. 23). Es stellte sich nämlich hierbei heraus, dass bei diesen Podophthalmen, denn als solche müssen wir die Porcellanen entschieden bezeichnen, die Augenganglien nicht wie sonst im Augenstiel liegen und mit dem Gehirn nicht vermittels eines langen Nervenstranges, dem sogenannten 1) Opticus verbunden sind, wie dies z. B. Fig. 12 von Palinurus zeigt, sondern dass ein solcher Stiel der Angenganglien, wie wir mit Berger(4) den Verbindungsstrang der letzteren mit dẹm Gehirn auch nennen könneu, bei den Porcellanen überhaupt nicht existirt. Die Augenganglien sitzen nämlich hier dem Gehirn direkt an, so dass letzteres in dieser Beziehung sehr an den Habitus des Gehirns edriophthalmer Krebse, z. B. an das von sphaeroma serratum erinnert, von welchem BeLLonci (3) eine gute Abbildung gegeben hat. Während bei den übrigen stieläugigen Krebsen, bei denen die Centralorgane der Photoreception vom Gehirn ab in die Augenstiele hineingerïckt sind, die vorderen Seitentheile des Gehirns, aus denen die sogen. Optici entspringen, fälschlicher Weise oft als Lobi optici bezeichnet werden, sind solche also bei Porcellana in Folge der Vereinigung der Augenganglien mit dem übrigen Gehirn in der That vorhanden, wie aus der Fig. 23 zu ersehen ist. Durch diese Vereinigung erscheint der Vordertheil des Porcellanagehirns im Gegensatz zu dem anderer Dekapoden in zwei scharf von einander abgesetzte Hemisphären getheilt, welche durch eine schmale Commissur mit einander verbunden sind. Der reiche, vordere Zellenbelag am proximalen Theile dieser Hemisphären (Fig. 23 agz) entspricht nicht etwa der Gruppe der $>$ cellulae superiores mediales", welche am Gehirn anderer Dekapoden vorn zwischen den Einmündungsstellen der sogen. Optici liegen, sondern gehört bereits den Augenganglien an. Bei dièsen anatomischen Verhältnissen ist

1) Wenn wir unter Opticus den Verbindungsstrang des Sehorgans mit den Centren der $>$ Photoreception $<$ verstehen, so ist dieser Ausdruck für die Verbindung der Stielaugen mit dem Gehirn nicht angebracht, wie bereits Claus (16), Berger (4) und Belloxci (3) betont haben, denn die Centren der Photoreception sind hier durch Ganglien im Augenstiel repräsentirt und der sogen. Opticus entspricht thatsächlich einer Gehirnkommissur. 
es klar, dass wir bei totaler Exstirpation der Augen mit dem Stiel bis zur Gelenkhaut doch nicht den gesammten Ganglienapparat mit entfernen, sondern höchstens dessen distalen Theil, vor Allem die "lame ganglionnaire « $(l g)$ verletzen oder auch ganz amputiren können. Wir haben also thatsächlich bei Porcellana, obgleich wir das ganze Stielange entfernt haben, doch im Grunde dieselbe Operation ausgeführt wie bei Palaemon und Eupagurus, wenn wir nur das eigentliche Auge entfernten, den Stiel dagegen stehen ließen.

Aus der Thatsache, dass Porcellana nach totaler Exstirpation der Augen mit dem Stiel im Gegensatze zu den anderen, von mir untersuchten Dekapoden wieder Augen erzeugt, geht nun aber hervor, dass zum mindesten bei dieser Gattung zur Augenregeneration nicht die Anwesenheit solcher Zellen nothwendig ist, welche an der Grenze von Stiel und eigentlichem Auge liegen und normaler Weise für die Vermehrung der Ommatidien des wachsenden Auges sorgen, sondern dass dazu auch Zellen befähigt sind, welche weiter proximalwärts an der Ansatzstelle des Stieles am Kopfbrustpanzer liegen, also der Gelenkhaut, die diesen mit jenen verbindet, angehören.

Wenden wir uns hiernach nun wieder den Momenten zu, welche - wie wir oben bei der Problemaufstellung ausführlich erörtert haben - die Natur des Regenerates beeinflussen könnten, so sind wir offenbar nach den vorstehenden Resultaten dazu berechtigt, die Entscheidung, ob an Stelle eines amputirten Auges wieder ein Auge entsteht oder nicht, der Anwesenheit oder dem Fehlen der Augenganglien zuzuschreiben, denn diese allein blieben bei Porcellana erhalten, während die normalerweise ommatidienliefernden Zellen am distalen Ende des Stieles mit diesem selbst amputirt worden waren. Die Entstehung neuer Augen wäre also bei Palaemon und Eupagurus nach Exstirpation, unter Schonung der Stiele eben so wie auch bei Porcellana nach Amputation mit dem Stiel von einem formativen Reize abhängig, der von den Augenganglien auf die anliegenden Partien der Hypodermis ausgeübt wird; und zum Antworten auf diesen Reiz wären nicht nur die Zellen am distalen Stielende, sondern auch solche an seiner Basis befähigt.

Der Beweis erscheint zunächst vollkommen einwandsfrei; er ist 
es aber leider nicht absolut, da man immer noch Folgendes erwidern könnte: Die Thatsache, dass bei Porcellana an Stelle der total mit dem Stiele exstirpirten Augen wieder Augen erzeugt werden, und dass die Augenganglien bei diesen Krebsen im Cephalothorax liegen, repräsentirt nur ein zufälliges, kein causales Zusammentreffen. Die Familie der Porcellaniden nimmt gegenüber den anderen untersuchten Dekapodenfamilien eine Stellung für sich ein, denn sie ist weder den Makruren noch den Brachyuren beizuzählen; und es erscheint auch nicht gerechtfertigt, sie mit den Paguriden zusammen als Anomuren zu bezeichnen. Das Regenerationsvermögen ist nun aber sogar bei einander nahe stehenden Formen oft recht beträchtlich verschieden; es ist darum nicht ausgeschlossen, dass der Unterschied der Regenerate, die nach totaler Augenexstirpation mit dem Stiele bei Porcellana einer- und den übrigen untersuchten Krebsen andererseits auftreten, seinen Grund in einem ganz anderen Umstande als in der Lage der Augenganglien hat. Ich könnte hierauf entgegnen, dass das verschiedenartige Regenerationsvermögen doch durch einen Unterschied in der Organisation bedingt sein muss, und dass dieser Unterschied doch wohl in der von der Regel so auffallend abweichenden Lage der Augenganglien gesucht werden mlisse, gebe jedoch zu, dass auch dieser Gegeneinwand meine Ansicht von der formativen Reizwirkung der Augenganglien nicht absolut sicher begründen kann. Ich muss desshalb die Resultate meiner Experimente mit Palaemon, Palinurus und Eupagurus abwarten, bei denen der Augenstiel erhalten blieb, die Ganglien darin aber entweder abgetödtet oder mit einer Pincette ausgerissen wurden.

Immerhin ist klar, dass ich auch jetzt schon guten Grund habe, die Wiedererzengung der Augen einer formativen Reizwirkung, welche von den Augenganglien auf die anliegenden Hypodermiszellen ausgeübt wird, zuzuschreiben.

Warnen möchte ich jedoch davor, mir hiernach etwa die Ansicht unterzuschieben, dass ich ganz allgemein für die Abhängigkeit der Ausgestaltung der Endorgane vom Nervensystem eintrete, da nach den vorliegenden Thatsachen die Vertretung einer solchen Ansicht ganz und gar unmöglich ist. Denn einmal hat LOEB (32) nachgewiesen, dass nach Durchschneidung des Rückenmarkes der vom Centralnervensystem abgetrennte hintere Theil der Larve von Amblystoma doch die Metamorphose zum fertigen Thier und zwar gleichzeitig mit dem vorderen Abschnitt durchmacht, dass also ein Einfluss des Centralnervensystems auf die morphogenetischen Vor- 
gänge in diesem Falle sicher nicht existirt; und sodann haben wir durch Schaper (44) erfahren, *dass das Centralnervensystem in einer gewissen frühen Entwickelungsperiode keinerlei bestimmenden Einfluss auf die typische Entwickelung des embryonalen Organismus hat«, während bekanntlich später ein Einfluss des Nervensystems auf die Erhaltung der zugehörigen Endorgane in ihrer typischen Ausbildung in verschiedenen Fällen festgestellt ist. So konnte Schaper z. B. zeigen, dass »bei vollständiger Abwesenheit der motorisehen Hirncentren und der Atrophie der Vorderhornzellen des Riickenmarkes « doch die Muskulatur bei den Froschlarven sich in derselben Weise wie sonst entwickelt, obwohl im postembryonalen Leben ihre Erhaltung von der Anwesenheit der zugehörigen Theile des Nervensystems abhängig ist. Angesichts dieser Thatsachen mag desshalb anch nicht unterlasseu sein, zu betonen, dass ich eine Causalbeziehung zwischen Augenganglien und Augenanlage nach dem vorliegenden Materiale auch nur für die Regeneration beim ansgebildeten Thier für wahrscheinlich halte und keineswegs diese meine Ansicht ohne Weiteres auch auf die Embryonalentwickelung ausgedehnt wissen will, wozu zunächst noch gar kein Grund vorliegt ${ }^{1}$.

Die Thatsache, dass bei Porcellana an Stelle des total mit dem Stiel exstirpirten Auges stets wieder ein Auge regenerirt wird, gestattet uns nun aber anßerdem einer Ansicht, welche wir bereits in der ersten Mittheilung mit gutem Grunde bekämpft hatten, jede Spur von Berechtigung abzuschneiden. Es handelt sich nämlich um jene, welche in den an Stelle von Augen erzeugten Antennulis atavistische Bildungen erblickt.

Ich habe bereits früher darauf hingewiesen, dass wir anch dann, wenn wir unsere heteromorphen Antennulae als atavistische Bildungen bezeichnen würden, doch herzlich wenig gewonnen hätten, denn wir hätten weiter nichts gethan, als die Entstehung von Antennulis an Stelle von Augen einer gewissen Kategorie von Erscheinungen ein-

1) Nebenbei möchte ich außerdem die Bitte aussprechen, mich nicht etwa in einen Topf mit Tornier (46) zusammenzuwerfen, der die bekannten Thatsachen der Abhängigkeit der Erhaltung der Endorgane von den zugehörigen Partien des. Nervensystems und umgekehrt dazu benutzt, um darzuthun, wie erworbene Eigenschaften durch Vermittelung des Centralnervensystems vererbt werden können. Näher auf die Art und Weise seiner Beweisführung einzugehen, ist hier nicht am Platze, aber wohl auch desshalb ganz unnöthig, weil die Nichtigkeit derselben leider nur allzu offen am Tage liegt. 
geordnet, ohne damit ein causales Verständnis ihres Auftretens erlangt zu haben. Kupfrer (30) und neuerdings Weisuans (48) geben nun zwar dies vollkommen zu, meinen aber, dass »anch die einfache Einsicht, dass hier Atavismns vorliegt, d. h. Rückschlag anf eine Vorfahrenform, schon eine ganz dankenswerthe Erkenntnis" ist, weil wir so wenigstens wüssten, „warum dem Krebse statt des Auges nicht etwa ein Federbusch oder ein Affenschwanz hervorgewachsen " sei. Mir scheint aber, dass wir Letzteres auch ohne die Anuahme, dass ein "Atavismus « vorliege, einfach desswegen wissen, weil der Krebsorganismus wohl die Potenzen zur Erzeugung von Antennulis etc. nicht aber von $\gg$ Affenschwänzen besitzt. Desswegen kann unter bestimmten, durch das Experiment gesetzten Bedingungeu an Stelle des Stielauges eine Antennula erzengt werden, ohne dass wir zu der ungeheuerlichen Annalime gezwungen sind, dass die podophthalmen Krebse an Stelle der Stielaugen oder vielmehr der Augenstiele, denn diese sollen natiurlich nur einer "Gliedmaße» entsprechen, ein zweites Paar ron Antennulis besessen haben, denn das müssten wir annehmen, wenn Atavismus Riickschlag anf die Stammform bedentet, und wir nicht mit unklaren Begriffen operiren wollen 1 :. Auch

1) Dies thut z. B. KupfFer, wenn er in seiner Rede sagt: „Anlangend nun die Heteromorphosen bei den Dekapoden, so ist die Annahme einer atavistischen Bildung zwar nicht durch den Nachweis eines gleichgestalteten und gleichgestellten Ahnenorgans zu begrïnden, aber sie ist immerhin zulässig.৫ Nein, sie ist ganz unzulässig! Denn wenn Atavismus sRiickschlag auf die Stammform. bedeutet, so muss das Organ, welches man als atavistische Bildung bezeichnet, bei den Vorfahren gleich-gestaltet und -gestellt gewesen sein, da man sonst den Begriff aufgiebt und somit eingesteht, dass es sich um einen Rückschlag auf die Stammform nicht handeln könne. Dieselbe Unklarheit findet sich bei WheELER (j0), der einen abnormen Seitenast an einem Bein von Dilophus tibialis als Rüekschlag auf die Antennenform der Vorfahren bezeichnet, welche doch offenbar an den Beinen keine Fühler hatten. Hierza kommt noch, dass die Bezeichnung des Anhanges als Antenne nur auf eine oberflächliche Ähnlichkeit hin begrïndet ist, da WHEELER nicht gezeigt hat, dass sich an ihm Sinnesorgane vorfinden, die sonst nur an den Fühlern der hypothetischen Vorfahren vorkommen. Die ïbrigen Thatsachen, welche sonst immer als Beispiel für Rückschlag bei Regeneration angeführt werden, die von FrITZ MüLLER (36), BRINDLEY (14), BORDAGE (5-10) etc., sind mir alle recht wohl bekannt, doch ich habe mich von der Richtigkeit einer solchen Annahme in keinem Falle iiberzeugen können. WEISMANN (48) giebt zwar selbst zu, sman könnte vielleicht diese Fäle so aufzufassen versuchen, als handle es sich dabei um eine zu geringe Kraft der Regeneration, die das verlorene Glied nur unvollkommen wiederzuersetzen vermöge $<$ meint aber, dass man den BARFurTu'schen (1) Befund der gelegentlichen Regeneration einer fünffingerigen Hand anstatt einer vierfingerigen beim Axolntl doch nur als Atavismus auffassen künne. 
der verblendetste Phylogenetiker wird natürlich die Annahme, dass die Vorfahren der stielängigen Krebse an Stelle der Augenstiele ein

Nun, mir scheint es sehr wilkürlich, die fünffingerige Hand herausangreifen und ihr allein atavistische Bedeutung zuzumessen, denen mit zwei oder drei Fingern (BAREuRth) oder mit sechs (GIARD 20] bei Pleurodeles) aber eine solche Bedeutung abzusprechen. Auch hitet man sich wohl, die Befunde von Tornier (46), der am Fuße vom $A x n l o t l$ sechs bis acht Zehen, bei einigen aber auch nur drei auftreten sah, oder diejenigen von PIANa (39) als atavistische Erscheinungen aufzufassen, welcher unter Anderem am rechten $F u ß$ eines jungen Triton cristatus an Stelle zweier amputirter Zehen die Entstehung von vier neuen beobachten konnte. Ein Peadant zu diesen Thatsachen liefern die Resultate von E. Schultz (45) bei Versuchen iiber die Regeneration von Spinnenfüßen. An Stelle von drei Klauen wurden nämlich an regenerirten Füßen bei Epheriden häufig nur zwei gebildet, und die Zähne an den Klauen waren ebenfalls in Bezug auf Zahl starken Schwankungen unterworfen, indem meistens weniger, manehmal aber auch wehr als an normalen Klauen entstanden. s So bildete ein regenerirter Fuß eine Klaue mit sieben, die andere mit zwei Zähnen, während die normale Zahl fünf und sechs ist.\& Für mich lehren diese und ähnliche Thatsachen nicht mehr, als dass bei der Regeneration, ebenso wie es häufig nur zu einer unrollkommenen Wiedererzeugung von geringerem Differenzirungsgrade kommt, anch bisweilen eine Überproduktion der verlorenen Theile anftreten kann. Selbst die bekannten Boulexger (11-12)-Wenner'schen (49) Angaben über die ataristische Beschuppung des Eidechsenschwanzes zeigen anch sur, dass eine komplicirtere Beschuppung bei der Regeneration häufig nicht zu Stande gebracht, sondern durch eine einfachere, weniger differeuzirte ersetzt wird, indem Tuberkelschuppen, Kämme, Dornen und Schuppenkiele nicht reproducirt werden. Den Anschein von Berechtigung gewinnt die Annahme von atavistischen Bildungen hier nur dadurch, dass die weniger differenzirte Beschuppung nach Regeneration eine Ähnlichkeit mit derjenigen von Formen besitzt, denen an und für sich eine weniger differenzirte Beschuppung zukommt, und die desshalb als die Stammformen angesehen werden. Die von Werner (49, pag. 130) bei Gecko vittatus und Phyllodactylus Stumpffii gemachte Beobachtung, nach welcher bei diesen Thieren bei erstmaliger Regeveration die Schuppen mit Tuberkeln, bei der zweiten jedoch ohne dieselben, also in weniger differenzirtem Zustande erzeugt werden können, zeigt aber deutlich, wie Recht ich habe, die einfachere, sogen. atavistische Beschuppung auf zur vollständigen Regeneration in ungenügendem Maße vorhandene Mittel zu schieben, denn in den beiden genannten Fiallen reichten dieselben zwar das erste Mal zur Herstellung der normalen, höher differenzirten Gebilde aus, das zweite Mial jedoch nicht mehr; sie waren reducirt worden. Eine Zusammenstellung von angeblichen Rückschlägen auf die Stammform bei Regeneration hat auch GIaRd (21) gegeben, doch ist dieselbe so unkritiscb, dass sich z. B. die Befunde Davenport's (19) über den verschiedenen Grad von Exaktheit, mit dem sich die Regeneration bei Obelia nach Amputation auf verschiedener Höhe vollzieht, darin aufgeführt finden, und ferner aus Abbildungen von PARONA (38) geschlossen wird, dass sich alle Papillen bei Tethys anstatt in unverzweigter in gegabelter Form, welche die ursprïngliche sein soll, regeneriren, während ein Blick auf dieselbe Figur, anf welche sich GIARD beruft, vollkommen genigt, um zu sehen, dass 
zweites Antennulapaar besaßen, für baren Unsinn erklären; nun gut, dann ist aber überhaupt die Einordnung meiner Entdeckung in die Kategorie »Atavismus « aufuugeben.

Wir wollen nun aber auch noch von dieser einwandsfreien $\mathrm{Ab}$ weisung des Atavismus absehen und noch einmal die Möglichkeit zugeben, dass die Auffassung der Entstehung ron Antennulis an Stelle total exstirpirter Augen als atavistische Erscheinung doch das Richtige trifft, weil vielleich KUPFFER darauf hinweisen wird, dass gerade die Thatsache, dass Eupagurus und Palaemon, denen wir auch noch Astacus anreihen können, bei totaler Exstirpation der Augen Antennulae, bei Amputation des eigentlichen Auges unter Schonung des Stieles aber wieder Angen erzengen, fur die Annahme einer atavistischen Erscheinung spricht. Wir müssen hierauf mit der Frage erwidern, wie es dann komme, dass Porcellana trotz des Besitzes von Stielaugen doch nie an deren Stelle eine Antennula, sondern stets wieder ein Auge erzeugt, obwohl die anderen von mir untersuchten Dekapoden bei Exstirpation des Auges mit dem Stiel wenn sie überhaupt regeneriren - stets eine Antennula erzeugen müssen? Hier zeigt sich deutlich, wie wenig mit phylogenetischen Spekulationen anzufangen ist, wie fruchtbar dagegen jene Betrachtungsweise der Entstehung von Formen ist, die sich jene in meiner Abhandlung iiber die formativen Reize (26) niedergelegten Anschauungen zur Richtschnur nimmt. Mit ihrer Hilfe ist es uns gelungen, die Entstehung von Augen an Stelle von solchen bei Porcellana nach totaler Exstirpation mit dem Stiel und unter Schonung des letzteren nach Amputation des eigentlichen Auges bei Palaemon etc. mit einem hohen Grad von Wahrscheinlichkeit auf eine Ursache zurtickzuführen, nämlich auf einen formativen Reiz, der von den Augenganglien auf die anliegenden Theile der Hypodermis des Augenstieles resp. des Kopfbrustpanzers ausgeübt wird, und bei dessen Wegfall in Folge dessen auch die Entstehung neuer Augen unterbleiben muss. $\mathrm{Ob}$

auch unter den regenerirten unverzweigte und unter den nicht regenerirten verzweigte vorkommen können. Letzteres kann man übrigens an jedem unverletzten Tethys-Exemplar feststellen. Endlich ist auf die Angabe KupfFER's, dass nach DARwiN (18) manche Orthopteren sanstatt der speciell differenzirten, langen, mächtigen Sprungbeine kiirzere Laufbeine reproduciren, zu erwidern, dass die Stelle bei G. R. Gray (22), auf welche sich Darwin bezieht, also lautet: sif it loses a leg by violence this is reproduced, but of a smaller size, at the next change of skin *, was längst nicht so viel aussagt wie der KupFFERsche Satz, sondern ganz für meine Auffassung der sogen. Riickschläge bei der Regeneration spricht. 
Über die Regeneration von antennenähnlichen Organen etc. IV. 283

wir nun in diesem formativen Reize einen »Umschaltungsreiz * vor uns haben, dessen Wegfall allein zum Inthätigkeitsetzen jener Bildungsprocesse, die zu Antennulis führen, ausreicht oder ob ihm eine andere causale Werthigkeit zukommt, dies zu entscheiden müssen wir der Zukunft überlassen.

\section{Die Exstirpation der Augen bei Isopoden und ihre Folgen.}

Wenn wir die anatomischen Verhältnisse des Isopodenkopfes ins Auge fassen und vor allen Dingen bedenken, dass die Augenganglien hier ähnlich wie bei Porcellana noch in enger Verbindung mit dem Gehirn stehen, so ist klar, dass wir auch bei gründlicher Exstirpation der Augen mittels eines Skalpellschnittes, der nicht nur das Auge, sondern auch einen Theil der anliegenden Kopfhaut entfernt, doch im Grunde genommen keine andere Operation ausführen, als wenn wir bei Krebsen mit Stielaugen nur das eigentliche Auge entfernen, den Stiel aber mit den darin befindlichen Ganglien stehen lassen. Wir sind also berechtigt, anch unsere Experimente mit sitzäugigen Krebsen dem Kapitel über die Versuche mit nur theilweise abgeschnittenen Augen einzufügen.

Wenn nun meine Ansicht, welche die Augenregeneration von der Anwesenheit der Augenganglien für abhängig erklärt, das Richtige trifft, so miissen auch die Isopoden an Stelle exstirpirter Augen - falls überhaupt Regeneration eintritt - wieder Augen regeneriren. Ob dies zutrifft, wird aus den folgenden Versuchen hervorgehen, die bereits im Herbste 1895 in Angriff genommen wurden.

Ich benutzte $\mathrm{zu}$ meinen Versuchen Idothea tricuspidata and Sphaeroma serratum, von denen sich die erste Art häufig, die zweite jedoch nur selten häutet. Die Operation wurde mittels eines Skalpells ausgeführt und so gründlich vollzogen, dass mit dem Auge ich wählte immer das rechte - zugleich ein Theil der angrenzenden Kopfhaut entfernt wurde.

Wie zu erwarten war, habe ich nun in keinem Falle das Auftreten einer Antennula an Stelle des Auges beobachtet, bei fünf Individuen dagegen die Entstehung kleiner, neuer Augen mit der größten Deutlichkeit festgestellt. Von diesen fünf Individuen gehören zwei der Gattung Idothea und die drei anderen der Gattung: Sphaeroma an.

Die am weitesten entwickelte Neubildung konnte ich bei einer 
Idothea feststellen, welche Ende Oktober 1895 operirt und am 15./12. 95 konservirt worden war (Fig. 24). Ihr neues Auge wies mindestens 1) 55 Ommatidien auf und stand mittels neu angelegter Retinafasern (anrf) bereits mit den Augenganglien in Verbindung. Da, wo die Ommatidien am besten ausgebildet waren, hatte sich die Cornea bereits auch zu den typischen Linsen differenzirt. Die chitinösen Krystallkegel waren in der für Idothea charakteristischen Weise ausgebildet und glichen ganz denen des normalen Auges ${ }^{2}$.

Bei der zweiten Neubildung, welche bei Idothea zur Beobachtung kam, zählte ich 39 Einzelaugen, von denen die am besten ausgebildeten in der Mitte des Regenerates ebenfalls bereits Cornealinsen besaßen. Auch hier verbanden Retinafasern das neue kleine Auge mit den Augenganglien. Das Thier war Mitte April 1896 operirt und am 8. Juni konservirt worden.

Nicht so weit wie die neuen Augen von Idothea waren jene von Sphacroma ausgebildet. Sie stammen alle drei von Thieren, welche Anfang November 1895 operirt und Mitte Mär 1896 gestorben waren. Das am weitesten entwickelte Auge wies hier nur circa 35 Ommatidien auf, die mittels der Retinafasern mit den Augenganglien verbunden waren und die typischen gedrungenen Sphaeromakrystallkegel aufwiesen. Die einzelnen Ommatidien bildeten keine geschlossene, calottenförmige Anlage, sondern waren zum Theil durch Lücken ron einander getrennt, was auch bei Idothea zu beobachten war.

Auf der tiefsten Stufe der Ausbildung stand das Regenerat eines Thieres, welches sich iiberhaupt noch nicht gehäutet hatte. Die Narbe war hier noch deutlich zu sehen; unter ihr war aber bereits - wie das Studium auf Schnitten erwies - eine neue kleine Augenanlage von circa 20 Ommatidien mit verschieden großen Krystallkegeln vorhanden. Dieser Befund macht es mir wahrscḥeinlich, dass ich die Zahl der Regenerate noch bedeutend hätte vermehren können, wenn ich noch mehr Sphaeromen, von denen sich die meisten nach vier Monaten noch nicht ein einziges Mal gehäutet hatten, konservirt und auf Schnitten untersucht hätte. Nun, es genügen aber auch

1) Ich zählte die Krystallkegel, von denen jedoch beim Schneiden des Objektes mancher herausgesprungen ist, so dass das neue Auge noch mehr als 55 Einzelatugen besessen hat.

2) Auch Przibram (41) theilt mit, dass er bei einer Idothea an Stelle des linken Auges, welches er smöglichst vollständig entfernt eines neuen feststellen konnte. 
schon die fünf Fälle zum Beweise, dass die sitzäugigen Isopoden an Stelle exstirpirter Augen wieder Augen regeneriren können.

Das Resultat schließt sich also den übrigen des Kapitels iber die Versuche mit nur theilweise entfernten Augen in der erwarteten Weise an und liefert einen weiteren Baustein zur Begründung der Ansicht, die ich mir über die Abhängigkeit der Augenregeneration von der Anwesenheit der Augenganglien gebildet habey.

Blicken wir nunmehr vom Ende dieses Kapitels über die »Versuche mit theilweise abgeschnittenen Augen" noch einmal auf seinen Anfang zurïck, wo die Resultate nach "Verletzung des Auges durch calottenförmige Abtragung " zur Sprache kamen, so sind wir jetat im Stande, mit einem ziemlichen Grad von Wahrscheinlichkeit jene Anfangsbedingungen namhaft zu machen, welche realisirt sein mussten, falls die Milse-Edwards'sche Missbildung heteromorpher Regeneration ihren Crsprung rerdankt.

Wir sind nämlich in Folge einer Reihe ron Thatsachen zu der Ansicht gefülırt worden, dass die Entstehung neuer Angen an Stelle exstirpirter von der Anwesenheit der Augenganglien, die Entstehung ron Antennulis an ihrer Stelle aber von der Abwesenheit dieser Ganglien abhängig ist. Trifft diese Ansicht das Richtige, und ist thatsächlich die von Milxe-EDwards entdeckte Missbildung als

1) Die Angabe Roux's (Kampf der Theile pag. 53, dass sich das Auge der Schnecken nach Carrière nur dann regenerire, wenn das Fiihlerganglion erhalten bleibt, beruht auf einem Irrthum, da CARrière gerade das Gegentheil gefunden bat: die Augen werden immer regenerirt, gleichviel ob die Augenträger ganz oder nur theilweise oberhalb des Ganglions abgeschnitten werden. Ja die Augenregeneration tritt sogar ein, wenn alle vier Tentakeln, Theile der Kopthaut und sogar des Schlundkopfes abgeschnitten worden sind. Nur bei Abtragung des Gehirns unterbleibt entgegen der Behanptung Spallanzani's die Regeneration der verloren gegangenen Theile; die Thiere gehen nach dieser tiefgreifenden Operation immer zu Grunde. Vgl. Carrière, Studien über die Regenerationserscheinungen bei den Wirbellosen. I. Würzburg 1880. Wie ich durch eine briefliche Mittheilung Prof. Roux's erfuhr, hat bereits JoH. MüLler (Lehrb. d. Physiologie. 1. Aufl. 1834. Bd. I. pag. 355 u. 368; 4. Aufl 1844. Bd. I. pag. 320) bei der Wiedererzeugung verloren gegangener Theile die beiden Möglichkeiten ins Auge gefasst, $>0 b$ die in dem Ganzen verbreitete organisirende Kraft, wie bei der ersten Entwickelung, diese Theile nacherzeugt, oder ob die noch unversehrt vorhandenen Centraltheile des Nervensystems die Wiedererzeugung der Theile, zu welchen sie Nerven ausschicken, einleiten (l. c. 1. Aufl. pag. 355$)$. 
Heteromorphose aufzufassen, so miissen durch die Verletzung - von der theilweisen Zerstörung des eigentlichen Auges abgesehen - auch die Ganglien aus dem Augenstiel entfernt worden sein. Wollen wir also die Möglichkeit der Entstehung ähnlicher Missbildungen wie die erwähnte nach theilweiser Abtragung des Auges nachweisen, so dürfen wir nicht nur einen calottenförmigen Theil des letzteren entfernen, wie wir dies im Anfange dieses Kapitels thaten, sondern wir mïssen zugleich auch die Augenganglien aus dem Stiel herausreißen. Die Prüfung dieser Schlussfolgerung auf ihre Richtigkeit hin habe ich bereits experimentell in Angriff genommen und hoffe, ihr Resultat in einer späteren Arbeit mittheilen zu können.

Blicken wir endlich noch etwas weiter zurück auf das erste Kapitel der vorliegenden Arbeit, in dem die weiteren Resultate nach totaler Exstirpation der Augen mit dem Stiel niedergelegt sind, so scheinen wir nunmehr anch die Grenzen des Gültigkeitsbereiches der dort niedergelegten Thatsachen angeben zu können. Da wir nämlich nach den Befunden bei Porcellana einigermaßen dazu berechtigt sind, als Bedingung für die Entstehung von Antennulis an Stelle von Augen die Abwesenheit der Augenganglien zu bezeichnen, so können wir sagen, dass alle jene Krebse, deren Augenganglien im Stiel liegen, an Stelle der total mit dem Stiel exstirpirten Augen Antennulae erzeugen müssen. Ich glaube, dass künftige Untersuchungen mit noch anderen stieläugigen Krebsen diese Abgrenzung des Gültigkeitsbereiches als richtig nachweisen werden, will aber trotzdem aus Vorsicht dem vorstehenden Satz noch die Klausel beiftigen: "falls die Krebse nicht etwa zum Theil die Fähigkeit besitzen sollten, die mit dem Stiel entfernten Augenganglien zu regeneriren«; denn durch die Wiedererzengung derselben wäre natürlich die Entstehung heteromorpher Antennulae ausgeschlossen, und die Regeneration neuer Augen an Stelle der alten ermöglicht.

Mendelpass bei Bozen, Ende Juni 1899.

\section{Litteraturverzeichnis.}

1. BARFURTh, D., Experimentelle Regeneration überschüssiger Gliedmaßentheile bei Amphibien. Dieses Archiv. Bd. I. 1894. pag. 91.

2. Bateson, W., Materials for the Study of Variation. 1894.

3. Bellonci, G., Sistema nervoso ed organi dei sensi dello Sphaeroma serratum. Mem. Accad. Linc. Vol. 10. 1881.

4. Berger, E., Untersuchungen über den Bau des Gehirns und der Retina der Arthropoden. Arb. zool. Inst. Wien. 1878. 
5. Bordage, Enm., Phénomènes d'autotomie observés chez les nymphes de Monandroptera inuncans Serv. et de Rhaphiderus scabrosus Serv. Compt. Rend. Bd. 124. 1897. pag. 210.

6. Derselbe, Phénomènes d'autotomie chez des Phasmides appartenant aux genres Monandroptera et Rhaphiderus. Ebendaselbst pag. 378.

7. Derselbe, Sur la régénération tétramérique du tarse des Phasmides. Ebendaselbst pag. 1536.

8. Derselbe, Sur les localisations des surfaces de régénération chez les Phasmides. C. R. Soc. Biol. Paris. Bd. 5. 1898. pag. 837.

9. Derselbe, Sur le mode probable de formation de la soudure fémoro-trochantérique chez les Arthropodes. Ebendaselbst pag. 839.

10. Derselbe, Sur la régénération chez les Phasmides. Ann. Soc. Ent. France. Vol. 67. pag. 87.

11. Boulenger, G. A., On the Scaling of the reproduced Tail in Lizards. Proc. Zool. Sos. London. 1888 . pag. 351.

12. Derselbe, Iguana with reproduced Tail. Ebendaselbst. 1891. pag. 466.

13. Braun, M., Über die histologischen Vorgänge bei der Häutung von Astacus fluviatilis. Arb. zool. Inst. Würzburg. Bd. 2. 1875. pag. 121.

14. Brivdley, H. H., On the Regeneration of the Legs in the Blattidae. Proc. Zool. Soc. London. 1897. pag. 903. Vgl. auch BATESON (2). pag. 63 u. 415.

15. Chantran, Expériences sur la régénération des yeux chez les écrevisses. Compt. rend. Bd. 76. 1873. pag. 240.

16. Claus, C., Untersuchungen iiber die Organisation und Entwickelung von Branchipus und Artemia. Arb. zool. Inst. Wien. Bd. 6. 1886. pag. 267.

17. Derselbe, Über den Organismus der Nebaliden und die systematische Stellung der Leptostraken. Evendaselbst. Bd. 8. 1888. pag. 1.

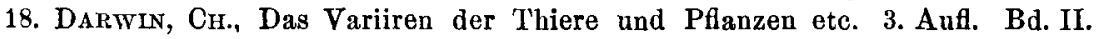
pag. 313.

19. Davenport, C. B., Studies in Morphogenesis. II. Regeneration in Obelia and its bearing on the diffusion in the Germplasma. Anat. Anz. Bd. 9. 1894. pag. 283 u. 391.

20. Grand, A., Polydactylie provoquée chez Pleurodeles Waltlii Michahelles. C. R. Soc. Biol. Bd. 2. 1895. pag. 789.

21. Derselbe, Sur les régénérations hypotypiques. Ebendaselbst. Bd. 4. 10me série, Année 1897. pag. 315.

22. Gray, G. R., Description of some singularly formed orthopterous. CharlesWorth's Mag. of Nat. Hist. Vol. I. 1837. pag. 145. (DARWIN [18] bezieht sich auf GraY, dieser jedoch wieder auf LansDown GuILding, dessen Originalarbeit mir nicht zugänglich war.)

23. Hensen, V., Studien über das Gehörorgan der Dekapoden. Zeitschr. wiss. Zool. Bd. 13. 1863 . pag. 319.

24. Herbst, C., Über die Regeneration von antennenähnlichen Organen an Stelle von Augen. I. Dieses Archiv. Bd. II, Heft 4. 1896.

25. Derselbe, Über die Regeneration etc. II. Versuche mit Sicyonia sculpta. Vierteljahrsschr. naturf. Gesellsch. Zürich. Jahrg. 41. 1896. pag. 435.

26. Derselbe, Über die Bedentung der Reizphysiologie für die causale Auffassung von Vorgängen in der thierischen Ontogenese. II. Haupttheil. Die formativen oder morphogenen Reize. Biolog. Centralblatt. Bd. 15. 1895. pag. $721 \mathrm{ff}$. 
27. Herrick, F. H., in W. K. Brooks and F. H. Herrick, The Embryology and Metamorphosis of the Macrura. Mem. Ac. Scienc. Washington. Bd. V. 1892.

28. Hofer, B., Ein Krebs mit einer Extremitït statt eines Stielauges. Verh. d. Deutsch. Zool. Gesellsch. 1894.

29. Kraepelin, K., Über die Geruchsorgane der Gliederthiere. Osterprogramm d. Realschule d. Johanneums. Hamburg 1883.

30. KupfFer, v., Eröffnungsrede d. Verhandl. d. anat. Gesellsch. auf d. 10. Vers. in Berlin 1896. Anat. Anz. Ergänzungsheft zam 12. Bd. 1896. pag. $2 \mathrm{ff}$.

31. Loeb, J., Untersuchungen zur physiologischen Morphologie der Thiere. I. Wirzburg 1891.

32. Derselbe, Hat das Centralnervensystem einen Einfluss auf die Vorgänge der Larvenmetamorphose? Dieses Archiv. Bd. IV. 1896. pag. 502.

33. Milne-Edwards, Sur un cas de transformation du pédoncule oculaire en une antenne, observé chez une langouste. Compt. rend. Bd. 59. 1864. pag. 710.

34. Morgan, T. H., A Study of Metamerism. Quart. Journ. Micr. Sc. Vol. 3i. 1895.

35. Derselbe, Regeneration and Liability to Injury. Zool. Bull. Vol. I. 1898. pag. 287.

36. Müller, F., Haeckel's biogenetisches Grundgesetz bei der Neubildung verlorener Glieder. Kosmos. Bd. 8. 1880/81. pag. 358.

37. Parker, G. H., The Retina and optic Ganglia in Decapods, especially in Astacus. Mitth. Zool. Stat. Neapel. Bd. 12, Heft 1 (Juli 1895). pag. $1 \mathrm{ff}$.

38. Parona, C., L'autotomia e la regenerazione delle appendici dorsali nella Tethys leporina. Atti d. R. Univ. Genova 1891.

39. Piana, Ricerche sulli polidactilia acquisita determinata sperimentale nei tritoni e sulla coda supernumeraria nelle lucertole. Ric. Lab. An. norm. Roma. Vol. 4. 1894. pag. 66.

40. Przibram, H., Regeneration bei den niederen Crustaceen. Zool. Anz. 1896. pag. 424.

41. Derselbe, Die Regeneration bei den Crustaceen. Arb. zool. Inst. Wien. Bd. 11, Heft 2. 1899 . pag. 47.

42. RAtH, 0 . vom, Über die Nervenendigungen der Hautsinnesorgane der Arthropoden nach Behandlung mit der Methylenblau- und Chromsilbermetbode. Ber. Nat. Gesellsch. Freiburg. Bd. 9. 1894. pag. 137.

43. Rosenstadt, B., Beiträge zur Kenntnis des Baues der zusammengesetzten Augen bei den Dekapoden. Arch. mikr. Anat. Bd. 47. 1896. pag. 748.

44. Schaper, A., Experimentelle Studien an Amphibienlarven. I. Haben kïnstlich angelegte Defekte des Centralnervensystems oder die vollständige Elimination desselben einen nachweisbaren Einfluss auf die Entwickelung des Gesammtorganismus junger Froschlarven? Dieses Archiv. Bd. VI. 1898. pag. 151.

45. Schultz, E., Über die Regeneration von Spinnenfüßen. Travaux de la Soc. Imp. Natur. St. Pétersbourg. Protokolle Vol. 29. 1898. pag. 94.

46. Tonnier, G., Ưber Hyperdaktylie, Regeneration und Vererbung mit Experimenten. Dieses Archiv. Bd. III. 1896. pag. 469 u. Bd. IV. pag. 180.

47. Viallanes, H., Études hist. et org. sur les centres nerveux et les organes des sens des animaux articulés. Premier mémoire. Le ganglion optique de la Langouste. Ann. scienc. nat. Zool. 6me série. Bd. 17. 1884. 
48. Weismann, A., Thatsachen und Auslegungen in Bezug auf Regeneration. Anat. Anz. Bd. 15. 1899. pag. 445.

49. Werner, F., Über die Schuppenbekleidung des regenerirten Schwanzes bei Eidechsen. Sitz. Ak. Wiss. Wien. Bd. 105, Abth. I. 1896. pag. 123.

50. Wheeler, W. MI., An Antenniform Extra-Appendage in Dilophus tibialis, Loew. Dieses Archiv. Bd. III. 1896. pag. 261.

\section{Erklärung der Abbildungen.}

\section{Buchstabenerklärung.}

ag Augenganglien,

agz Augenganglienzellen,

ant.I Nervus antennarius $\mathrm{I}$,

ant.II - - II,

am Augenmuskeln,

anrf Anlage neuer Retinafasern,

ash Sinneshaaranlage,

bh Bildungsherd neuer Ganglieu und Nervenfasern,

coe Schlundkommissur; Commissura circumoesophagealis,

ex Exopodit,

$e x_{1}$ dessen Ast mit den sog. Riechfüden,

$e x_{2}$ dessen Geißel,

en Endopodit,

$d n$ distaler Nervenstrang, aus den Riechfäden in die Ganglien tretend,

g Ganglien,

gn gemeinsamer, nach dem Gehirn strebender Nervenstamm der proximalen Nervenstränge der Sinneshaarganglien,

kr Krystallkegelschicht,

lg lame ganglionnaire, d. h. das am weitesten distalwärts gelegene der vier Augenganglien,

nt Nervus tegumentarius,

Oculomotorius,

Opticus,

Protopodit,

proximale Nervenstränge, von den Sinneshaarganglien dem Gehirn zustrebend,

re Retinulaschicht,

rf Retinafasern, welche das Auge mit den Augenganglien verbinden,

sh Sinneshaare, sogen. Riechfäden oder Riechschläuche,

st stehengebliebener Stumpf des Augenstieles.

\section{Tafel VIII-X.}

Fig. $1 a$ und $b$. Heteromorphe Antennula an Stelle des linken Auges von $P a$ laemon serratus in zwei auf einander folgenden Entwickelungsstadien. Operirt Anfang Oktober 1895; konservirt Anfang Juni 1896. Vergrößerung 11.

Fig. $2 a$ und $b$. Heteromorphe Antennula an Stelle des linken Auges von $\mathrm{Pa}$ laemon rectirostris. Operirt am 12./5. 97. a Haut vom 22./10.97, $b$ Haut vom 27./5. 98. Von der langen Geißel nur einige Glieder gezeichnet. Der kürzere, dickere Ast des Exopoditen mit den Sinneshaarreihen ist in $b$ in Regeneration begriffen. Die Größenzunahme der Antennula während des Zeitraumes vom 22./10.97-27./5.98 ist an dem für $e x_{1}$ und $e x_{2}$ gemeinsamen Stiuck $e x$ zu bemerken. $b$ ist in einer Lage gezeichnet, die gegen diejenige von $a \mathrm{um} 180^{\circ}$ verdreht ist. Vergrößerung ca. 141/2. 
Fig. 3. Heteromorphe Antennula mit Außen- und Innenast von Palaemon rectirostris. Der kürzere, dickere Ast des Exopoditen ist abnorm gestaltet. Operirt Anfang Oktober 1897; konservirt 28./5. 98. Vergrößerung ca. 141/2.

Fig. 4. Heteromorphe Antennula mit Außen- und Innenast von Palaemon rectirostris. Der Innenast (en) war abgebrochen und ist nach einer Häutung wieder regenerirt worden. Am Protopoditenrudiment $(p r)$ ist der Büschel Fiederhaare zu beachten. Operirt Anfing Oktober 1897; am 2.,11. 98 Antennula abgeschnitten. Vergrößerung ca. 18.

Fig. $5 a$ und $b$. Mächtig entwickelte heteromorphe Antennula an Stelle des linken Auges nebst normaler linker Antennula von Palaemon rectirostris. a ganz gezeichnet, $b$ nur der proximale Theil. Operirt Anfang Oktober 1897, gezeichnet nach Haut vom 17./12.95. Vergrößerung von $a 2$, von $b$ ca. 9 .

Fig. 6. Längsschnitt durch den hornförmigen Ansatz zu einer heteromorphen Antennula von Palaemon serratus. Genạ gezeichnet mit allen Zufälligkeiten (z. B. Abhebung der Chitindecke von der Hypodermis), die durch das Fixirungsmittel und durch das Messer verursacht waren. Operirt Anfang Oktober 1895, konservirt am 6./6.96 mit Pikrinosmiumessigsäure nach vom RATH. Vergrößerung 86.

Fig. 7. Theil eines Sagittalschnittes durch den kürzeren Ast des Exopoditen der in Fig. 4 dargestellten Neubildung. Konservirt mit Sublimat am 2./11.95. Die Konservirung genügt zum Nachweis der Sinnesharganglien und der Nervenstränge, welche distalwärts von diesen zu den Sinneshaaren und proximalwärts, zu einem dickeren Stamme (gn) vereinigt, zum Gehirn ziehen. Bei $d n^{*}$ Eintritt eines distalen Nervenstranges in das zugehörige Ganglion. Zur Ermittelung feinerer Strukturverhältnisse ist die Fixirung mit Sublimat absolut unbrauchbar. Vergrößerung ca. 205.

Fig. 8. Heteromorphe, an Stelle des linken Auges erzeugte Antennula von Palaemonetes varians. Bei * Beginn des Regenerates. Operirt 18./11. 97; konservirt 29./5. 98. Vergrößerung ca. 29.

Fig. 9. Heteromorphe, an Stelle des linken Auges erzeugte Antennula von Astacus fluciatilis. Unter der alten, stellenweise schon aufgeplatzten Chitinhaut liegt, in zahlreiche Falten gelegt, die neue. Zu beachten der zahnartige Stachel am Protopoditen. Bei * Beginn des Regenerates. Operirt 29./1. 96, gestorben Ende März 1897 kurz vor einer weiteren Hüutung. Vergrößerung ca. $141 / 2$.

Fig. 10. Kopf von Palinurus vulgaris mit heteromorpher Antennula an Stelle des linken Auges. Operirt 10./6.96, gestorben 18./1.95 während der Häutung. Ungefähr natïrliche Größe.

Fig. 11. Heteromorphe Antennula von demselben Thier, gezeichnet nach der abgeworfenen Haut vom 17./18. März 1897 von der Ventralseite. Vergrößerung 22.

Fig. 12. Letztes beobachtetes Entwickelnngsstadium derselben beteromorphen Antennula sammt rechtem Auge, Gehirn und Nerven. Gezeichnet nach einem Totopräparate. Das reehte Ange aufgeschnitten; schematisch gezeichnet. Bei * Beginn des Regenerats. Die Schlundkommissuren (coe) und die Nerven für die ersten Antennen bilden in natura einen Winkel von ca. $90^{\circ}$ zu einander, was in der Zeichnung nicht deutlich zur Wiedergabe gekommen ist. Vergrößerung ca. 6 .

Fig. 13. Drei Glieder der in Fig. 12 dargestellten Heteromorphose bei stärkerer Vergrößerung zur Demonstrirung des Sinneshaarbesatzes. Nur die eine 
Reihe der Riechfäden in ihrer ganzen Länge wiedergegeben, von der zweiten nur das äußerste Haar links. Vergrößerung 44.

Fig. 14. Sagittalschnitt durch drei Glieder derselben Heteromorphose zur Lllustrirang des Nervenapparates der Sinneshaare. Obgleich das Thier einfach nach dem Tode in Alkohol von $90^{\circ}$ eingelegt worden war, war der Erhaltungszustand doch ein guter, viel besser als nach Konservirung mit komplicirten Flüssigkeiten. Da das Thier gerade während der Häutung gestorben war, so ist die wider Erwarten gute Konservirung auf die leichte Durchdringlichkeit der neuen Chitinhaut zurückzuführen. Vergrößerung 86.

Fig. 15a. Heteromorphe, an Stelle des linken Auges erzeugte Antennula von Scyllarus arctus. Operirt Frübjahr 1896; konservirt 11./11. 96. Vergrößerung 22. Fig. $15 b$ einzelnes Riechhaar davon, bei Vergrößerung von 86 gezeichnet.

Fig. 16a-c. An Stelle von linken Augen erzeugte heteromorphe Antennulae verschiedenen Ausbildungsgrades von Eupagurus Prideauxii. Operirt Anfang Mai 1897, gestorben während der Sommermonate. Vergrößerung 44.

Fig. $17 a$ und $b$. Augenstiele mit Anlagen zu neuen Augen, $a$ von Palaemon serratus, $b$ von $P$. rectirostris. In $b$ sind $z$ wei weit von einander getrennte Bildungsherde vorhanden. Operirt Ende November 1896, gestorben im Sommer 1897. Vergrößerung ca. 141/2.

Fig. 18. Theil eines Längsschnittes durch die in Fig. 17 a dargestellte Neubildung. Der Krebs war einfach in Alkohol von $90^{\circ}$ eingelegt worden. Die Chitindecke hatte sich in Folge dessen von der etwas geschrumpften Hypodermis etc. abgehoben; in der Zeichnung ist sie der letzteren wieder angelegt worden. Sonst Präparat genau ohne irgend welche Schematisirung wiedergegeben. Vergrößerung ca. 205.

Fig. 19. Augenstiel mit Augenanlage von Eupagurus Prideauxii. Die eigentliche Augenanlage war im Leben von einem röthlichen Ring umgeben, wie dies bei den normalen Augen der Fall ist. Operirt Mitte Januar 1896, konservirt 7./6. 96 mit heißem Alkohol. Vergrößerung ca. 141/2.

Fig. 20. Theil eines Längsschnittes durch die in Fig. 19 dargestellte Neubildung. Die Chitindecke ist in Folge der Behandlung mit heißem Alkohol merkwürdig gequollen. Man sieht, wie die Augenanlage allmählich in die Hypodermis übergeht. Unter der Angenanlage sieht man den in Wiederherstellung begriffenen Ganglienapparat mit einem mächtigen Belag langgestreckter Kerne. Vergrößerung ca. 205.

Fig. 21. Rechtes, normales und linkes, regenerirtes Auge von Porcellana platycheles, gezeichnet von der Ventralseite. Operirt Ende November 1895, konservirt 5./6.96. Vergrößerung 22.

Fig. 22. Theil eines Schnittes durch ein regenerirtes Auge von Porcellana platycheles. Operirt December 1895, konservirt 5./6.96. Das Chitin wurde nach einer mir von BETHE guitigst mitgetheilten Methode mittels $\mathrm{HNO}_{3}$ in Alkohol erweicht. BETHE, dem ich für seine Mittheilung meinen besten Dank ausspreche, bringt die Objekte allmählich in eine $8 \%$ ige Lösung von $\mathrm{HNO}_{3}$ in starkem Alkohol, indem er von dem abgemessenen Quantum Säure jeden Tag etwas zum Alkohol zutropft. Ich brachte die Objekte zunächst in Alkohol von $90 \%+5 \% \mathrm{HNO}_{3}$ von ca. $33 \%$, dann nach einiger Zeit alluählich in Alc. abs. $+10 \% \mathrm{HNO}_{3}$ und schließlich in Alc. abs. + $12 \% \mathrm{HNO}_{3}$ von ca. $49 \%{ }_{0}^{\prime}$. Die Objekte blieben $4-\mathrm{S}$ Wochen in dem sal- 
292 C. Herbst, Über die Regeneration von antennenähnlichen Organen etc. IV.

petersauren Alkohol liegen. - Die Cornea war in Folge der Konservirung mit Alkohol von der Hypodermis abgehoben, in der Abbildung ist sie an dieselbe darangezeichnet worden. Vergrößerung ca. 205.

Fig. 23. Horizontalschnitt durch den vorderen Theil des Cephalothorax von

Porcellana longicornis zur Demonstrirung der Augenganglien, welche im Gegensatz zu den übrigen Krebsen mit Stielaugen vom Gehirn nicht getrennt sind. Das Objekt war mit Formol $1 \%$ in Seewasser fixirt worden. Nach meinen Erfahrungen ist Formol in Seewasser (die Stärke der Lösung spielt keine wichtige Rolle) das beste Konservirungsmittel für Crastaceen, da es das Chitin leicht und rasch durchdringt. Nach zwei Tagen führe ich die Objekte aus dem Formol in Alkohol uiber. Das Chitin war auch hier 4 Wochen lang in Alkohol $+\mathrm{HNO}_{3}$ erweicht worden. Vergrößerung ca. 57.

Fig. 24. Theil eines Schnittes durch die Augenanlage von Idothea tricuspidata. Operirt Ende Oktober 1895, konservirt am 15./12. 95 leider mit Sublimat, vor dem za warnen ist. Genau nach dem Präparat mit allen Zufälligkeiten gezeichnet, die durch das Fixirungsmittel oder das Mikrotommesser (Verschiebung der Krystallkegel) verursacht sind. Chitin in Alkohol + $\mathrm{HNO}_{3}$ erweicht. Vergrößerung ca. 205. 